\title{
Oxime radicals: generation, properties and application in organic synthesis
}

\author{
Igor B. Krylov, Stanislav A. Paveliev, Alexander S. Budnikov and Alexander O. Terent'ev*
}

Review

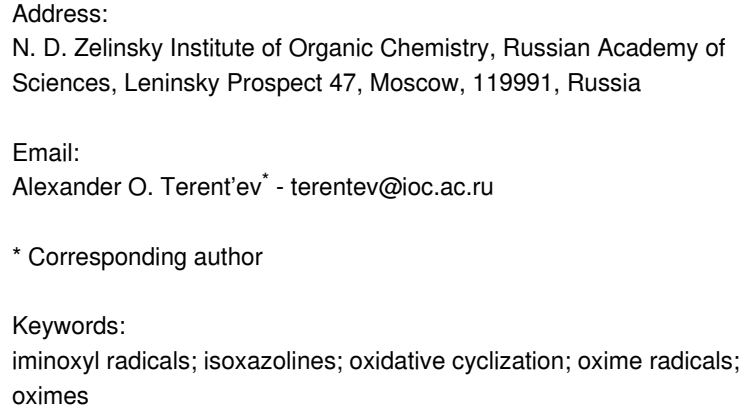

\author{
Beilstein J. Org. Chem. 2020, 16, 1234-1276. \\ doi:10.3762/bjoc.16.107 \\ Received: 01 January 2020 \\ Accepted: 15 May 2020 \\ Published: 05 June 2020 \\ Associate Editor: C. Stephenson \\ (C) 2020 Krylov et al.; licensee Beilstein-Institut. \\ License and terms: see end of document.
}

\begin{abstract}
$\mathrm{N}$-Oxyl radicals (compounds with an $\mathrm{N}-\mathrm{O}^{\bullet}$ fragment) represent one of the richest families of stable and persistent organic radicals with applications ranging from catalysis of selective oxidation processes and mechanistic studies to production of polymers, energy storage, magnetic materials design and spectroscopic studies of biological objects. Compared to other $N$-oxyl radicals, oxime radicals (or iminoxyl radicals) have been underestimated for a long time as useful intermediates for organic synthesis, despite the fact that their precursors, oximes, are extremely widespread and easily available organic compounds. Furthermore, oxime radicals are structurally exceptional. In these radicals, the $\mathrm{N}-\mathrm{O}^{\bullet}$ fragment is connected to an organic moiety by a double bond, whereas all other classes of $\mathrm{N}$-oxyl radicals contain an $\mathrm{R}_{2} \mathrm{~N}-\mathrm{O}^{\bullet}$ fragment with two single $\mathrm{C}-\mathrm{N}$ bonds. Although oxime radicals have been known since 1964, their broad synthetic potential was not recognized until the last decade, when numerous selective reactions of oxidative cyclization, functionalization, and coupling mediated by iminoxyl radicals were discovered. This review is focused on the synthetic methods based on iminoxyl radicals developed in the last ten years and also contains some selected data on previous works regarding generation, structure, stability, and spectral properties of these $N$-oxyl radicals. The reactions of oxime radicals are classified into intermolecular (oxidation by oxime radicals, oxidative $\mathrm{C}-\mathrm{O}$ coupling) and intramolecular. The majority of works are devoted to intramolecular reactions of oxime radicals. These reactions are classified into cyclizations involving $\mathrm{C}-\mathrm{H}$ bond cleavage and cyclizations involving a double $\mathrm{C}=\mathrm{C}$ bond cleavage.
\end{abstract}

\section{Introduction}

Free radicals in which an unpaired electron is localized on the $\mathrm{N}-\mathrm{O}$ fragment ( $\mathrm{N}$-oxyl radicals, Figure 1 ) occupy a special place in organic chemistry due to the increased stability and ease of generation, the diversity of their structures, properties, and applications.
Stable $N$-oxyl radicals (mainly of the aminoxyl type, Figure 1, I) are used in the development of organic magnetic materials [1], organic batteries [2-4], in the preparation of polymers by living polymerization [5,6], in the studies of biomolecules and living systems by EPR [7] and NMR [8] techniques. Stable 


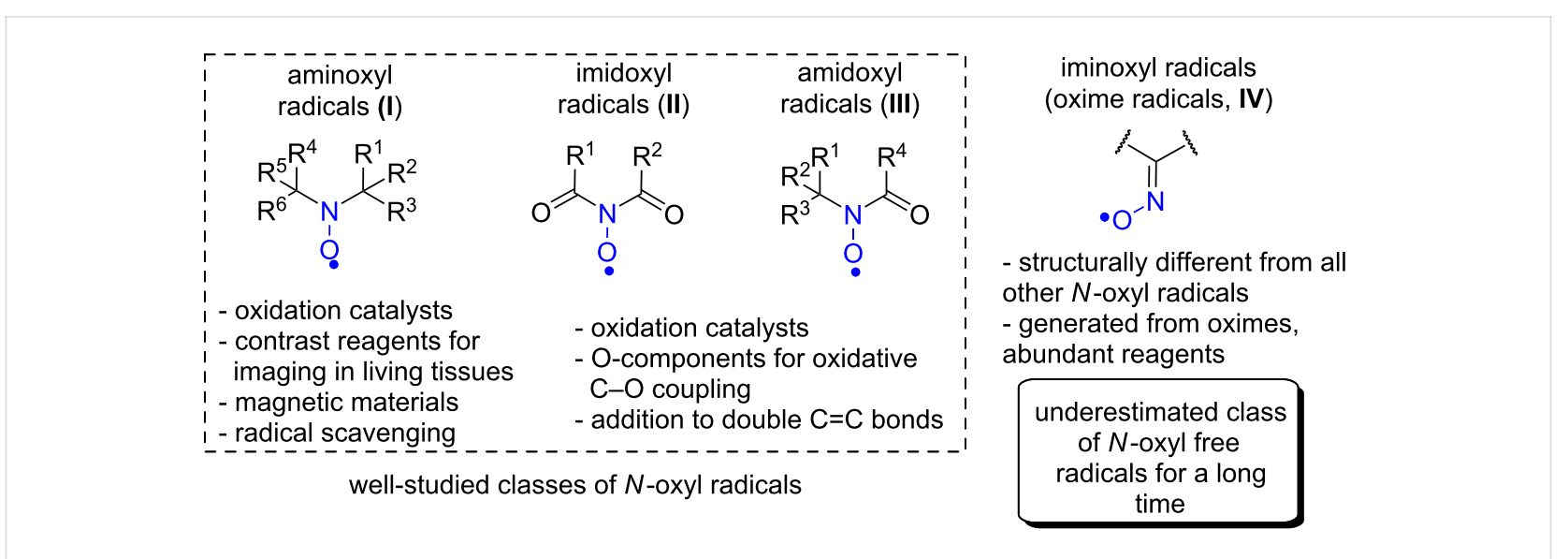

Figure 1: Imine-N-oxyl radicals (IV) discussed in the present review and other classes of N-oxyl radicals (I-III).

$N$-oxyl radicals occupy a central place in organic chemistry as scavengers of C-centered radicals [9] and selective oxidation organocatalysts (for example, in the oxidation of alcohols to the corresponding carbonyl compounds [10,11]). Recently, highly reactive imidoxyl radicals (Figure 1, II) have found a wide application in the processes of hydrogen atom abstraction with cleavage of the $\mathrm{C}-\mathrm{H}$ bond [12-18] and in the processes of functionalization of $\mathrm{C}=\mathrm{C}$ double bonds $[19,20]$. Amidoxyl radicals (Figure 1, III) are applied in the functionalization of the double bonds [21-26] and in mild oxidations [27].

In contrast to the mentioned $N$-oxyl radical classes (Figure 1, I-III) which have two single nitrogen-carbon bonds, the iminoxyl radicals (also known as oxime radicals, Figure 1, IV) have a carbon-nitrogen double bond. This structural feature is responsible for principal differences in the electronic structure, spectral properties, and chemical reactivity between oxime radicals and other types of $\mathrm{N}$-oxyl radicals.

For a long time, the synthetic potential of iminoxyl radicals remained underestimated and their chemistry was mainly represented by fundamental physico-chemical studies. The precursors of imine- $N$-oxyl radicals are oximes, a widely available and fundamental class of organic compounds. However, oxime radicals almost did not find synthetic use until recently, probably due to the low stability of the majority of representatives of this type of radicals. The applications of oxime radicals in organic synthesis have developed rapidly during the last years, and we believe that this review is essential for the demonstration of a new face of the chemistry of this class of $N$-oxyl radicals. There are reports on the iminoxyl radical involvement in redox processes occurring in living organisms, for example, in microsomal oxidation of $N$-hydroxyguanidines and amidoximes [28], oxidation of tyrosine phenolic moiety in the presence of $\mathrm{NO}$ [29-33].
This review focuses on the synthetic use of oxime radicals. Most of the works on this topic have been published over the past ten years. In most cases, these are intramolecular reactions of oxidative cyclization. Examples of intermolecular reactions of oxime radicals, a brief description of their structure, stability, and spectral properties are also given. The chemistry of iminoxyl radicals (including their generation, structure, EPR spectroscopy, and reactions) was reviewed in 1978 before the discovery of their substantial synthetic potential [34]. A book chapter was dedicated to the chemistry of stable di-tert-alkyl iminoxyl radicals [35]. Kinetic [36] and EPR data [37] of iminoxyl radicals were previously compiled in tabular form.

\section{Review}

\section{General information about iminoxyl radicals: generation, structure, stability, and spectral data}

Iminoxyl radicals were first discovered in 1964 by EPR spectroscopy as short-living intermediates formed from the oximes of both aromatic and aliphatic ketones and aldehydes, as well as from the oximes of quinones under the action of a strong singleelectron oxidant, cerium(IV) ammonium nitrate, in methanol [38]. To record EPR spectra, a flow system was used, which allowed observation of radicals with lifetimes of about $10^{-2} \mathrm{~s}$ [39]. The EPR spectra of iminoxyl radicals are characterized by large values of the hyperfine splitting constants of an unpaired electron with a ${ }^{14} \mathrm{~N}$ nucleus $\left(\mathrm{a}^{\mathrm{N}} \approx 28-33 \mathrm{G}\right.$ [35-38]), which are very different from those for other $N$-oxyl radicals, such as imidoxyl $\left(\mathrm{a}^{\mathrm{N}} \approx 4.2-4.9 \mathrm{G}\right.$ [40]), amidoxyl $\left(\mathrm{a}^{\mathrm{N}} \approx 5-8 \mathrm{G}[41,42]\right)$, and aminoxyl ( $\mathrm{a}^{\mathrm{N}} \approx 15 \mathrm{G}$ [43]). The characteristic ${ }^{14} \mathrm{~N}$ hyperfine splitting constant makes EPR spectroscopy a convenient method for the identification of iminoxyl radicals, and for many of them, EPR is the only observation method due to low stability, and therefore low concentration in investigated 
systems. For the most stable iminoxyl radicals, sufficiently concentrated solutions were obtained and investigated by IR spectroscopy. The IR spectra show the absence of the line of stretching vibrations of the $\mathrm{O}-\mathrm{H}$ bond, characteristic of the parent oximes, as well as the appearance of a new intense band corresponding to the asymmetric vibrations of the $\mathrm{C}=\mathrm{N}-\mathrm{O}^{*}$ fragment $\left(1550 \mathrm{~cm}^{-1}\right.$ for the diacetyliminoxyl radical [44], $1595 \mathrm{~cm}^{-1}$ for the di(1-adamantyl)iminoxyl, and $1610 \mathrm{~cm}^{-1}$ for the di-tert-butyliminoxyl radical [45]).

Various oxidants were used for the generation of iminoxyl radicals from oximes, including transition metal compounds, such as $\left(\mathrm{NH}_{4}\right)_{2} \mathrm{Ce}\left(\mathrm{NO}_{3}\right)_{6}[38,46], \mathrm{Fe}\left(\mathrm{ClO}_{4}\right)_{3}[44,46], \mathrm{Cu}\left(\mathrm{ClO}_{4}\right)_{2}$ [46], $\mathrm{Pb}(\mathrm{OAc})_{4}$ [44,46-51], $\mathrm{PbO}_{2}$ [52], $\mathrm{Mn}(\mathrm{OAc})_{3}$ [46], $\mathrm{KMnO}_{4}$ [46], $\mathrm{Ag}_{2} \mathrm{O}$ [53], $\mathrm{AgO}$ [54], Horseradish peroxidase $/ \mathrm{H}_{2} \mathrm{O}_{2}$ [55], metal-free oxidants $\mathrm{PhI}(\mathrm{OAc})_{2}$ [46], $t$-BuOO $t$-Bu [53] or quinones [56] under UV irradiation. Anodic oxidation was also reported [57].
The establishing of the self-decay pathways of iminoxyl radicals is complicated by the formation of a large number of products, some of the initially formed products are not stable. Moreover, participation of the oxidizing agent not only in the radical generation, but also in its decay also possible [53]. The products formed during the decomposition of iminoxyl radicals 2 generated from oximes 1 under the action of $\mathrm{Ag}_{2} \mathrm{O}$ [53] were studied by K. U. Ingold et al. (Figure 2).

In most cases, the reaction was accompanied by the release of $\mathrm{N}_{2}$ and $\mathrm{N}_{2} \mathrm{O}$, as well as the corresponding carbonyl compounds (3a-c). Dimerization of iminoxyl radicals with the formation of a $\mathrm{C}-\mathrm{O}$ bond (dimer $\mathbf{4 b}$, oxidation of diisopropyl oxime $\mathbf{1 b}$ ), an $\mathrm{O}-\mathrm{N}$ bond (dimer $\mathbf{4 c}$, oxidation of benzophenone oxime 1c), and an N-N bond (dimer $\mathbf{4 d}$, oxidation of benzaldoxime 1d, see also [58]) was observed. As a rule, the initial dimers of iminoxyl radicals are unstable, which makes their analysis difficult. Azine- $N$-oxides $\mathbf{5 b}, \mathbf{c}$ were also obtained in significant

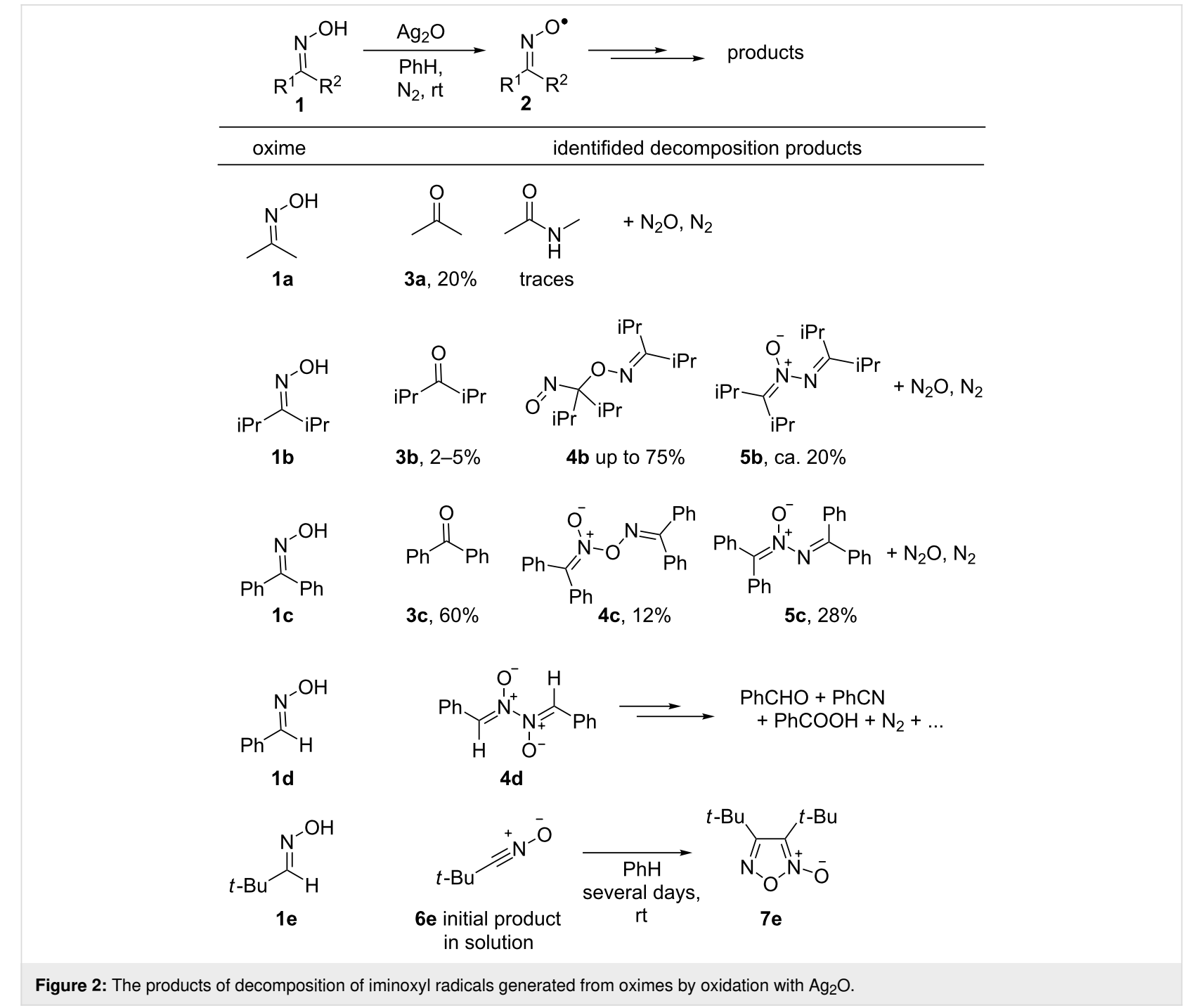


amounts from oximes $\mathbf{1 b}, \mathbf{c}$ (yields $20-28 \%$ ). The $\mathrm{C}-\mathrm{O}$ dimeric product $\mathbf{4 b}$ of the diisopropyl iminoxyl radical is unstable at room temperature even in solution. At the same time, it gives a sufficiently strong EPR signal corresponding to the free iminoxyl radical, which indicates the reversibility of dimerization [53]. During the oxidation of pivalic aldoxime $1 \mathrm{e}$ by $\mathrm{Ag}_{2} \mathrm{O}$, the formation of nitrile oxide $\mathbf{6 e}$ was observed, which then slowly dimerized to the corresponding furoxan $\mathbf{7 e}$.

The kinetics of the decomposition of dialkyl, arylalkyl, and diaryl oxime radicals was also studied by EPR spectroscopy [53]. Radicals were generated under inert atmosphere directly in the EPR cavity by photolysis of the added di-tert-butyl peroxide (Scheme 1).

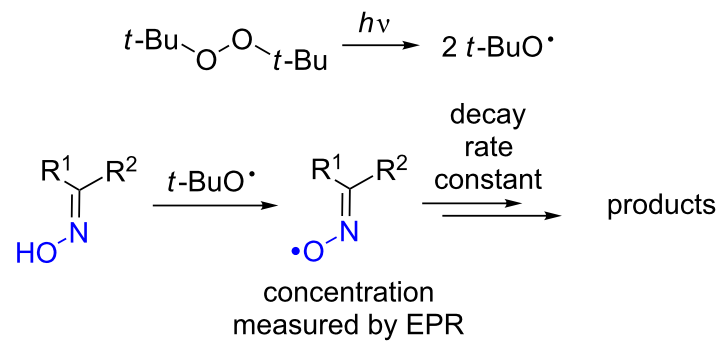

Scheme 1: Generation of oxime radicals and study of the kinetics of their decay by photolysis of the solution of $t$-BuOOt-Bu and oxime in an EPR spectrometer cavity.

The authors pointed out the complexity of the processes of iminoxyl radicals' decomposition and the difficulties associated with the interpretation of the obtained data [53]. During EPR monitoring of the generation and decomposition of iminoxyl radicals, the formation of several free-radical products of a noniminoxyl type, probably of the general formula $\mathrm{R}^{1} \mathrm{R}^{2} \mathrm{NO}$, was observed. It was established that the studied iminoxyl radicals reversibly dimerized in the solution. For sterically unhindered dialkyliminoxyl radicals, the radical-dimer equilibrium was quickly reached, shifted toward the dimer, while a first-order decay kinetics of was observed for the iminoxyl radical. For sterically hindered tert-butylmethyliminoxyl and diisopropyliminoxyl radicals, as well as for diaryl and alkylaryliminoxyl radicals, the radical-dimer equilibrium was reached slowly, it was shifted toward the free radical, and a second-order decay kinetics was observed.

The first synthesized long-lived iminoxyl radical that did not undergo decomposition and dimerization in the solution for a time sufficient to use it as a reagent was the di-tert-butyliminoxyl radical (8) [45,59]. It was obtained by oxidation of di-tert-butyl ketoxime (1f) with silver(I) oxide $\left(\mathrm{Ag}_{2} \mathrm{O}\right)$ in benzene at $25{ }^{\circ} \mathrm{C}$ (Scheme 2). This radical is stable at $25{ }^{\circ} \mathrm{C}$ in $n$-hexane. In pure form it is storable only at $-78^{\circ} \mathrm{C}$ as a solid. At room temperature, radical $\mathbf{8}$ is a blue oil. When storing $\mathbf{8}$ in the dark without solvent at $25{ }^{\circ} \mathrm{C}$ for a week, the following decomposition products were identified: di-tert-butyl ketone (9, $42 \%)$, di-tert-butyl nitroimine (10,20\%), and pivalonitrile (11, 4\%) [45].

The proposed scheme for the decomposition of di-tert-butyliminoxyl radical $(\mathbf{8})$ is presented in Scheme $3[35,45]$. It includes formation of $\mathrm{C}-\mathrm{O}$ dimer $\mathbf{4 f}$ followed by the fragmentation to iminyl radical 12, ketone $\mathbf{9}$, and nitric oxide. The formation of nitroimine $\mathbf{1 0}$ is explained by the interaction of oxime radical $\mathbf{8}$ with nitric oxide. Pivalonitrile (11) is presumably formed via $\beta$-scission of iminyl radical 12 (Scheme 3). During the decomposition of oxime radical $\mathbf{8}$ an EPR signal typical for a dialkyl aminoxyl radical (type I in Figure 1) was also observed, it was assigned to the di-tert-butyl nitroxyl radical (13).

The proposed pathway of $N$-nitroimine $\mathbf{1 0}$ formation (Scheme 3) was confirmed by additional experiments. It was established that the di-tert-butyliminoxyl radical was not stable in NO atmosphere, the reaction proceeds at room temperature for an hour, and $N$-nitroimine $\mathbf{1 0}$ is formed [45].

Attempts to increase the stability of the iminoxyl radical by replacing the tert-butyl substituent with a bulkier triethylmethyl or other acyclic tert-alkyl substituents were not successful. In the case of $\mathrm{Me}_{3} \mathrm{C}\left(\mathrm{Et}_{3} \mathrm{C}\right) \mathrm{C}=\mathrm{NO}^{\bullet}$ radical 14, a monomolecular decomposition process was proposed, associated with an intramolecular hydrogen atom abstraction by an iminoxyl radical leading to the intermediate 15 (Scheme 4) [35,60,61].

In 1974, a di(1-adamantyl)iminoxyl radical 16 was synthesized analogously to di-tert-butyliminoxyl radical (8) from the corre-

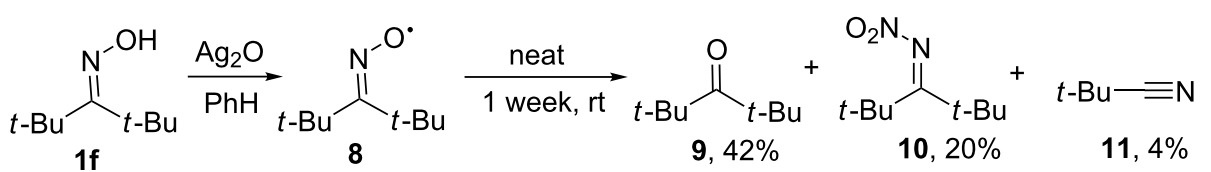



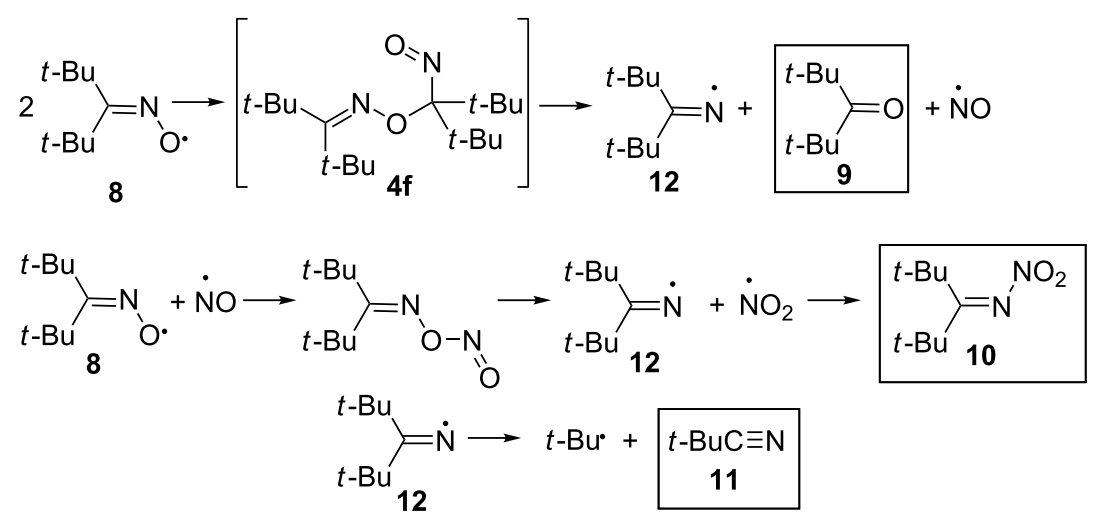

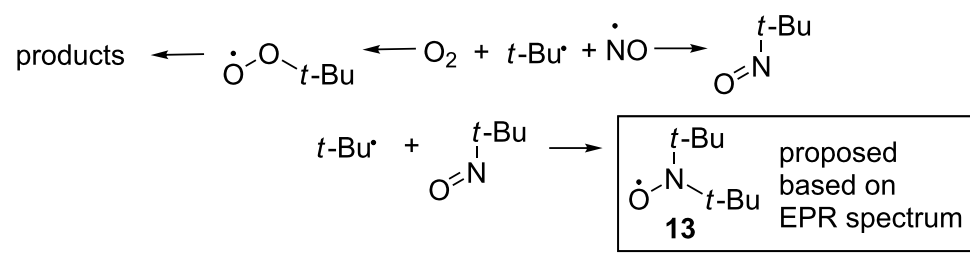

Scheme 3: The proposed reaction pathway of the decomposition of di-tert-butyliminoxyl radical (experimentally identified products are highlighted by rectangles).

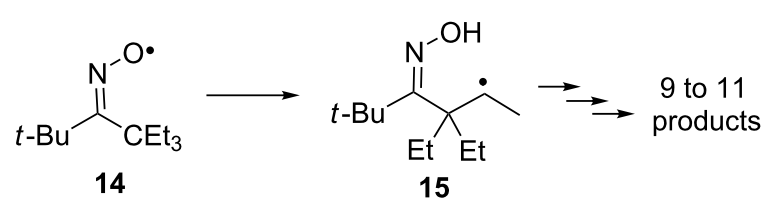

Scheme 4: Monomolecular decomposition of the tert-butyl(triethylmethyl)oxime radical.

sponding oxime 1g (Scheme 5). Oxime radical 16 is a pale blue crystalline compound that is stable at room temperature [35,62], whereas liquid neat di-tert-butyliminoxyl radical (8) decomposed within a week [59]. The di(1-adamantyl)iminoxyl radical (16) was characterized by IR, UV-vis, EPR, and NMR spectroscopy, and its dipole moment in the benzene solution was measured (2.90 D).
Besides the mentioned sterically hindered iminoxyl radicals $\mathbf{8}$ and 16, iminoxyl radicals with electron-withdrawing substituents at the $\mathrm{C}=\mathrm{NO}^{\circ}$ fragment also demonstrate increased stability compared to ordinary alkyl and aryl iminoxyl radicals. For example, a number of long-lived diacyl iminoxyl radicals 18 were generated by the action of tetranitromethane [63] or $\mathrm{NO}_{2}$ [64] on the corresponding $\beta$-diketones $\mathbf{1 7}$ or barbituric acid. The formation and decay of radicals were studied by EPR spectroscopy [64]. The lifetimes of radicals in the solution ranged from several hours to several days (Scheme 6) $[63,64]$.

Recently, a method for the preparative synthesis of diacetyliminoxyl radical 20 in high yield via the oxidation of diacetyl oxime 19 by $\mathrm{Pb}(\mathrm{OAc})_{4}$ was developed [44] (Scheme 7). The resulting radical can be stored for 2-5 days in the solution at room temperature without decomposition according to EPR and IR

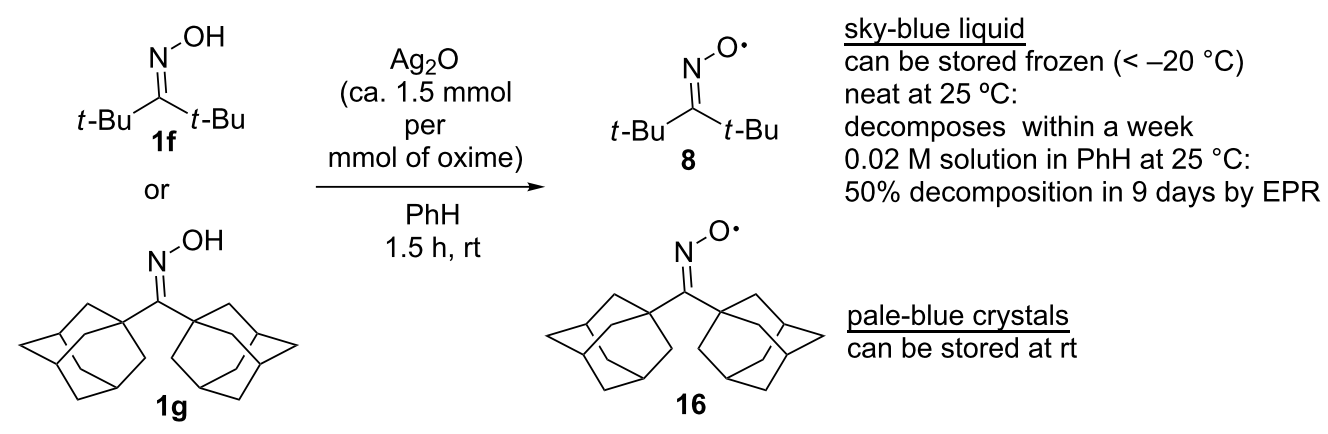

Scheme 5: The synthesis and stability of the most stable dialkyl oxime radicals - di-tert-butyliminoxyl and di-(1-adamantyl)iminoxyl. 


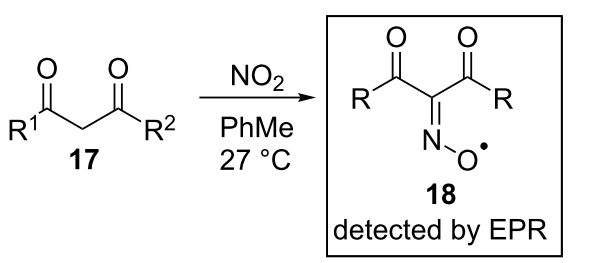

$R^{1}=R^{2}=$ Me - EPR signal observed for several days

$\mathrm{R}^{1}=\mathrm{R}^{2}=\mathrm{Ph}$

$\mathrm{R}^{1}=\mathrm{R}^{2}=\mathrm{CF}_{3}$

EPR signal

observed for

$\mathrm{R}^{1}=$ thiophen-2-yl, $\left.\mathrm{R}^{2}=\mathrm{CF}_{3}\right\} \quad 4-6 \mathrm{~h}$

Scheme 6: The formation of iminoxyl radicals from $\beta$-diketones under the action of $\mathrm{NO}_{2}$.

spectroscopy. Compound 20 represents a very rare example of sterically unhindered, but nonetheless extremely persistent oxime radical.

Other long-living oxime radicals with electron-withdrawing substituents are also known, for example, based on N-containing heterocycles (isoxazolones, pyrazolones, pyrazolidin-3,5diones, and 1,2,3-triazolones [52]), sulfones [65], and phosphonates [54] (Scheme 8).
Based on the data of EPR spectroscopy $[35,38,49,50,66]$ and quantum chemical calculations [67], the maximum spin density in iminoxyl radicals is located on oxygen and on nitrogen. A lone electron pair of $\mathrm{sp}^{2}$ hybridized nitrogen located in the plane of the $\mathrm{C}=\mathrm{N}-\mathrm{O}$ fragment serves for the delocalization of an unpaired electron. Thus the unpaired electron is localized on the orbital that is orthogonal to the $\mathrm{C}=\mathrm{N} \pi$-bond, and therefore, the oxime radicals are considered as $\sigma$-radicals [35]. The electronic structure of the iminoxyl radical can be represented by two<smiles>CC(=O)C(=NO)C(C)=O</smiles>

1) $\mathrm{Pb}(\mathrm{OAc})_{4}(1 \mathrm{mmol})$ $\mathrm{CH}_{2} \mathrm{Cl}_{2}(4 \mathrm{~mL})$ $\underset{\text { 2) column }}{\stackrel{\text { rt, } 10 \mathrm{~min}}{\text { chromatography }}}$ 19 (2 mmol)<smiles>CC(=O)C(=N[O-])C(C)=O</smiles>

20

90-98\%

by EPR solution in $\mathrm{CH}_{2} \mathrm{Cl}_{2}$

(50 mL, ca $0.04 \mathrm{M})$

storable for $2-5$ days

at rt $\left(18-23^{\circ} \mathrm{C}\right)$

Scheme 7: Synthesis of the diacetyliminoxyl radical.<smiles>O=C1ON=C(I)C1=N[OH2+]</smiles><smiles>CCN1N=C(I)C(=N[OH2+])C1=O</smiles><smiles>O=C1C(=NO)C(=O)N(c2ccccc2)N1c1ccccc1</smiles><smiles>O=C1/C(=N/[O-])N=NN1c1ccccc1</smiles>

detected by EPR, "surviving for several hours at rt"<smiles>[R]C(=NO)S([R])(=O)=O</smiles>

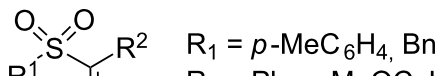

$\mathrm{R}_{2}=\mathrm{Ph}, p-\mathrm{MeOC}_{6} \mathrm{H}_{4}, p-\mathrm{ClC}_{6} \mathrm{H}_{4}, 2,6-\mathrm{Cl}_{2} \mathrm{C}_{6} \mathrm{H}_{3}, \mathrm{Me}, \mathrm{Et}$ $\mathrm{N} \mathrm{O}^{\cdot}$ "halflives of several minutes"

detected by EPR<smiles>[R]C(=NO)P(=O)(OCC)OCC</smiles><smiles>CC(C)C(=O)OOc1ccc(O)c(O)c1</smiles><smiles>[R]C(=N[O])P(=O)(OCC)OCC</smiles>
detected by EPR 
main resonance forms presented below. The calculated and experimental data indicate that the localization of an unpaired electron on the NO fragment is also valid for the case of arylalkyl and diaryl oximes - conjugation of the radical center with $\pi$-systems of aryl rings is not observed [47,49,50,67].

It is known that the angular structure is characteristic for the CNO fragment of oxime radicals, and in the case of different substituents at the carbon atom, two isomers $(E$ and $Z)$ exist. The isomerization of oxime radicals proceeds much easier than for the corresponding oximes; the observation of individual isomers is generally possible only at low temperatures $[68,69]$ (about $190 \mathrm{~K}$ ). According to quantum chemical calculations, the oxime radicals have an increased $\mathrm{C}=\mathrm{N}-\mathrm{O}$ angle and a shortened $\mathrm{N}-\mathrm{O}$ bond compared to the corresponding oximes (Figure 3) [44,52,70].
One of the important quantitative values that determine the reactivity of $\mathrm{O}$ radicals is the $\mathrm{O}-\mathrm{H}$ bond dissociation enthalpy (BDE) in the parent $\mathrm{OH}$ compound (Figure 4). This value affects both the ease of the generation of radicals from the corresponding $\mathrm{OH}$ compounds and the oxidative properties of the $\mathrm{O}$ radicals. The $\mathrm{O}-\mathrm{H}$ BDE values were determined for a number of oximes by the computational $[67,70,71]$ and experimental $[70,72]$ methods. It was established that the BDE decreased with an increase in the volume of substituents at the $\mathrm{C}=\mathrm{NOH}$ fragment, which was consistent with the spatial structure of the oxime radicals - an increase in the $\mathrm{C}=\mathrm{N}-\mathrm{O}$ angle in the radical compared to the oxime led to a decrease in steric repulsion between the substituents at the carbon atom and the oxygen atom. It should also be noted that there is no noticeable decrease in the O-H BDE in diaryl oximes compared to dialkyl oximes (some examples are shown in Figure 4 [71]), which is consistent with

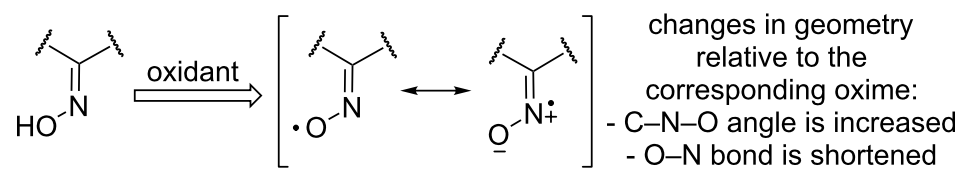

Figure 3: The electronic structure iminoxyl radicals and their geometry compared to the corresponding oximes.

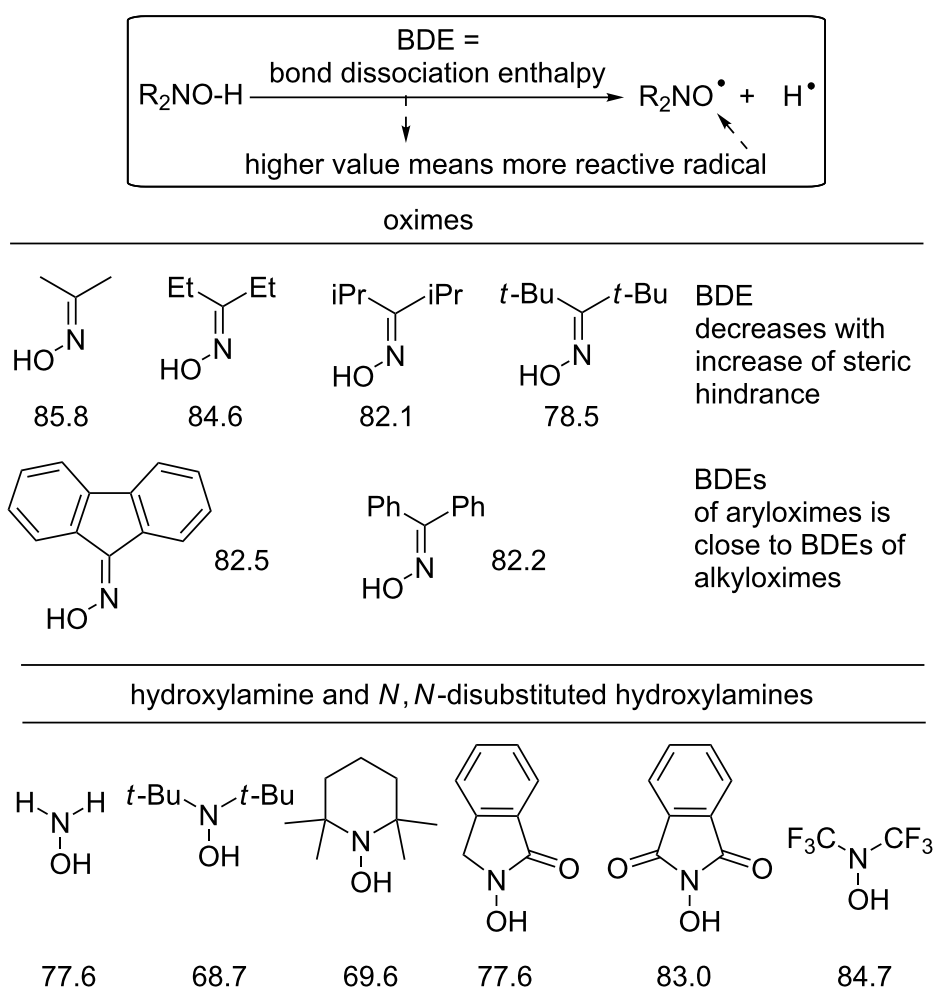

Figure 4: Bond dissociation enthalpies ( $\mathrm{kcal} / \mathrm{mol})$ of oximes and $N, N$-disubstituted hydroxylamines calculated on UB3LYP/6-311+G(d,p) level using an isodesmic reaction referencing the experiment $\mathrm{BDE}$ of phenol. 
the idea that an unpaired electron is delocalized by the conjugation with a lone pair of the nitrogen atom, but not by the conjugation with the $\pi$-system of the molecule.

Figure 4 also shows examples of the calculated values of the $\mathrm{O}-\mathrm{H}$ BDE of non-oxime compounds with a $\mathrm{NOH}$ fragment [71]. The $\mathrm{O}-\mathrm{H}$ bond in oximes is stronger than in hydroxylamines with a similar structure, except for hydroxylamines with strong electron-withdrawing groups (such as carbonyl and $\mathrm{CF}_{3}$ ).

Oxime radicals did not find wide application in organic synthesis and were mainly the subject of fundamental physicochemical studies for a long time since their discovery in 1964. The possible reason is the low stability of the majority of iminoxyl radicals. Only the relatively stable di-tert-butyliminoxyl radical was studied as a reagent in oxidative transformations of various substrates, such as unsaturated hydrocarbons, phenols, amines, and organometallic compounds. A breakthrough in the synthetic use of iminoxyl radicals has occurred in recent years when they found a wide application in intramolecular processes of oxidative cyclization with functionalization of $\mathrm{C}-\mathrm{H}$ and $\mathrm{C}=\mathrm{C}$ fragments.

In the majority of works related to synthetic use of oxime radicals, intramolecular reactions are reported. Perhaps this is due to the low stability of oxime radicals. The main preparative reactions involving oxime radicals include the addition of the oxime radical to the $\mathrm{C}=\mathrm{C}$ double bond or hydrogen atom abstraction. Due to the delocalization of the unpaired electron between the oxygen and nitrogen atoms in the oxime radicals, they can form both $\mathrm{C}-\mathrm{O}$ and $\mathrm{C}-\mathrm{N}$ bonds. As a rule, a $\mathrm{C}-\mathrm{O}$ bond is formed in intermolecular reactions, intramolecular cyclization generally occurs with the formation of a five-membered cycle of isoxazoline ( $\mathrm{C}-\mathrm{O}$ bond formation) or nitrone $(\mathrm{C}-\mathrm{N}$ bond formation).

\section{Application of the oxime radicals in organic synthesis: intermolecular reactions}

Selective intermolecular reactions involving oxime radicals are relatively rare compared with intramolecular ones. Many of these reactions involve a stable di-tert-butyliminoxyl radical. Violuric acid and $N, N$ '-dimethylvioluric acid, precursors of the corresponding persistent iminoxyl radicals, were studied as mediators for the electrochemical oxidation of lignin [73] and enzymatic oxidations [74-76] but have not been widely used in organic synthesis.

The di-tert-butyliminoxyl radical proved to be quite unreactive with respect to a $\mathrm{C}=\mathrm{C}$ double bond containing substrates that are considered as effective scavengers of free radicals (Scheme 9). It remains unchanged [45] when dissolved in styrene $\left(2\right.$ hours, $25^{\circ} \mathrm{C}$ ) or vinyl acetate $\left(20\right.$ minutes, $60{ }^{\circ} \mathrm{C}$; conversion of the oxime radical was less than $10 \%$ after 3 days at $25^{\circ} \mathrm{C}$ ). The inertness of the di-tert-butyliminoxyl radical with respect to the mentioned substrates with a $\mathrm{C}=\mathrm{C}$ double bond was explained by the steric hindrance of the iminoxyl radical.

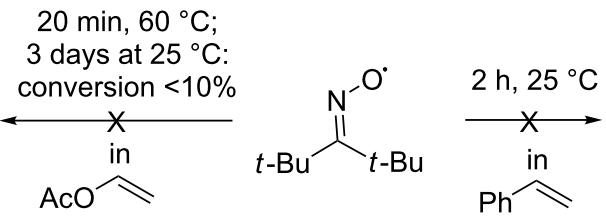

Scheme 9: Examples demonstrating the low reactivity of the di-tert butyliminoxyl radical towards the substrates with double $\mathrm{C}=\mathrm{C}$ bonds styrene and vinyl acetate.

On the other hand, di-tert-butyliminoxyl radical (8) can react with unsaturated hydrocarbons by abstracting the hydrogen atom from the allyl or benzyl position (Scheme 10) $[35,45,60,61]$. The $\mathrm{C}$-centered radicals formed after hydrogen atom abstraction from the allyl or benzyl position couple with the di-tert-butyliminoxyl radical forming the oxime ethers 21 and 22. 1,4-Cyclohexadiene is dehydrogenated to benzene instantly and exothermally at room temperature [45]. The solvent-free reaction of oxime radical 8 and cyclohexene takes $1 \mathrm{~h}$ at $25{ }^{\circ} \mathrm{C}$ [61]. The benzyl hydrogen atoms are abstracted at higher temperatures $[35,45]$.

Reactions of di-tert-butyliminoxyl radical (8) with allylic moieties can theoretically occur by two pathways that give the same final product - the $O$-allyl derivative of the oxime [35,77]. In the first pathway (Scheme 11A), the initial addition of the di-tert-butyliminoxyl radical to the double bond is followed by hydrogen atom abstraction from the resulting alkyl radical $\mathbf{2 4}$. The second pathway (Scheme 11B) begins with the abstraction of an allylic hydrogen atom, then the di-tert-butyliminoxyl radical adds to either end of the resulting allylic radical 25 . However, the results of pathways A and B are different for selectively deuterated cyclohexene $\mathbf{2 3}$ in Scheme 11. The addition-abstraction pathway (A) results in a single deuterated product 26a, whereas the abstraction-addition pathway (B) gives two products: the product obtained by pathway A (26a) and a product 26b unique to pathway $B$. The abstraction-addition process (B) is dominant for three alkenes studied, namely, cyclohexene, cyclooctene, and 3-hexene, with $90-92 \%$ of the overall reaction occurring by this mechanism [77].

The reactions of the di-tert-butyliminoxyl radical with phenol and its derivatives are faster than with alkenes. The highest reaction rates are observed in the case of electron-donating substituents $(\mathrm{Y})$ in $4-\mathrm{YC}_{6} \mathrm{H}_{4} \mathrm{OH}[35,78]$. The hydrogen atom 

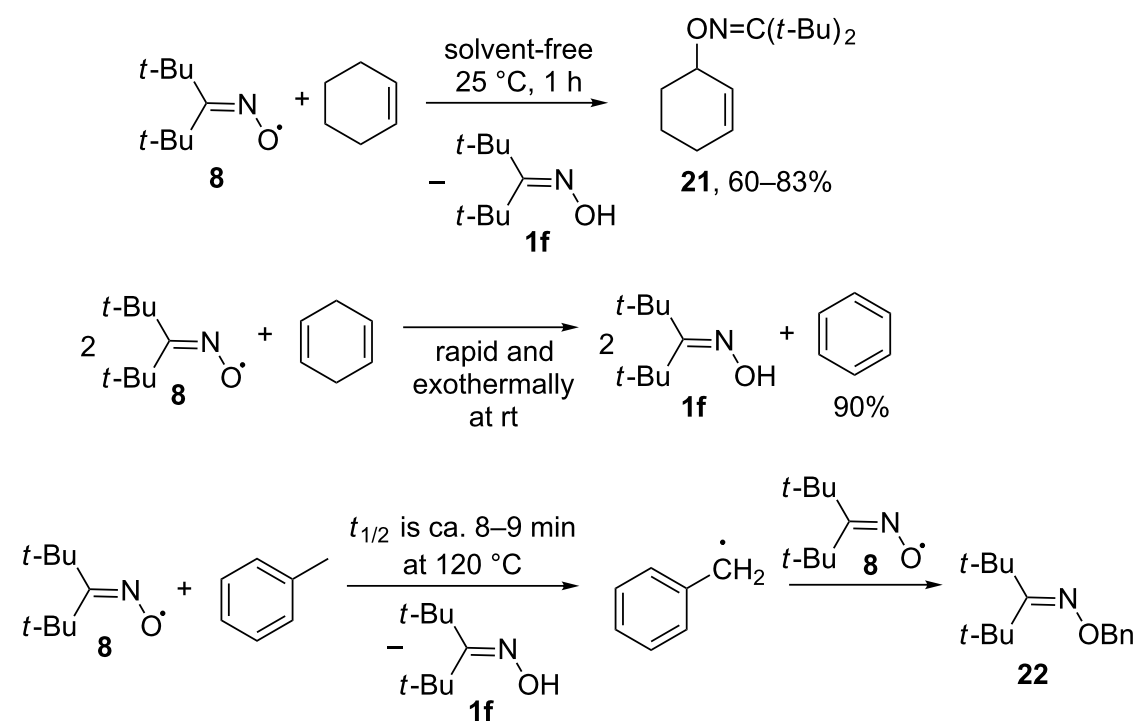

Scheme 10: The reactions of di-tert-butyliminoxyl radical with unsaturated hydrocarbons involving hydrogen atom abstraction.

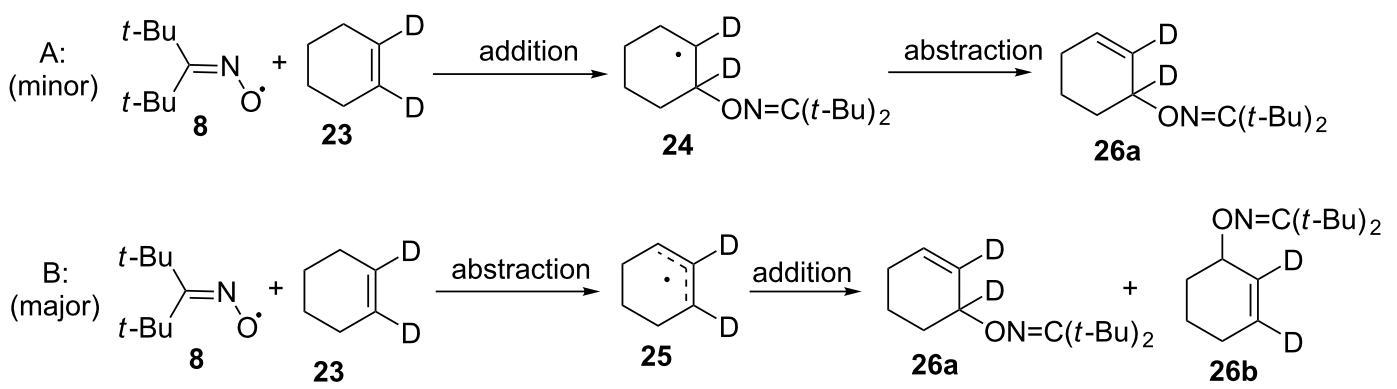

Scheme 11: Possible mechanisms of reaction of di-tert-butyliminoxyl radical with alkenes.

abstraction rate accelerating effect of electron-donating substituents was explained by the decrease of the $\mathrm{O}-\mathrm{H}$ bond dissociation energy by the electron-donating substituent Y [35,79-84].

The result of these reactions depends on the phenol structure. 4-Methylphenol (27a) and 2,6-di-tert-butyl-4-methylphenol (BHT, 27b) gave 4-methyl-4-iminooxycyclohexadienones 28a,b (Scheme 12). Phenol (29) and 1-naphthol (30) were transformed into 4,4-bisoximes $\mathbf{3 1}$ and 32, respectively (Scheme 12) [35,78].

Imines 37-40 were obtained with good yields by the reaction of di-tert-butyliminoxyl radicals with primary and secondary amines 33-36 for several hours at room temperature in pentane or hexane (Scheme 13) [85]. Due to the low stability of most imines, they were not isolated in pure form but were transformed into 2,4-dinitrophenylhydrazones. For example, the yields of 2,4-dinitrophenylhydrazones from $\mathbf{3 7}, \mathbf{3 8}$ and $\mathbf{3 9}$ were

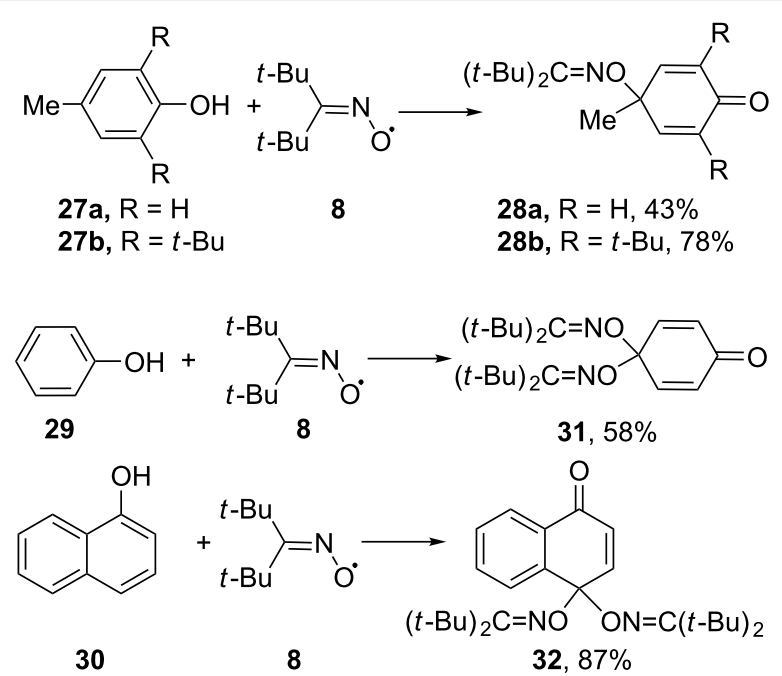

Scheme 12: Products of the reaction between di-tert-butyliminoxyl radical and phenol derivatives. 
79, 68 and 78\%, respectively [85]. The example of $N$-benzylidenemethylamine (40), shows the dependence of the imine yield on reaction time and temperature (Scheme 13). Higher yields of $\mathbf{4 0}$ were achieved at lower temperatures but longer reaction times were necessary in this case [85].

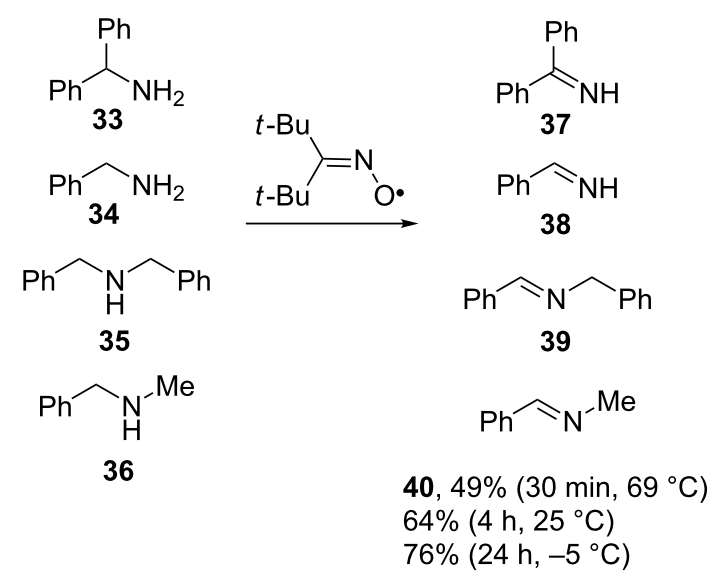

Scheme 13: The reaction of di-tert-butyliminoxyl radical with amines.

Di-tert-butyliminoxyl radicals react with Grignard reagents and organolithium reagents 41 at $0{ }^{\circ} \mathrm{C}$ in $\mathrm{Et}_{2} \mathrm{O}$ forming mainly di-tert-butyl oxime $\mathbf{1 f}$ and the products of $\mathrm{C}-\mathrm{O}$ coupling [86]. The reactions were performed by addition of the solution of the organometallic compound $\mathbf{4 1}$ in $\mathrm{Et}_{2} \mathrm{O}$ to the solution of di-tertbutyliminoxyl radical in $\mathrm{Et}_{2} \mathrm{O}$. The product yields obtained employing organolithium reagents are presented below (Scheme 14). The Grignard reagents demonstrated very similar results that are omitted.

Among the major $\mathrm{C}-\mathrm{O}$ coupling product (oxime ether $\mathbf{4 2}$ ) small amounts of $\mathrm{C}-\mathrm{N}$ coupling products (nitrones $\mathbf{4 3}$ ) were detected in the case of sterically unhindered organolithium reagents. Presumably, the reaction proceeds via SET from the organometallic compound and iminoxyl radical with the formation of an oxime anion and an intermediate $\mathrm{C}$-centered radical. In the case of $\mathrm{MeLi}$ and $\mathrm{PhLi}$, which correspond to the most reactive methyl and phenyl radicals, products $\mathbf{4 4}$ of hydrogen atom abstraction from $\mathrm{Et}_{2} \mathrm{O}$ followed by $\mathrm{C}-\mathrm{O}$ coupling of the resultant $\mathrm{C}$-centered radical with the iminoxyl radical was observed.

Recently, examples of selective intermolecular $\mathrm{C}-\mathrm{O}$ coupling between oxime radicals generated in situ from oximes and different types of $\mathrm{CH}$-reagents have been reported. 1,3-Diketones and 1,3-ketoesters 45 undergo cross-dehydrogenative C-O coupling with oximes under the action of oxidizing agents [46], such as $\mathrm{KMnO}_{4}, \mathrm{Mn}(\mathrm{OAc})_{3}$ or the $\mathrm{KMnO}_{4} / \mathrm{Mn}(\mathrm{OAc})_{3}$ system (Scheme 15). A radical mechanism is suggested for the formation of the $\mathrm{C}-\mathrm{O}$ coupling products $\mathbf{4 6}$ in which the oxidizing agent serves to generate oxime radicals from oximes and perform one-electron oxidation of 1,3-dicarbonyl compounds 45. The formation of oxime radicals under the reaction conditions was confirmed by EPR spectroscopy [46].

1,3-Diketones and 1,3-ketoesters with easily oxidizable groups, such as allyl and benzyl, were tolerated (46i and $\mathbf{4 6} \mathbf{j})$. The yield of the $\mathrm{C}-\mathrm{O}$ cross-coupling products $\mathbf{4 6}$ increases with the rise in the stability of the corresponding oxime radicals. For example, in the row $\mathbf{4 6} \mathbf{f}-\mathbf{h}$ the yield becomes higher with the increase of the steric effect of the alkyl substituents attached to the oxime group. The lowest yield was obtained with an aromatic oxime (product 46e, yield 27\%).

Later, the $\mathrm{Cu}\left(\mathrm{BF}_{4}\right)_{2}$ (cat.)/t-BuOOH oxidative system [87] was proposed as an alternative to stoichiometric metal-containing oxidants, such as $\mathrm{KMnO}_{4}, \mathrm{Mn}(\mathrm{OAc})_{3}$, and $\mathrm{KMnO}_{4} / \mathrm{Mn}(\mathrm{OAc})_{3}$ (Scheme 16).

1,3-Ketoesters (products $\mathbf{4 6 a}, \mathbf{b}, \mathbf{4 6} \mathbf{m}, \mathbf{n}$ ), 1,3-diketones (product 46r), as well as lactones (products $\mathbf{4 6 0 - q}$ ) were used in the oxidative $\mathrm{C}-\mathrm{O}$ coupling reaction. The coupling of oximes with $1,3-$ diketones proceeded in lower yields than with 1,3-ketoesters (products 46a and 46r). Despite the presence of $t$-BuOOH in the system, a Kharash peroxidation of 1,3-dicarbonyl compounds [88-93] did not occur, and a selective formation of the $\mathrm{C}-\mathrm{O}$ product with oximes was observed.

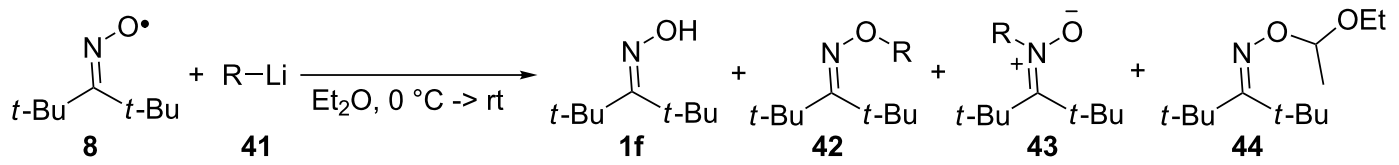

$$
\begin{aligned}
& \mathrm{R}= \\
& \mathrm{Me} \quad 65 \\
& n-\mathrm{Bu} \quad 63 \\
& t \text {-Bu } 60 \\
& \mathrm{Ph} 54
\end{aligned}
$$

-
20
18
10




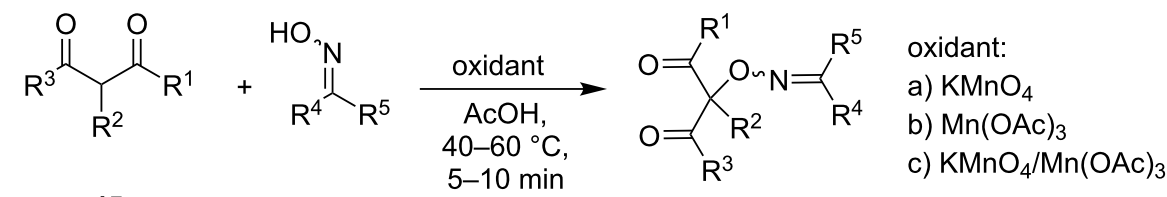

45

46, $27-92 \%$

examples of synthesized products, yields<smiles>CCOC(=O)C(C)=NOC(C)(C(C)=O)C(=O)OCC</smiles>

$46 a, 91 \%^{a}, 92 \%^{b}, 92 \%^{c}$<smiles>CCCCCCCCC(C)=NOC(C)(C(C)=O)C(C)=O</smiles>

$46 e, 27 \%$ b 46b, $(E / Z=10: 1)$, $39 \%^{\mathrm{a}}, 70 \%^{\mathrm{b}}, 71 \%^{\mathrm{c}}$<smiles>CCC(CC)=NOC(C)(C(C)=O)C(C)=O</smiles>

$46 f, 7 \%^{a}, 60 \%$<smiles>CCOC(=O)C(C)(ON=C(C)C(C)(C)C)C(C)=O</smiles>

46c, $(E / Z=12: 1)$, $41 \%^{\mathrm{a}}, 86 \%^{\mathrm{b}}, 81 \%^{\mathrm{c}}$<smiles>CCCCCCCCCCCCCCCCCCCCC(C)(OC(C)=O)C(C)=O</smiles>

$46 \mathrm{~g}, 43 \%^{\mathrm{a}}, 74 \%^{\mathrm{b}}$<smiles>CC(=O)C(C)(ON=C(C(C)C)C(C)C)C(C)=O</smiles>

46d, $52 \%^{a}, 76 \%^{b}, 72 \%^{c}$<smiles>CC(=O)C(C)(ON=C(C(C)C)C(C)C)C(C)=O</smiles>

$46 h, 57 \%^{a}, 81 \%^{b}$<smiles>C=CCC(ON=C(C(C)=O)C(C)=O)(C(C)=O)C(=O)OCC</smiles>

$46 \mathbf{i}, 76 \%^{\mathrm{b}}$<smiles>CCOC(=O)C(=NOC(Cc1ccccc1)(C(C)=O)C(=O)OCC)OCC</smiles>

$46 j, 52 \%^{a}, 72 \%^{b}, 71 \%^{c}$<smiles>CC(=O)C(=NOC1(C(C)=O)CCCC1=O)C(C)=O</smiles><smiles>CCC(C#N)=NOC(C)(C(C)=O)C(C)=O</smiles>

$46 k, 63 \%^{a}$

46I, $(E / Z=4: 1), 36 \%^{\mathrm{a}}, 58 \%$ b

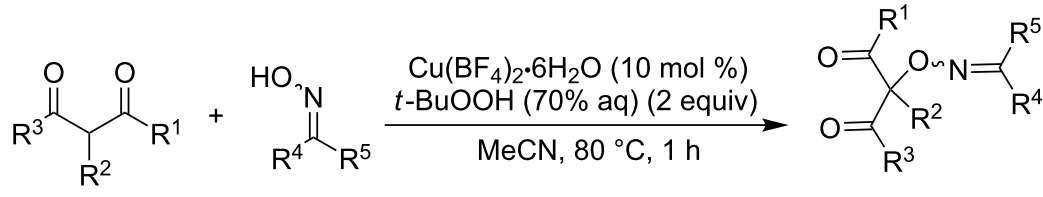

45

examples of synthesized products, yields<smiles>CCOC(=O)C(C)(ON=C(C(C)=O)C(C)=O)C(C)=O</smiles>

46a, $77 \%$<smiles>CCOC(=O)C(=NOC1(C(=O)OCC)CCCC1=O)C(=O)OCC</smiles>

$460,52 \%$<smiles>CCOC(=O)/C(C)=N/OC(C)(C(C)=O)C(=O)OCC</smiles>

46b, $E / Z=10: 1,38 \%$<smiles>CCOC(=O)C(C)(ON=C(C(=O)C(C)(C)C)C(=O)C(C)(C)C)C(C)=O</smiles>

$46 \mathrm{~m}, 25 \%$<smiles>CC(=O)C(=NOC1(C(C)=O)CCOC1=O)C(C)=O</smiles>

$46 p, 65 \%$<smiles>CCOC(=O)C(=NOC1(C(C)=O)CCOC1=O)C(=O)OCC</smiles>

$46 q, 50 \%$<smiles>CCOC(=O)CC(ON=C(C(C)=O)C(C)=O)(C(C)=O)C(C)=O</smiles>

$46 n, 25 \%$<smiles>CC(=O)C(=NOC(C)(C(C)=O)C(C)=O)C(C)=O</smiles>

$46 r, 51 \%$ 
Benzylmalononitrile (47) was introduced into the oxidative $\mathrm{C}-\mathrm{O}$ coupling with diacetyl oxime (19) analogously to 1,3dicarbonyl compounds [46], but $\mathrm{Cu}\left(\mathrm{ClO}_{4}\right)_{2}$ afforded a better yield of the $\mathrm{C}-\mathrm{O}$ coupling product $\mathbf{4 8}$ then the manganese-based oxidants in this case (Scheme 17) [94].

A radical mechanism was suggested. The copper(II) ion reacts with oxime 19 to generate iminoxyl radical 20 and also forms complex 49 with dinitrile 47 . Interaction of radical 20 and complex 49 results in the coupling product 48 (Scheme 18). The formation of radical $\mathbf{2 0}$ from the oxime $\mathbf{1 9}$ under the action of $\mathrm{Cu}\left(\mathrm{ClO}_{4}\right)_{2}$ in acetonitrile was proved by EPR spectroscopy [46].

Free-radical oxidative $\mathrm{C}-\mathrm{O}$ coupling of pyrazolones $\mathbf{5 0}$ with different classes of $N$-hydroxy compounds, including oximes, was demonstrated [44]. In contrast to the cross-dehydrogenative coupling of oximes with 1,3-dicarbonyl compounds, both one-electron oxidants $\left(\mathrm{Fe}\left(\mathrm{ClO}_{4}\right)_{3},\left(\mathrm{NH}_{4}\right)_{2} \mathrm{Ce}\left(\mathrm{NO}_{3}\right)_{6}\right)$ and twoelectron oxidants $\left(\mathrm{PhI}(\mathrm{OAc})_{2}, \mathrm{~Pb}(\mathrm{OAc})_{4}\right)$, that vary greatly in properties, are applicable for this process. After optimization of the reaction conditions $\mathrm{Fe}\left(\mathrm{ClO}_{4}\right)_{3}$ was chosen as the optimal oxidant for the synthesis of $\mathrm{C}-\mathrm{O}$ cross-dehydrogenative coupling products 51 (Scheme 19).

The extremely persistent diacetyliminoxyl radical (20) [44] was directly introduced into the reaction with pyrazolones $\mathbf{5 0}$ with the formation of the corresponding $\mathrm{C}-\mathrm{O}$ coupling products $\mathbf{5 1}$ (Scheme 20). The yields were close to that obtained with in situ generated of iminoxyl radicals (Scheme 19).

Recently, the oxidative $\mathrm{C}-\mathrm{O}$ coupling of oximes with acetonitrile, esters 52, and ketones $\mathbf{5 3}$ was realized [95] (Scheme 21). The authors suggested a radical mechanism in which the iminoxyl radical is generated from the oxime anion under the action of perfluorobutyl iodide through the formation of an EDA complex (electron donor-acceptor complex, which is also called charge-transfer complex). The perfluorobutyl radical formed at this step served for the hydrogen atom abstraction from the $\mathrm{CH}$-reagent $(\mathrm{MeCN}, \mathbf{5 2}$ or $\mathbf{5 3})$.

Ketone oximes of both aromatic (products 54a-c) and aliphatic structures $(\mathbf{5 4 d}, \mathbf{e})$ were successfully used in coupling with acetonitrile. The $\mathrm{C}-\mathrm{O}$ coupling product $\mathbf{5 4 f}$ of acetonitrile with benzaldoxime was obtained in a lower yield. The aromatic oximes reacted with esters and ketones to give oxidative coupling products in moderate to good yields (products 55a-e and 56a-e, respectively). In the case of asymmetric ketones, the $\mathrm{C}-\mathrm{H}$ bond at the more substituted carbon was cleaved (products 56d,e).

Recently, the copper-catalyzed addition of oximes to the $\mathrm{C}=\mathrm{C}$ double bond of maleimides was reported [96]. The iminoxyl radicals were detected by EPR spectroscopy, but the non-radical<smiles>N#CC(C#N)Cc1ccccc1</smiles>

47<smiles>CC(=O)C(=NO)C(C)=O</smiles>

19

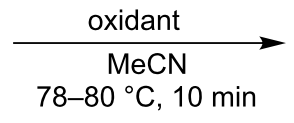

$78-80^{\circ} \mathrm{C}, 10 \mathrm{~min}$<smiles>CC(=O)C(=NOC(C)(C#N)Cc1ccccc1)C(C)=O</smiles>

$\begin{array}{ll}\text { oxidant } & \text { yield, \% } \\ \mathrm{Cu}\left(\mathrm{ClO}_{4}\right)_{2} \cdot 6 \mathrm{H}_{2} \mathrm{O} & 65 \\ \mathrm{Mn}(\mathrm{OAc})_{3} \cdot 2 \mathrm{H}_{2} \mathrm{O} & 25 \\ \mathrm{KMnO}_{4} & 10\end{array}$

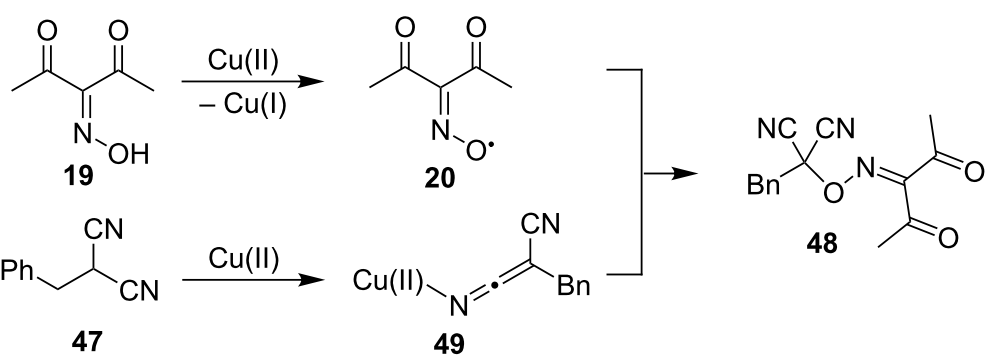


<smiles>[R]C1=C([R])C(=CC)N([R])N1</smiles>

51a, $91 \%$

examples of synthesized products, yields<smiles>CC(=O)C(=NOC1(Br)C(=O)NN=C1C)C(C)=O</smiles><smiles>CC(=O)OC1(ON=C(C(C)=O)C(C)=O)C(=O)NN=C1C</smiles>

51b, $77 \%$<smiles>CC(=O)C(=NOC1(C)C(=O)N(c2ccccc2)N=C1C)C(C)=O</smiles>

51c, $83 \%$<smiles>CC1=NNC(=O)C1(C)ON=C(C(C)(C)C)C(C)(C)C</smiles>

51d, $65 \%$<smiles>CCOC(=O)/C(C)=N/OC1(C)C(=O)NN=C1C</smiles>

51e, $E / Z=8: 1,18 \%$<smiles>CC1=NNC(=O)C1(Cc1ccccc1)ON=C1C(=O)OC(C)(C)OC1=O</smiles>

$51 \mathrm{~g}, 45 \%$<smiles>CC1=NNC(=O)C1(Br)ON=C1C(=O)N(C)C(=O)N(C)C1=O</smiles>

$51 \mathrm{~h}, 66 \%$

Scheme 19: Oxidative $\mathrm{C}-\mathrm{O}$ coupling of pyrazolones with oximes under the action of $\mathrm{Fe}\left(\mathrm{ClO}_{4}\right)_{3}$.<smiles>[R]c1c(C)[nH]n([R1])c1=O</smiles>

$50 a$

$50 \mathrm{~b}$

$$
\mathrm{R}^{1}=\mathrm{H}, \mathrm{R}^{2}=\mathrm{Bn}
$$$$
\mathrm{R}^{1}=\mathrm{H}, \mathrm{R}^{2}=\mathrm{iPr}
$$$$
\mathrm{R}^{1}=\mathrm{Ph}, \mathrm{R}^{2}=\mathrm{Me}
$$<smiles>[R]N1N=C(C)C([R])(ON=C(C(C)=O)C(C)=O)C1=O</smiles><smiles>CC(=O)C(=NO)C(C)=O</smiles>

oxime recovered

$50 \mathrm{c}$ 51a, $82 \%$

51b, $77 \%$

$50 \%$

51c, $71 \%$

$52 \%$ mechanism (copper-catalyzed Michael addition) can not be excluded completely.

\section{Application of the oxime radicals in organic synthesis: intramolecular reactions}

There are two main types of intramolecular reactions involving oxime radicals (Scheme 22). In the first type, an initial hydrogen atom abstraction is followed by a cyclization (transformation of $\mathbf{5 7}$ to 58). In the second type, an addition of oxime radicals to a $\mathrm{C}=\mathrm{C}$ double bond takes place (transformation of $\mathbf{5 9}$ to 60 or 61). As a result of the reaction, a 5-membered cycle is formed via the formation of $\mathrm{C}-\mathrm{O}$ (products 58 and $\mathbf{6 0}$ ) or $\mathrm{C}-\mathrm{N}$ bond (product $\mathbf{6 1}$ ) in accordance with the ability of oxime radicals to act as $\mathrm{O}$ - or N-radicals.
The formation of the heterocycles, mainly isoxazolines/isoxazoles, from unsaturated oximes can be achieved through different ways including addition of electrophiles to the $\mathrm{C}=\mathrm{C}$ double bond of the unsaturated oxime followed by intramolecular nucleophilic attack of the oxime group [97-100], metal-catalyzed cyclization [98,101-108], cyclization under the action of photocatalysts $[109,110]$, cyclization of nitroso intermediate [111], etc. [112,113]. At least some of these reactions do not involve oxime radicals as intermediates. It should be noted that free-radical cyclizations mediated by iminoxyl radicals frequently afford products that are hardly achievable or not achievable by non-radical methods. In this review only works in which the participation of iminoxyl radicals was confirmed or assumed are discussed.

\section{Oxidative cyclization with the cleavage of the $\mathrm{C}-\mathrm{H}$ bond}

In one of the first works in this area oximes with activated $\mathrm{C}-\mathrm{H}$ bond in the $\beta$-position were transformed into isoxazolines or isoxazoles by oxidative cyclization [114] under the action of TEMPO and $\mathrm{K}_{2} \mathrm{CO}_{3}$ (Scheme 23).

The presence of aryl substituents at the $\beta$-position of the oxime contributed to high yields of the desired products $(63 \mathbf{a}-\mathbf{c}$, $55-87 \%$ ), in the presence of only methyl substituents moderate yields were observed (63d, 34\%). The reaction proceeds exclusively with the closure of the five-membered cycle and participation of the $\mathrm{C}-\mathrm{H}$ bond located exclusively in the $\beta$-position with respect to the oxime group. This regularity is maintained even when the activated benzylic $\mathrm{C}-\mathrm{H}$ bond is present in the 


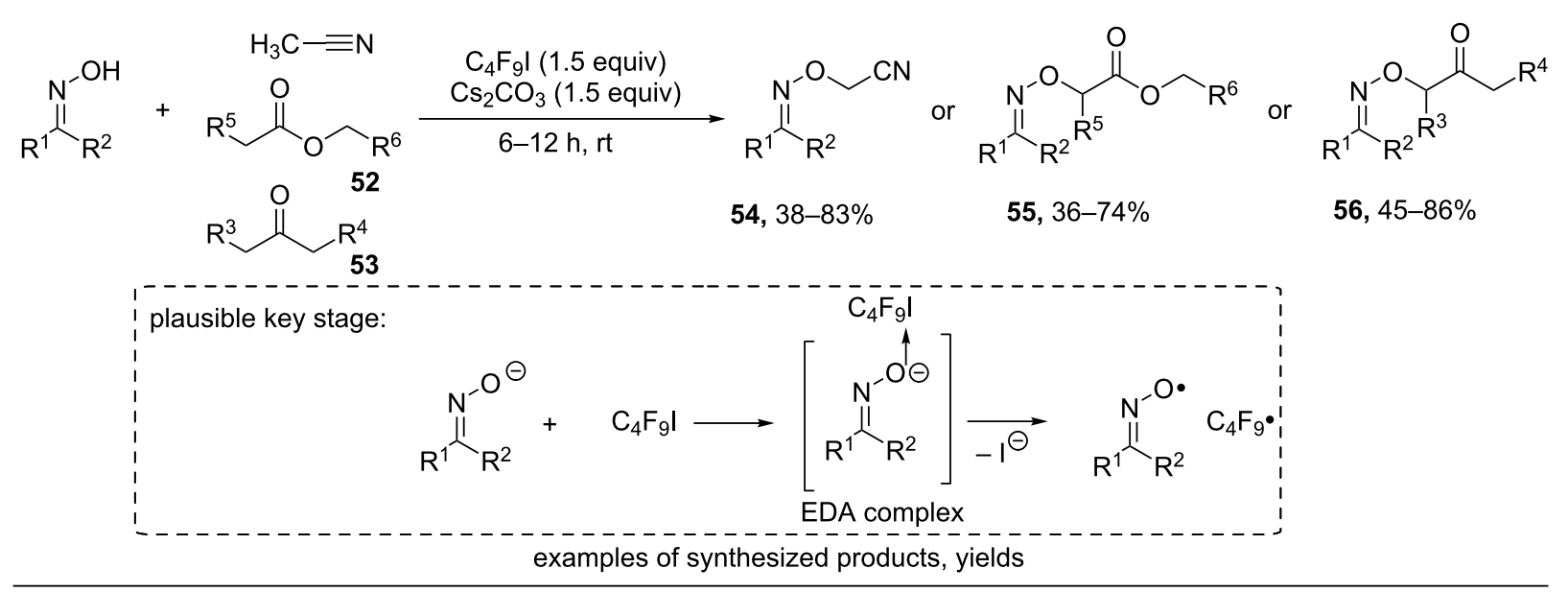<smiles>C/C(=N\OCC#N)c1ccccc1</smiles>

54a, $82 \%$<smiles>C/C(=N\OCC#N)c1ccc(N)cc1</smiles>

54b, $88 \%$<smiles>CCC/C(=N\OCC#N)c1ccccc1</smiles>

54c, $83 \%$<smiles>N#CCON=C1CCCCC1</smiles>

54d, $70 \%$<smiles>CC(C)=NOCC#N</smiles>

54e, $55 \%$ (by NMR)

54f, $38 \%$<smiles>CCOC(=O)CO/N=C(\C)c1ccccc1</smiles>

55a, $72 \%$<smiles>CC(=O)CO/N=C(\C)c1ccccc1</smiles>

56a, $75 \%$<smiles>COC(=O)CO/N=C(\C)c1ccccc1</smiles>

55b, $72 \%$<smiles>C/C(=N\OC(C)(C)C(=O)C(C)C)c1ccccc1</smiles>

56b, $90 \%$<smiles>CCOC(=O)C(C)O/N=C(\C)c1ccccc1</smiles>

55c, $50 \%$<smiles>C/C(=N\OC1(C)CCCC(C)C1=O)c1ccccc1</smiles>

56c, $70 \%$<smiles>CCOC(=O)C(OCC)O/N=C(\C)c1ccccc1</smiles>

55d, $45 \%$<smiles>COC(O/N=C(\C)c1ccccc1)C(C)=O</smiles>

56d, $55 \%$<smiles>C/C(=N\OC1CCCOC1=O)c1ccccc1</smiles>

55e, $36 \%$<smiles>CC(=O)C(C)(C)O/N=C(\C)c1ccccc1</smiles>

56e, $45 \%$

Scheme 21: Oxidative $\mathrm{C}-\mathrm{O}$ coupling of oximes with acetonitrile, ketones, and esters.

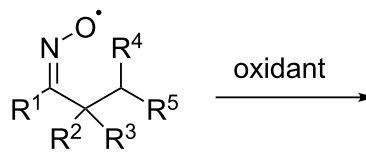

57

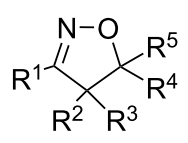

58<smiles>[R]C(=C)C([R])([R])/C([R])=C\OC</smiles>

59

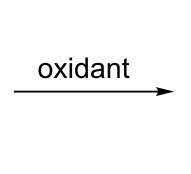<smiles>[X]CC1([R])ON=C([R])C1([R])C[R]</smiles>
or

$60, n=0$

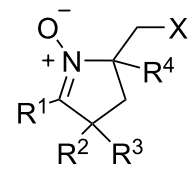

61, $n=1$

Scheme 22: Intramolecular cyclizations of oxime radicals to form substituted isoxazolines or cyclic nitrones.

$\gamma$-position with respect to the oxime group (example 63e, yield $14 \%)$. Almost in all examples, an aryl substituent $\left(\mathrm{R}^{1}=\mathrm{Ph}\right.$ or substituted phenyl) was located at the oxime group; the product 63f with $\mathrm{R}^{1}=$ Et was obtained in a moderate yield of $40 \%$. In the presence of only one aryl group in the $\beta$-position $\left(\mathrm{R}^{3}=\mathrm{H}\right.$, $\mathrm{R}^{2}=\mathrm{Ar}$ ) and further processing of the reaction mixture with atmospheric oxygen, an aromatization occurs with the formation of isoxazoles (64a,b 55-95\%). 
<smiles>[R]C([R])C([R])NO</smiles>

62

$$
\begin{gathered}
\underset{\text { TEMPO ( } 3 \text { equiv) }}{\mathrm{K}_{2} \mathrm{CO}_{3} \text { ( } 2 \text { equiv) }} \\
\underset{\mathrm{DMF}, 140{ }^{\circ} \mathrm{C}}{8-31 \mathrm{~h}}
\end{gathered}
$$

$32-95 \%$<smiles>[R]C1=NOC([R])([R])C1[R]</smiles>

63 (if $\mathrm{R}^{3}$ not $\mathrm{H}$ )<smiles>[R]c1noc([R])c1[R]</smiles>

64 (if $R^{3}=H$ )

examples of synthesized products, yields<smiles>Cc1ccc(C2=NOC(c3ccccc3)(c3ccccc3)C2)cc1</smiles>

$63 a, 82 \%$<smiles>c1ccc(C2=NOC(c3ccccc3)(c3c[nH]c4ccccc34)C2)cc1</smiles>

63b, $87 \%$<smiles>CC1(c2ccccc2)CC(c2ccccc2)=NO1</smiles>

$63 c, 55 \%$<smiles>CC1(C)CC(c2ccccc2)=NO1</smiles>

$63 d, 34 \%$<smiles>c1ccc(C2=NOC(C3CC(c4ccccc4)C3)C2)cc1</smiles>

63e, $14 \%$<smiles>CCC1=NOC(c2ccccc2)(c2ccccc2)C1</smiles>

63f, $40 \%$<smiles>c1ccc(-c2cc(-c3ccccc3)on2)cc1</smiles>

$64 a, 55 \%$<smiles>c1ccc(-c2noc(-c3ccccc3)c2-c2ccccc2)cc1</smiles>

64b, $95 \%$

Scheme 23: TEMPO-mediated oxidative cyclization of oximes with $\mathrm{C}-\mathrm{H}$ bond cleavage

Presumably, the reaction of TEMPO with oxime $\mathbf{6 2}$ affords the iminoxyl radical 65 (Scheme 24). 1,5-HAT in the radical 65 gives a C-centered radical 66, which is captured by TEMPO to form intermediate 67. Elimination of TEMPOH leads to a $\beta$-unsaturated oxime $\mathbf{6 8}$, which could undergo cyclization by ionic or radical mechanisms to give isoxazoline $\mathbf{6 3}[114,115]$

A similar cyclization with the formation of isoxazolines $\mathbf{7 0}$ was realized [116] by the oxidation of oximes 69 by the Selectfluor/ $\mathrm{Bu}_{4} \mathrm{NI}$ system (Scheme 25). A radical mechanism was proposed in which the hypoiodite formed from the oxime undergoes a homolytic cleavage of the $\mathrm{O}-\mathrm{I}$ bond with the formation of the iminoxyl radical.
As a rule, $\mathrm{R}^{1}$ is an aromatic ring, and the yield of the target product weakly depends on the electronic effects of substituents in this ring (products 70a-d). Good yields were obtained even with substrates having inert non-benzyl $\mathrm{C}\left(\mathrm{sp}^{3}\right)-\mathrm{H}$ bonds (products 70f-h). It is important to note that products with two substituents in the $\alpha$-position to the oxime group (70i,j) were obtained with good yields. The formation of 70i and $\mathbf{7 0} \mathbf{j}$ is impossible through an intermediate similar to intermediate $\mathbf{6 8}$ in Scheme 24.

Oxidative cyclization of $N$-benzyl amidoximes $\mathbf{7 1}$ was realized [117] under the action of molecular oxygen with the formation of either 1,2,4-oxadiazoles $\mathbf{7 2}$ or quinazolinones $\mathbf{7 3}$<smiles>[R]C(=NO)C([R])C([R])[R]</smiles>

62<smiles>[R]C1=NOC([R])([R])C1[R4]</smiles><smiles>CC#CC</smiles>

63<smiles>[R]/C(=N/[O-])C([R])C([R])[R]</smiles>

65<smiles>[R]C(=NO)C([R])=C([R])[R]</smiles>

- TEMPOH<smiles>[R]C(=NO)C([R])C([R])C</smiles>

TEMPO<smiles>[R]/C(=N/O)C([R])C([R])(O)O[I-]#N</smiles>

67 


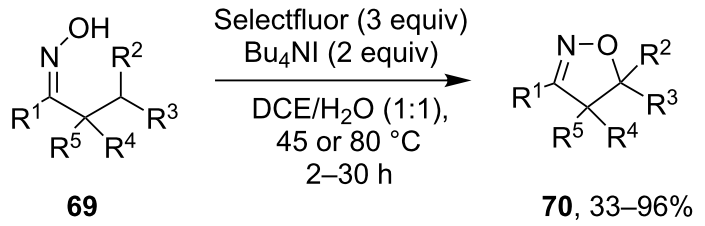

examples of synthesized products, yields<smiles>COc1ccccc1C1=NOC(c2ccccc2)C1</smiles>

$70 a, 96 \%$<smiles>CCOC(=O)C1(C(=O)OCC)CC(c2ccccc2)=NO1</smiles>

$70 f, 42 \%$ 70b, $94 \%$<smiles>c1ccc(C2=NOC3(CCCCC3)C2)cc1</smiles>

$70 \mathrm{~g}, 82 \%$<smiles>c1ccc(C2CC(c3cccs3)=NO2)cc1</smiles>

$70 d, 82 \%$

$70 c, 87 \%$<smiles>CC1(C)CC(c2ccccc2)=NO1</smiles>

$70 \mathrm{~h}, 73 \%$<smiles>CC1(C)C(c2ccccc2)=NOC1c1ccccc1</smiles>

$70 i, 81 \%$<smiles>COC1CC(c2ccccc2)=NO1</smiles>

70 e, $91 \%$

Scheme 25: Selectfluor/Bu $4 \mathrm{NI}$-mediated C-H oxidative cyclization of oximes.

(Scheme 26), depending on the reaction conditions. The 1,2,4oxadiazole ring was selectively obtained in DMF at $60^{\circ} \mathrm{C}$ under oxygen atmosphere $(1 \mathrm{~atm})$ in the presence of an excess of
$\mathrm{K}_{3} \mathrm{PO}_{4}$, whereas in DMSO at $100{ }^{\circ} \mathrm{C}$ under air and in the presence of $\mathrm{Cs}_{2} \mathrm{CO}_{3}$ quinazolinones $\mathbf{7 3}$ were selectively synthesized.<smiles>[R]c1ccc(-c2nc([R2])no2)cc1</smiles>

$72,48-86 \%$<smiles>[R]/C(=N/O)NCc1ccccc1</smiles>

71<smiles>[R]c1ccc2c(=O)[nH]c([R])nc2c1</smiles>

$73,45-58 \%$

examples of synthesized compounds, yields<smiles>c1ccc(-c2noc(-c3ccccc3)n2)cc1</smiles>

$72 a, 78 \%$<smiles>Cn1cc(-c2noc(-c3ccccc3)n2)c2ccccc21</smiles>

72d, $71 \%$<smiles>Cn1cc(-c2nc3ccccc3c(=O)[nH]2)c2ccccc21</smiles>

73d, $45 \%$ (with $12 \%$ of $\mathbf{7 2 d}$ )<smiles>Brc1ccccc1-c1noc(-c2ccccc2)n1</smiles>

72b, $48 \%$<smiles>c1ccc(-c2nc(-c3ccncc3)no2)cc1</smiles>

72e, $72 \%$<smiles>O=c1[nH]c(-c2ccncc2)nc2ccccc12</smiles>

$73 e, 49 \%$ (with $3 \%$ of $72 \mathbf{e}$ )<smiles>c1ccc(-c2nc(C3CCCCC3)no2)cc1</smiles>

72c, $53 \%$<smiles>COc1ccc(-c2nc(-c3ccccc3)no2)cc1</smiles>

72f, $78 \%$<smiles>COc1ccc2c(=O)[nH]c(-c3ccccc3)nc2c1</smiles>

73f, $58 \%$ (with $9 \%$ of $72 f$ ) 
The authors proposed that 1,2,4-oxadiazoles were formed by a mechanism [117], analogous to the mechanism of the TEMPOmediated oxidative oxime cyclization (Scheme 23 [114]). Apparently, both 1,2,4-oxadiazoles $\mathbf{7 2}$ and quinazolinones $\mathbf{7 3}$ are produced via the common intermediate, 4,5-dihydro-1,2,4oxadiazole. An example of such intermediate $\mathbf{7 4}$ is shown in Scheme 27. Oxidative aromatization of $\mathbf{7 4}$ leads to 1,2,4-oxadiazole 72a (Scheme 26). The second pathway, hydrogen abstraction followed by $\beta$-scission presumably leads to iminyl radical, which forms the observed quinazolinone 73a (Scheme 27) [118].<smiles>c1ccc(C2=NC(c3ccccc3)ON2)cc1</smiles>

74

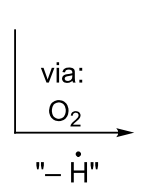

DMSO, $100^{\circ} \mathrm{C}, 2 \mathrm{~h}$ air (1 atm)<smiles>[R]c1ccc(C(=O)NC(=[V])c2ccccc2)cc1</smiles><smiles>O=c1[nH]c(-c2ccccc2)nc2ccccc12</smiles>
$77 \%$
Scheme 27: The formation of quinazolinone 73a from 5-phenyl-4,5dihydro-1,2,4-oxadiazole $\mathbf{7 4}$ under air.

The method for oxidative cyclization of thiohydroximic acids 75 under the action of DDQ and $p$-TsOH with the formation of the corresponding 1,4,2-oxathiazoles 76 was developed (Scheme 28) [119]. The authors noted that reaction in the absence of $p-\mathrm{TsOH}$ proceeded with lower yield of 76 .

A radical mechanism was proposed in which the oxime moiety is oxidized by DDQ to the iminoxyl radical 77, which undergoes 1,5-HAT to give a C-centered radical 78 stabilized by a sulfur atom. 78 is oxidized by DDQ to a carbocation $\mathbf{7 9}$, followed by the closure of the oxathiazole ring (Scheme 29). Later, DDQ-mediated oxidative cyclization of amidoximes with the formation of 1,2,4-oxadiazoles (analogous transformation with $\mathrm{K}_{3} \mathrm{PO}_{4} / \mathrm{O}_{2}$ system was shown above in Scheme 26) was realized without the addition of TsOH [120].

Isoxazolines 82 were synthesized by a one-pot sequence, which included the substitution of a halogen atom in $\alpha$-halogenated oxime $\mathbf{8 0}$ by dicarbonyl compound $\mathbf{8 1}$ and oxidative cyclization (Scheme 30) [121].

The introduction of electron-donating substituents into the benzene ring of the oxime increases the yield of the reaction product (example 82d, 90\%), and the introduction of the electron-withdrawing substituents decreases it (example 82e, 64\%). Non-aromatic oximes of chloro- or bromoacetone are not suitable for this method; product $\mathbf{8 2 f}$ was observed in trace amounts. According to the proposed reaction pathway, the nucleophilic substitution of the halogen atom with the formation of intermediate $\mathbf{8 3}$ proceeds in the presence of a base (Scheme 31). Oxidation of $\mathbf{8 3}$ with silver(I) affords the iminoxyl radical $\mathbf{8 4}$, which undergoes cyclization to form $\mathbf{8 5}$. Subsequent oxidation leads to intermediate $\mathbf{8 6}$, which is deprotonated to form the final product $\mathbf{8 2}$.

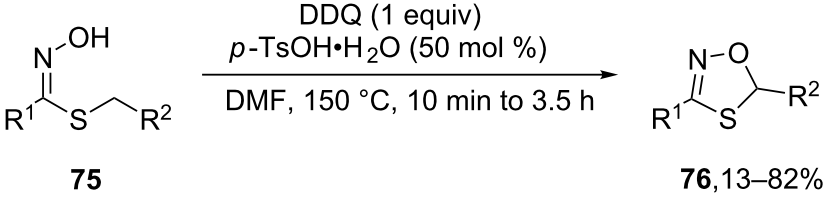

examples of synthesized compounds, yields<smiles></smiles>

$76 a, 82 \%$<smiles>c1ccc(C2ON=C(C3CCCCC3)S2)cc1</smiles>

$76 e, 80 \%$<smiles>c1ccc(C2=NOC(c3cccnc3)S2)cc1</smiles>

$76 b, 22 \%$<smiles>c1ccc(CCC2=NOC(c3ccccc3)S2)cc1</smiles>

$76 f, 63 \%$<smiles>[PH3+]c1ccccc1C=CC1ON=C(c2ccccc2)S1</smiles>

$76 c, 68 \%$

$76 d, 68 \%$<smiles>C=CC1ON=C(c2ccccc2)S1</smiles>

76g, $38 \%$ 


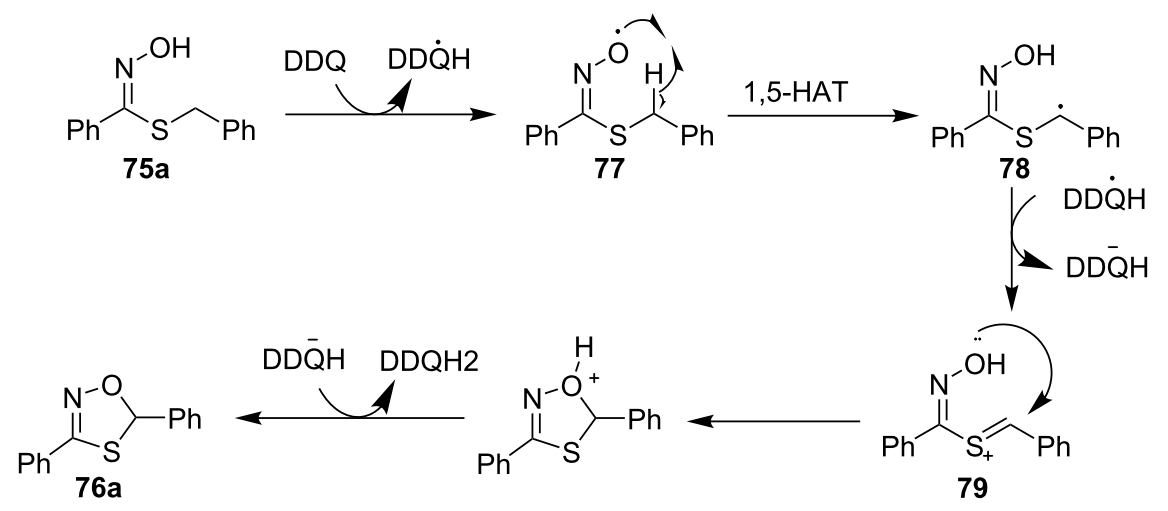

Scheme 29: Plausible mechanism of the oxidative cyclization of thiohydroximic acids.

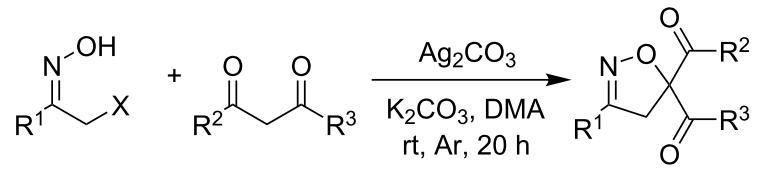

80

81

$82,21-93 \%$

examples of synthesized compounds, yields<smiles>CC(=O)C1(C(=O)OCc2ccccc2)CC(c2ccccc2)=NO1</smiles>

82a, $93 \%$<smiles>CC(=O)C1(C(=O)Nc2ccccc2)CC(c2ccccc2)=NO1</smiles>

82b, $63 \%$

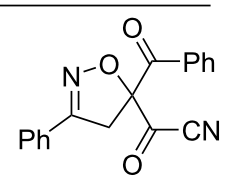

82c, $53 \%$<smiles>COc1ccc(C2=NOC(C(C)=O)(C(C)=O)C2)cc1</smiles>

82d, $90 \%$<smiles>CC(=O)C1(C(C)=O)CC(c2ccc(N)cc2)=NO1</smiles>

$82 e, 64 \%$<smiles>CC(=O)C1(C(C)=O)CC(C)=NO1</smiles>

82f, trace
Scheme 30: Silver-mediated oxidative cyclization of $\alpha$-halogenated ketoximes and 1,3-dicarbonyl compounds.
A convenient method for the synthesis of 1,2,4-oxadiazolines $\mathbf{8 8}$ by oxidative cyclization of amidoximes $\mathbf{8 7}$ under the action of molecular oxygen and visible light in the presence of catalytic amounts of 2,4,6-tris(4-fluorophenyl)pyrilium tetrafluoroborate (T $(p-\mathrm{F}) \mathrm{PPT})$ was proposed (Scheme 32) [122].

Pyrrolidinyl oxime derivatives having both aromatic (products 88a-d) and aliphatic (products 88e,f) substituents are applicable. Oximes with an isoindoline or tetrahydroisoquinoline fragment also undergo this transformation to give substituted oxadiazolines (products $\mathbf{8 8 g}, \mathbf{h}$ ). The authors note that $\mathrm{T}(p-\mathrm{F}) \mathrm{PPT}$ plays the role of a photocatalyst that promotes the formation of an oxime radical that undergoes 1,5-HAT to form the target product.

\section{Oxidative cyclization with the cleavage of $\pi$-bond $\mathrm{C}=\mathrm{C}$}

Early examples of oxidative cyclization of iminoxyl radicals with an attack on $\pi$-bonds were reported in the 1980s [123]. However, the structure of the products was not exactly proved, the scope of application and preparative potential of these reactions was not studied (Scheme 33).<smiles>[Y][R18]([R3])=C(CC([R])=N[O])C([R])=C([R])O</smiles><smiles>[R]C(=O)C1(C([R])=O)CC([R])=NO1</smiles>

82<smiles>[R]C1=NOC(C([R])O)(C([R])O)C1</smiles>

86<smiles>[R]C(=O)C1(C([R])O)CC([R])=NO1</smiles>

85

Scheme 31: Possible pathway of one-pot oxidative cyclization of $\alpha$-halogenated ketoximes and 1,3-dicarbonyl compounds. 


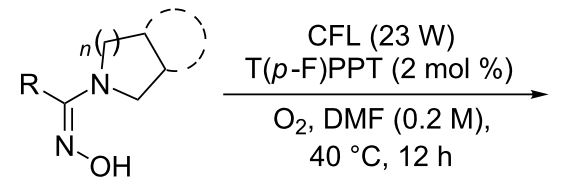

87

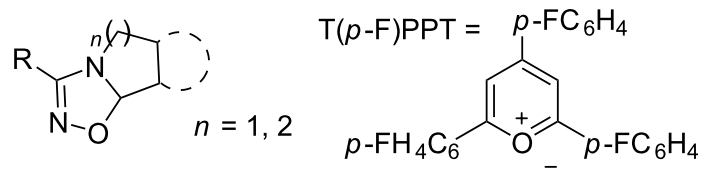

$88,32-87 \%$
$\mathrm{BF}_{4}^{-}$

examples of synthesized compounds, yields

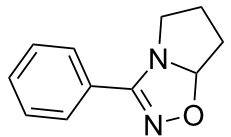

$88 a, 82 \%$

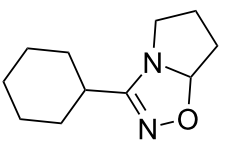

$88 \mathrm{e}, 78 \%$

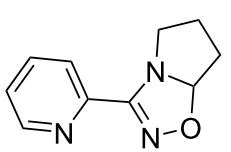

88b, $76 \%$

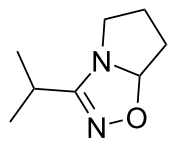

88f, $74 \%$

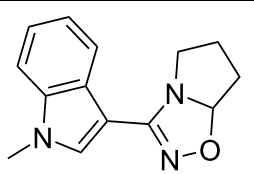

88c, $58 \%$<smiles>Clc1ccc(C2=NOC3CCCN23)s1</smiles>

88d, $64 \%$

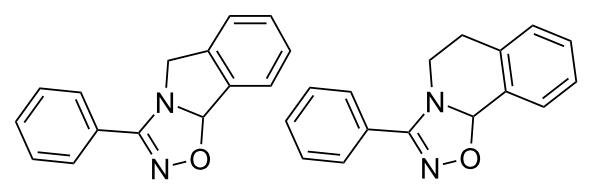

$88 g, 61 \%$

88h, $32 \%$

Scheme 32: T(p-F)PPT-catalyzed oxidative cyclization of oximes with the formation of 1,2,4-oxadiazolines.<smiles>[R]C(=N)c1ccccc1N=Nc1ccccc1</smiles>

89

$\mathrm{R}=\mathrm{Me}, \mathrm{Ph}$

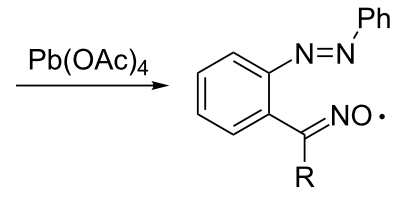

90

proposed based on EPR spectrum<smiles>C/C=C\c1ccccc1/C(=N\O)c1ccccc1</smiles>

$92 \mathrm{Ph}$<smiles>CC(C)=NC(=N[O+])c1ccccc1-c1ccccc1</smiles>

93

proposed based on EPR spectrum<smiles>[R]C1([NH+]([O-])[N-]C)C2C=CC=CC2=NN1PN</smiles><smiles>[R]c1c2ccccc2nn1-c1ccccc1</smiles>

91<smiles>CC1c2ccccc2C(c2ccccc2)=[N+]1[O-]</smiles>

94<smiles>CC1C2CCC1(c1ccccc1)N([O-])C2c1ccccc1</smiles>

95 proposed based on EPR spectrum
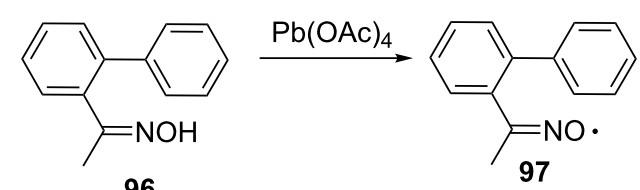<smiles>Cc1ccc2c(c1)c(C)[n+]([O-])c1ccccc21</smiles><smiles>Cc1nc2ccccc2c2ccccc12</smiles>

99<smiles>O/N=C(/C(=[Al])C(=C(c1ccccc1)c1ccccc1)c1ccccc1)c1ccccc1</smiles>

100

$\mathrm{Ar}=\mathrm{Ph}, \mathrm{o}-\mathrm{MeC}_{6} \mathrm{H}_{4}$<smiles>[Y]/C(=N\O[Ga])C(=C(c1ccccc1)c1ccccc1)c1ccccc1</smiles><smiles>[N-]C1=C(c2ccccc2)C(c2ccccc2)=C2C=CC=CC12[N+](=O)[O-]</smiles> 
When the oxime 89 with an azo fragment was treated by lead(IV) acetate at $-60{ }^{\circ} \mathrm{C}$, an EPR signal with the HFS constant $\mathrm{a}^{\mathrm{N}}=31 \mathrm{G}$ was observed which indicated the formation of the iminoxyl radical 90. Presumably, the radical 90 underwent cyclization involving the azo group to form indazole $\mathbf{9 1}$.

During the photolysis of a mixture of di-tert-butyl peroxide with oxime 92 containing an alkenyl fragment at temperatures from -30 to $-10{ }^{\circ} \mathrm{C}$, two signals were observed in the EPR spectrum with a constant $\mathrm{HFC} \mathrm{a}^{\mathrm{N}}=30 \mathrm{G}$ and $32 \mathrm{G}$, corresponding to iminoxyl radicals 93. At higher temperature $\left(+10^{\circ} \mathrm{C}\right)$, only one signal was observed with $\mathrm{a}^{\mathrm{N}}=19.75 \mathrm{G}$. This HFS value is characteristic of bicyclic nitroxyl radicals [123]. The authors suggested that the formed iminoxyl radical underwent cyclization with the formation of alkyl radical 94. The latter attacked the nitrone moiety to form the bicyclic nitroxyl radical
95. When oxime 96 was oxidized with lead(IV) acetate, products 98 and 99 were observed. This result can be explained by the intramolecular attack of iminoxyl radical 97 on the phenyl $\pi$-system. According to EPR data, the authors suggested that iminoxyl radicals 101 generated from oximes 100 by photolysis with the addition of the di-tert-butyl peroxide gave nitroxides $\mathbf{1 0 2}$ [123].

The widespread use of iminoxyl radicals in organic synthesis involving a radical addition to a $\mathrm{C}=\mathrm{C}$ bond started to develop extensively only after 2010 . The oxidation of $\beta, \gamma$ - and $\gamma, \delta$-unsaturated oximes (103 and 104, respectively) using the TEMPO/ DEAD system or only DEAD (diethyl azodicarboxylate) afforded 5-exo-trig radical cyclization [124] with the formation of the corresponding isoxazolines $\mathbf{1 0 5}$ and $\mathbf{1 0 6}$ or cyclic nitrones 107 and 108 (Scheme 34).
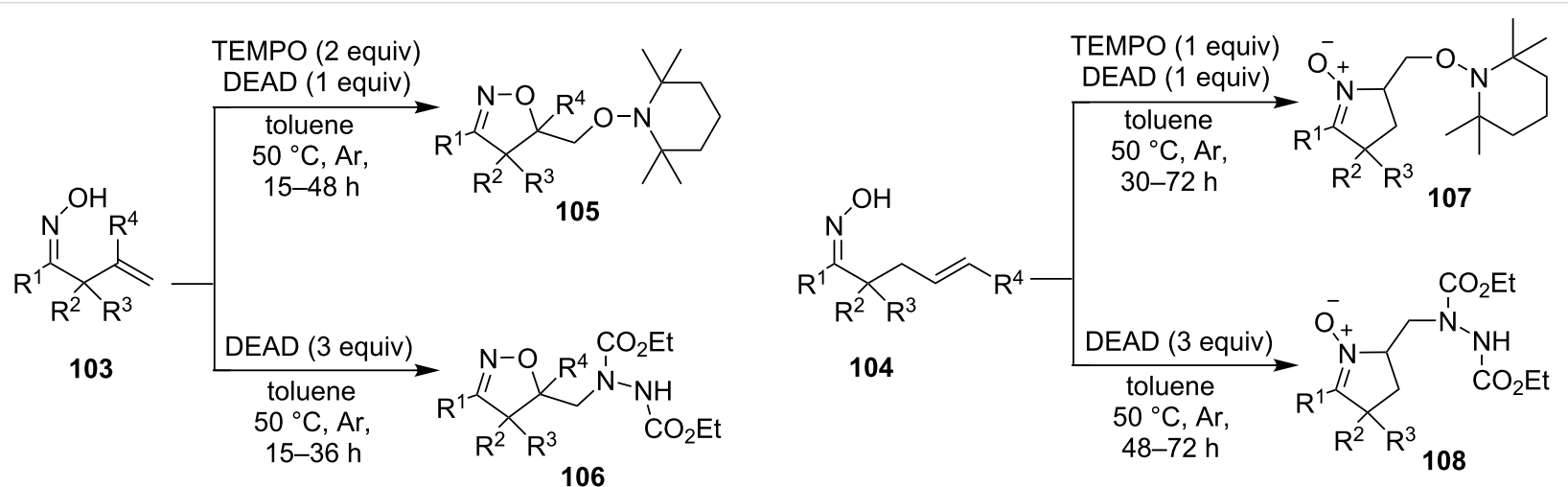

examples of synthesized compounds, yields

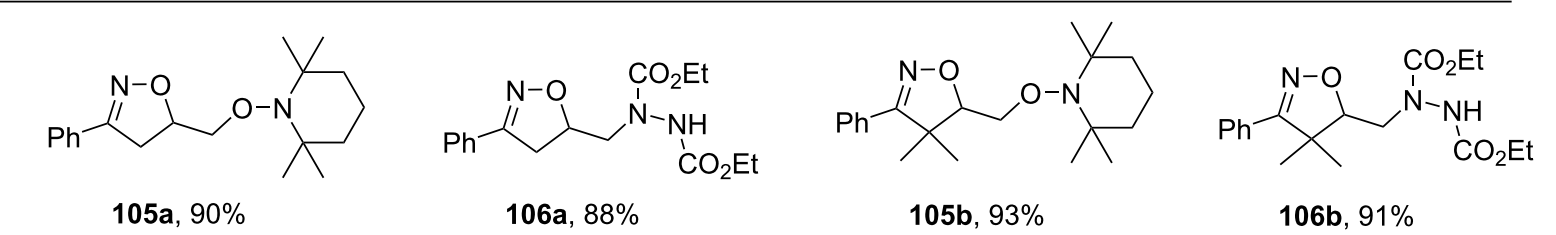

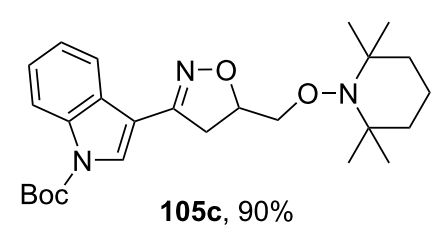<smiles>CCOC(=O)NN(C(=O)OCC)[C@H]1CCC[C@H]2C(c3ccccc3)=NO[C@H]21</smiles>

$106 c, 88 \%$ $\mathrm{dr}=95: 5$<smiles>CC1(C)CC(CON2C(C)(C)CCCC2(C)C)[N+]([O-])=C1c1ccccc1</smiles>

$107 a, 80 \%$<smiles></smiles>

$107 \mathrm{~b}, 83 \%$ $\mathrm{dr}=50: 50$<smiles>CC1(CON2C(C)(C)CCCC2(C)C)CC(c2ccccc2)=NO1</smiles>

105d, 93\%<smiles>CCOC(=O)NN(C(=O)OCC)C(c1ccccc1)C1CC(C)(C)C(c2ccccc2)=[N+]1[O-]</smiles>

108a, $71 \%$ $\mathrm{dr}=64: 36$<smiles>CC(C)(C)C1=NOC(CON2C(C)(C)CCCC2(C)C)C1</smiles>

105 e, $77 \%$

108b, $68 \%$ dr >99:1 
A variety of $\beta, \gamma$-unsaturated oximes $\mathbf{1 0 3}$ with an aromatic substituent at the $\mathrm{C}=\mathrm{NOH}$ group reacted with the formation of isoxazolines (products 105a-d, 106a-c, yields 88-93\%). Product 105e containing a non-aromatic tert-butyl $\mathrm{R}^{1}$ group was synthesized in good yield (77\%). When $\gamma, \delta$-unsaturated oximes were applied the formation of cyclic nitrones was observed (products $\mathbf{1 0 7} \mathbf{a}, \mathbf{b}, \mathbf{1 0 8 a}, \mathbf{b})$. In this case, the intermediate oxime radicals reacted as $\mathrm{N}$-centered radicals, which was consistent with the calculations [124]. If the double bond of the starting oxime was endocyclic, high stereoselectivity was observed with the formation of trans-products (examples 106c and 108b).

The oxidative cyclization of $\beta, \gamma$-unsaturated oximes 109 under the action of molecular oxygen and catalytic amounts of bis(5,5-dimethyl-1-(4-methylpiperazin-1-yl)hexane-1,2,4trione)cobalt(II) $\left(\mathrm{Co}(\mathrm{nmp})_{2}\right)$ resulted in isoxazolines $\mathbf{1 1 0}$ with a hydroxylmethyl group or methylisoxazolines 111 (Scheme 35) [125].

The reaction in $\mathrm{iPrOH}$ under an oxygen atmosphere with the addition of $10 \mathrm{~mol} \%$ of $t-\mathrm{BuOOH}$ (conditions A) produced hydroxymethylisoxazolines $\mathbf{1 1 0}$, and the reaction in toluene under air with the addition of 20 equivalents of cyclohexa-1,4diene (CHD) as hydrogen atom donor (conditions B) led to methylisoxazolines 111. Both aromatic (examples 110a-c,f, 111a,b,f) and aliphatic (examples 110d,e and 111c-e) $\beta, \gamma-$ unsaturated oximes undergo this cyclization. The conditions A were also applied for the oxidation of $\alpha, \beta$-unsaturated oxime 109'. As a result, 5-endo-trig cyclization affording hydroxyisoxazoline 110' in good yield was observed.

Another approach to the synthesis of hydroxy-substituted isoxazolines $\mathbf{1 1 3}$ is the manganese(III) acetylacetonate catalyzed reaction of $\beta, \gamma$-unsaturated oximes 112 with oxygen of air (Scheme 36) [126].

The peroxide initially formed in the reaction was reduced by treatment with a saturated $\mathrm{Na}_{2} \mathrm{~S}_{2} \mathrm{O}_{4}$ solution. The formation of peroxide was confirmed by a control experiment in which the hydroperoxide 113b' was isolated when the treatment of the reaction mixture with sodium dithionite was omitted. High yields were reached for both monosubstituted (products 113a,d,f,h) and disubstituted $\mathrm{C}=\mathrm{C}$ bonds (products 113b,c,e,g). Aliphatic oximes also undergo this transformation in high yields (products $113 \mathbf{c}, \mathbf{g}, \mathbf{h}$ ).

The photocatalytic oxidative cyclization of $\beta, \gamma$-unsaturated oximes 114 was carried out under the action of a PC-I/TEMPO

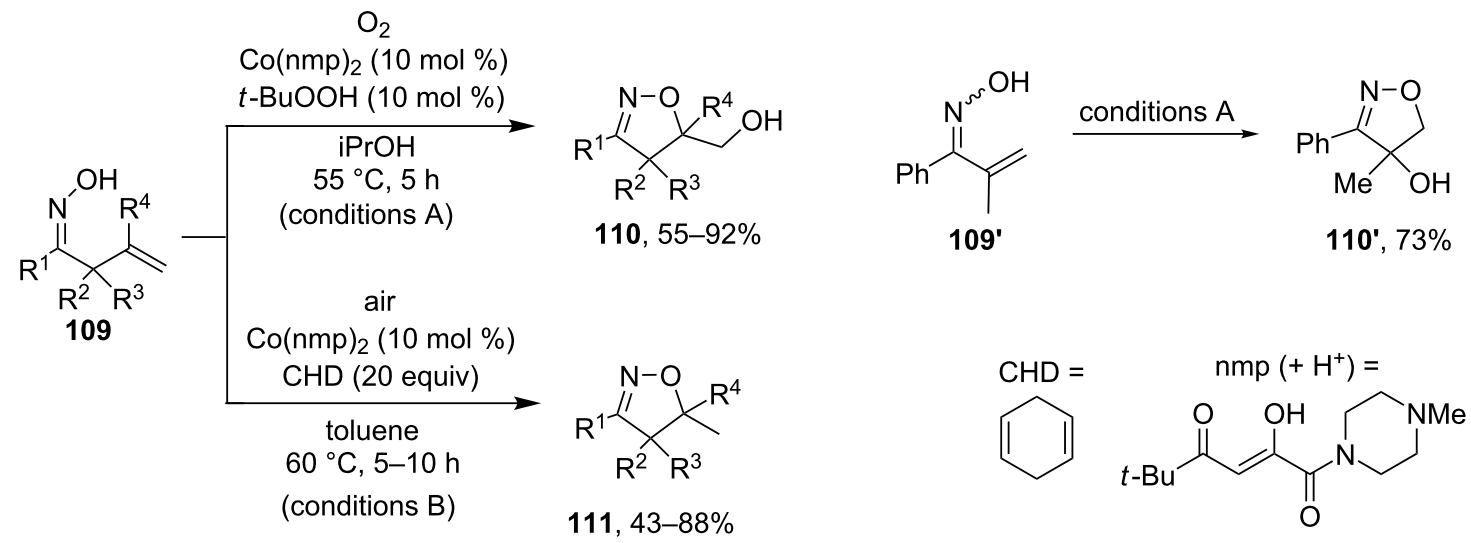

examples of synthesized compounds, yields

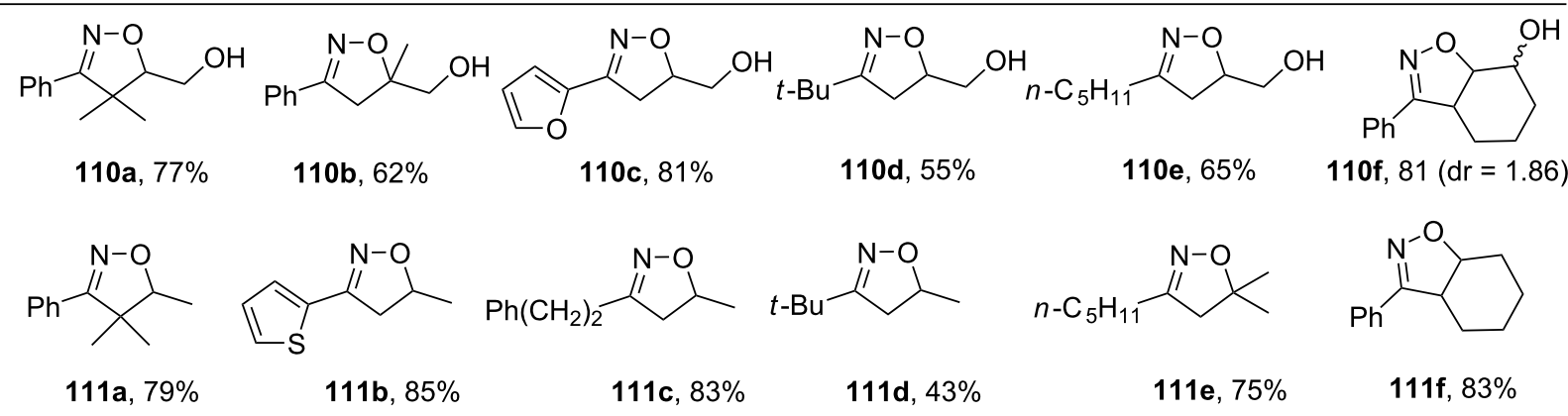




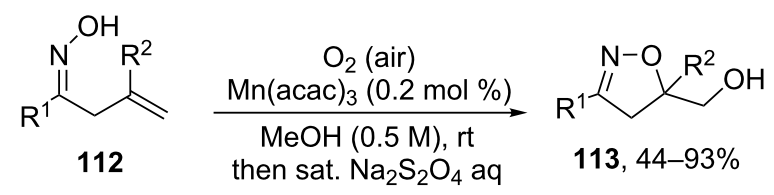

examples of synthesized compounds, yields<smiles>OCC1CC(c2ccccc2)=NO1</smiles>

$113 e, 82 \%$
$113 a, 93 \%$

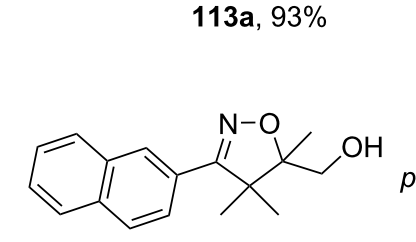<smiles>CC1(CO)CC(c2ccccc2)=NO1</smiles>

$113 b, 81 \%$<smiles>CC1(CO)CC(C(C)(C)C)=NO1</smiles>

$113 \mathrm{c}, 88 \%$<smiles>OCC1CC(c2ccco2)=NO1</smiles>

113d, $59 \%$
$113 b^{\prime}$

(intermediate isolated without। $\mathrm{Na}_{2} \mathrm{~S}_{2} \mathrm{O}_{4}$ addition)<smiles>COCCC1CC(CO)ON1</smiles>

$113 f, 82 \%$<smiles>CC1(CO)CC(CCc2ccccc2)=NO1</smiles>

$113 g, 82 \%$<smiles>OCC1CC([14CH2]O[SnH3])=NO1</smiles>

$113 \mathrm{~h}, 79 \%$

Scheme 36: Manganese-catalyzed aerobic oxidative cyclization of $\beta, \gamma$-unsaturated oximes.

catalytic system and the irradiation of blue LEDs (Scheme 37) [127].

A variety of electronically rich and electronically poor aryl or heteroaryl groups at the oxime group $\left(\mathrm{R}^{1}\right)$ are well-tolerated (products 115a-e). Oximes with disubstituted double $\mathrm{C}=\mathrm{C}$ bond also successfully undergo this cyclization (products 115f-h).
$\mathrm{C}$-centered radicals generated in a radical 5-exo-trig cyclization of $\beta, \gamma$-unsaturated oximes 116 upon oxidation by the TBAI/ TBHP system were trapped by an isonitrile group of 2-arylphenyl isonitriles 117 to synthesize substituted phenanthridines 118 (Scheme 38) [128].

Both aliphatic (example 118c) and aromatic (examples 118a,b,d-h) $\beta, \gamma$-unsaturated oximes enter this cascade cycliza-<smiles>[R]C=C([R])C/C([R])=N\O</smiles>

114
PC-I (5 mol \%) TEMPO (10 $\mathrm{mol} \%)$

$7 \mathrm{~W}$ blue LEDs $(450-460 \mathrm{~nm})$ $\mathrm{MeCN}, \mathrm{O}_{2}$, rt then $\mathrm{PPh}_{3}$ (1 equiv)<smiles>[R]C1=NOC([R])(C([R])O)C1</smiles>

$115,60-97 \%$

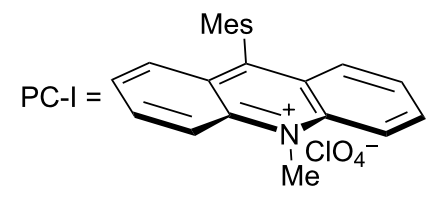

examples of synthesized compounds, yields<smiles>OCC1CC(c2ccccc2)=NO1</smiles>

115a, $97 \%$<smiles>CCCCC1=NOC(CO)C1</smiles>

115b, $70 \%$

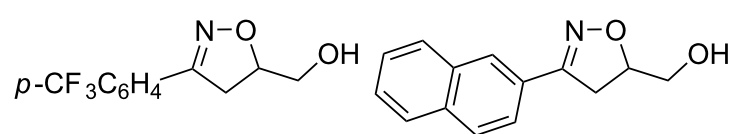

$115 c, 60 \%$
$115 d, 95 \%$<smiles>OCC1CC(c2cccs2)=NO1</smiles>

$115 e, 94 \%$<smiles>CC1(CO)CC(c2ccccc2)=NO1</smiles>

$115 f, 78 \%$<smiles>OC1CCCC2C(c3ccccc3)=NOC12</smiles>

$115 \mathrm{~g}, 65 \%$ $\mathrm{dr}=5: 2$<smiles>OC(c1ccccc1)C1CC(c2ccccc2)=NO1</smiles>

$115 \mathrm{~h}, 73 \%$ $\mathrm{dr}=5: 3$ 


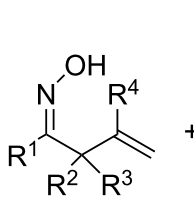

116<smiles>[R2][Z]1ccc(-c2[R]cccc2[N+]#[C-])cc1</smiles>

117
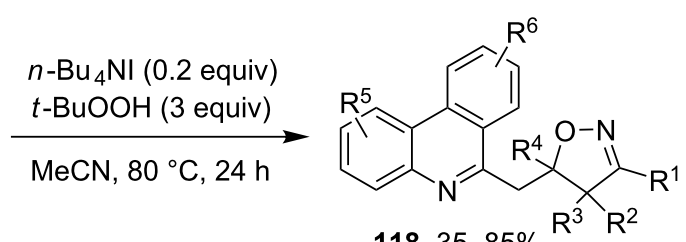

examples of synthesized compounds, yields<smiles>CC1(C)C(c2ccccc2)=NOC1Cc1nc2ccccc2c2ccccc12</smiles>

118a, $82 \%$<smiles>Cc1ccc2nc(CC3ON=C(c4ccccc4)C3(C)C)c3ccccc3c2c1</smiles>

118e, $74 \%$<smiles>CC1(C)C(c2cccs2)=NOC1Cc1nc2ccccc2c2ccccc12</smiles>

118b, $74 \%$<smiles>COc1ccc2c(c1)c(CC1ON=C(c3ccccc3)C1(C)C)nc1ccccc12</smiles>

118f, $65 \%$<smiles>CC1(C)C(CCP)=NOC1Cc1nc2ccccc2c2ccccc12</smiles>

118c, $60 \%$<smiles>CC1(C)C(c2ccccc2)=NOC1Cc1nc2ccc(C#N)cc2c2ccccc12</smiles>

118g, 35\%<smiles>CC1(Cc2nc3ccccc3c3ccccc23)CC(c2ccccc2)=NO1</smiles>

118d, $58 \%$<smiles>CC1(C)C(c2ccccc2)=NOC1Cc1nc2ccccc2c2ccc(Cl)cc12</smiles>

118h, 50\%

Scheme 38: TBAI/TBHP-mediated radical cascade cyclization of the $\beta, \gamma$-unsaturated oximes.

tion. Relatively low yields were obtained with electron-withdrawing substituents in isonitrile 117 (examples 118g,h).

Another example of a cascade oxidative cyclization involving an isonitrile group is the reaction of $\beta, \gamma$-unsaturated oximes 119 with vinyl isocyanides $\mathbf{1 2 0}$ to form substituted isoquinolines 121 (Scheme 39) [129].

Both $\alpha, \alpha$-disubstituted aromatic oximes (products 121a,b,e-h) and unsubstituted $\left(\mathrm{R}^{2}=\mathrm{R}^{3}=\mathrm{H}\right.$, products $\left.121 \mathrm{c}, \mathbf{d}\right)$ undergo the<smiles>[R]/C(=C/[CH-])C([R])([R])/C([R])=N/O</smiles>

119<smiles>[R]C(=O)/C([Y19])=C(\[R7])c1[R]cccc1</smiles>

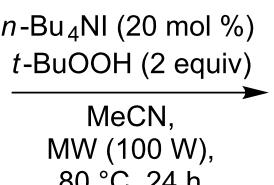

120<smiles>[R]Cc1nc(CC2([R])ON=C([R])C2([R])[R])c2ccccc2c1[R8]</smiles>

$121,57-91 \%$

examples of synthesized compounds, yields<smiles>COC(=O)c1nc(CC2ON=C(c3ccccc3)C2(C)C)c2ccccc2c1-c1ccccc1</smiles>

121a, $91 \%$<smiles>CCCCc1c(C(=O)OC)nc(CC2ON=C(c3ccccc3)C2(C)C)c2cc(C)ccc12</smiles>

$121 e, 76 \%$<smiles>COC(=O)c1nc(CC2ON=C(Pc3ccccc3)C2(C)C)c2ccccc2c1-c1ccccc1</smiles>

$121 b, 85 \%$<smiles>CCOC(=O)c1nc(CC2ON=C(c3ccccc3)C2(C)C)c2ccccc2c1-c1ccccc1</smiles>

$121 f, 75 \%$<smiles>COC(=O)c1nc(CC2CC(c3ccccc3)=NO2)c2ccccc2c1-c1ccccc1</smiles>

$121 c, 79 \%$<smiles>CC1(C)C(c2ccccc2)=NOC1Cc1nc(C(=O)N2CCCC2)c(-c2ccccc2)c2ccccc12</smiles>

121g, $71 \%$<smiles>COC(=O)c1nc(CC2(C)CC(c3ccccc3)=NO2)c2ccccc2c1-c1ccccc1</smiles>

121d, $61 \%$<smiles>CC1(C)C(c2ccccc2)=NOC1Cc1nc(C(=O)N2CCCCC2)c(-c2ccccc2)c2ccccc12</smiles>

121h, $69 \%$

Scheme 39: TBAI/TBHP-mediated radical cascade cyclization of vinyl isocyanides with $\beta, \gamma$-unsaturated oximes. 
reaction successfully. The authors noted the effect of substituents in the phenyl fragment attached to the oxime group $\left(\mathrm{R}^{1}\right)$ : high yields were obtained with para- and meta-substituted substrates; however, when ortho-substituents were present, the product 121 was not observed. Two aryl groups at the vinyl fragment of the isocyanide are important for a successful synthesis of products 121. In the case of $\mathrm{R}^{6}=\mathrm{H}$ or alkyl the formation of the oxidative cyclization product $\mathbf{1 2 1}$ was not observed [129].

The oxidative cyclization of unsaturated oximes $\mathbf{1 2 2}$ under the action of $t$-BuONO (TBN), followed by treatment with $\mathrm{NEt}_{3}$ leads to isoxazolines $\mathbf{1 2 3}$ or cyclic nitrones $\mathbf{1 2 4}$ with an additional oxime group (Scheme 40) [130].

The authors showed that the initial product of the oxidative cyclization of oxime 122a under the action of TBN was the dimer $\mathbf{1 2 7}$ of the nitroso compound 126, which was formed, presumably, as a result of nitrosation of the C-centered radical $\mathbf{1 2 5}$ by TBN [130]. Intermediate $\mathbf{1 2 7}$ was isolated in $96 \%$ yield and its structure was confirmed by a single-crystal X-ray diffraction. Under the action of $\mathrm{Et}_{3} \mathrm{~N}$, the dimeric nitroso compound $\mathbf{1 2 7}$ was converted into the more stable oxime tautomeric form 123a (Scheme 41).

$$
\begin{gathered}
\text { 1) TBN (3 equiv) } \\
\text { MeCN, Ar, rt, 0.5 h }
\end{gathered}
$$

examples of synthesized compounds, yields<smiles>CC1(C)C(c2ccccc2)=NOC1/C=N\O</smiles>

123a, $93 \%$ $\mathrm{dr}=0.63: 1$<smiles>CC1(C)CC(/C=N\O)/C(=[N+]\[O-])C1c1ccccc1</smiles>

$124 a, 82 \%$ $\mathrm{dr}=0.52: 1$<smiles>COc1ccc(C2=NOC(/C=N\O)C2)cc1</smiles>

123b, $90 \%$ $\mathrm{dr}=0.8: 1$<smiles>COc1ccc(C2=[N+]([O-])C(/C=N\O)CC2(C)C)cc1</smiles>

124b, $84 \%$ $\mathrm{dr}=0.54: 1$<smiles>CC1(C)C(CCc2ccccc2)=NOC1/C=N\O</smiles>

123c, $88 \%$ $\mathrm{dr}=0.75: 1$<smiles>CC1(C)CC(/C=N\O)[N+]([O-])=C1CCc1ccccc1</smiles>

124c, $82 \%$ $\mathrm{dr}=0.50: 1$<smiles>CC1(C)C(/C=N\O)=NOC1c1cccs1</smiles>
$\mathrm{dr}=0.96: 1$

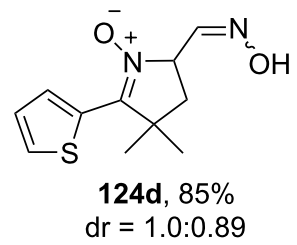

Scheme 40: tert-Butylnitrite-mediated oxidative cyclization of unsaturated oximes with the introduction of an additional oxime group.

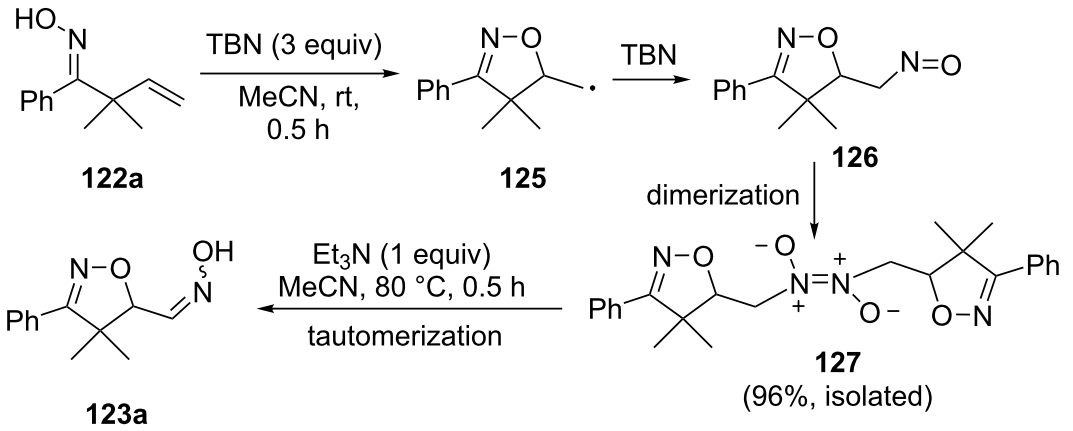

Scheme 41: Transformation of unsaturated oxime to oxyiminomethylisoxazoline via the confirmed dimeric nitroso intermediate. 
Another reaction pathway of a TBN-mediated oxidative cyclization of $\beta, \gamma$-unsaturated oximes $\mathbf{1 2 8}$ was achieved by switching from the argon atmosphere to air or oxygen atmosphere and by lowering the reaction temperature to $-10{ }^{\circ} \mathrm{C}$ [131]. Oximes 128 undergo cyclization to form nitrooxymethylsubstituted isoxazolines $\mathbf{1 2 9}$ (Scheme 42). THF was found to be the optimal solvent.

Aliphatic (examples $\mathbf{1 2 9 b}, \mathbf{f}, \mathbf{g}$ ) and aromatic (examples 129a, c,d,e,h) unsaturated oximes undergo this cyclization. Oximes containing disubstituted double bonds also give the corresponding isoxazolines $\mathbf{1 2 9} \mathbf{c}, \mathbf{h}$. The authors proposed a mecha- nism involving a 5-exo-trig cyclization of the oxime radical followed by the addition of molecular oxygen to the formed $\mathrm{C}$-centered radical with a formation of a peroxyl radical. The interaction of the latter with NO leads to the final oxynitro compound [131].

Cyano-substituted oxazolines $\mathbf{1 3 1}$ were synthesized from unsaturated oximes 130 using a combination of $t$-BuONO and a ruthenium catalyst (Scheme 43) [132]. The authors proposed that the interaction of unsaturated oxime with TBN produced a hydroxyiminomethylisoxazoline (Scheme 40) [130] that was transformed into the cyano-substituted oxazoline in the pres-<smiles>[R4]C(=C)C([R])([R])/C([R])=N\O</smiles>

128

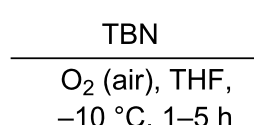

$-10^{\circ} \mathrm{C}, 1-5 \mathrm{~h}$<smiles>[R]C1=NOC([R2])([R])C1([R])CO[Na]</smiles>

$129,73-98 \%$

examples of synthesized compounds, yields

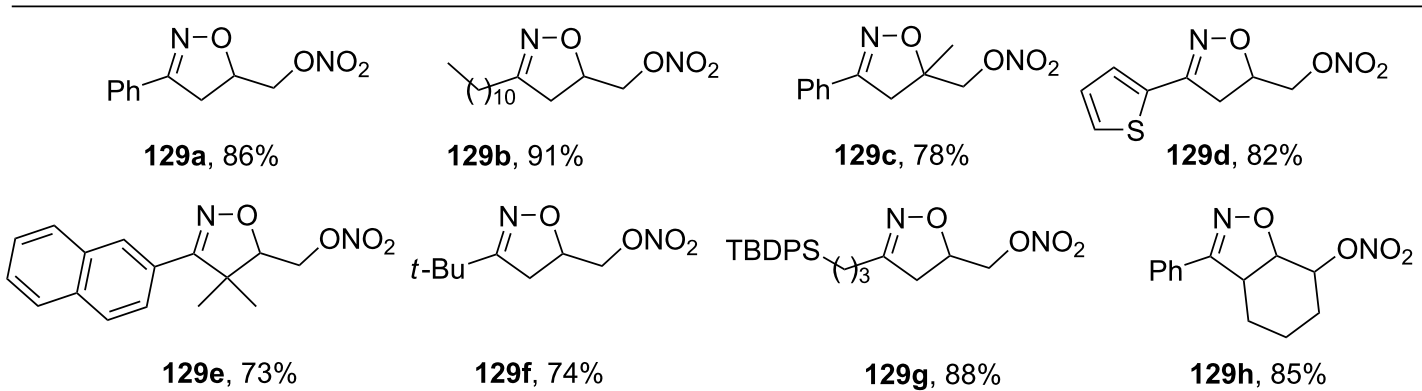

Scheme 42: tert-Butylnitrite-mediated oxidative cyclization of unsaturated oximes with the introduction of a nitrooxy group

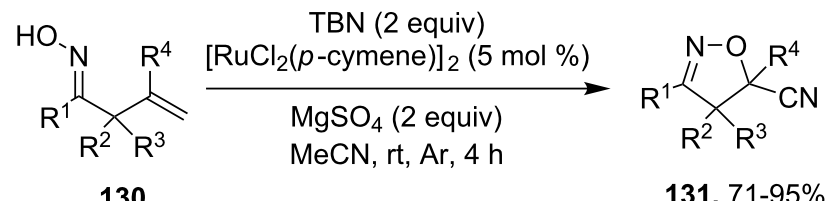

examples of synthesized compounds, yields

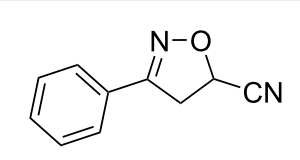

$131 \mathrm{a}, 86 \%$<smiles>N#CC1CC(c2ccco2)=NO1</smiles>

131 e, $76 \%$<smiles>N#CC1CC(c2cc(Br)cc(Br)c2)=NO1</smiles><smiles>N#CC1CC(c2ccc([N+](=O)[O-])cc2)=NO1</smiles>

131c, $85 \%$<smiles>[13CH3]C1=NOC(C#N)C1</smiles><smiles>CCCC1=NOC(C#N)C1</smiles>

131d, $71 \%$<smiles>[B][Si]([B])(P)O[As](C)(C1=NOC(C#N)C1)c1ccccc1</smiles> 
ence of a ruthenium catalyst. This possible reaction pathway was confirmed by a control experiment in which the hydroxyiminomethylisoxazoline was transformed to a nitrile in the presence of $\left[\mathrm{RuCl}_{2}(p \text {-cymene })\right]_{2}$.

Aromatic oximes with various substituents, as well as heteroaromatic oximes, give cyano-substituted oxazolines in good yields (products 131a-e). Aliphatic oximes also enter this transformation, including an oxime containing a TBDPS protecting group (products 131f-h)

The combination of $\mathrm{AgSCF}_{3}$ and catalytic amounts of $\mathrm{Cu}(\mathrm{OAc})_{2}$ was used for the synthesis of trifluoromethylthiolated isoxazolines $\mathbf{1 3 3}$ from unsaturated oximes $\mathbf{1 3 2}$ (Scheme 44) [133].
Substrates with both aryl (products 133a,d-h) and alkyl substituents (product 133b) at the oxime fragment $\left(\mathrm{R}^{1}\right.$ in 132) were successfully used for the oxidative cyclization. The proposed reaction mechanism involves the formation of an oxime radical and its 5-exo-trig cyclization to form a C-centered radical, which undergoes a trifluoromethylthiolation by $\bullet \mathrm{SCF}_{3}$-radicalgenerated from $\mathrm{AgSCF}_{3}$ [133]. The iminoxyl radical 5-exo-trig cyclization step was confirmed in experiments with the capture of a C-centered radical by TEMPO. It should be noted that in the case of $\gamma, \delta$-unsaturated oxime an unusual six-membered oxazine 133h was reported as the major product [133].

A similar cyclization of oximes $\mathbf{1 3 4}$ with the introduction of an azido group was carried out using $\mathrm{TMSN}_{3}$ as an azide source (Scheme 45) [134].

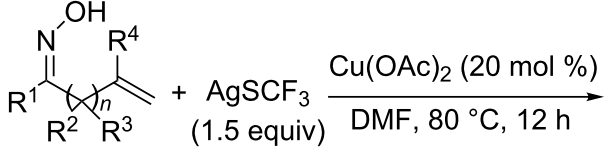

132<smiles>[R]C1=NOC([R])(CSc2ccccc2)C1([R])[R]</smiles>

$133,52-90 \%$

examples of synthesized compounds, yields

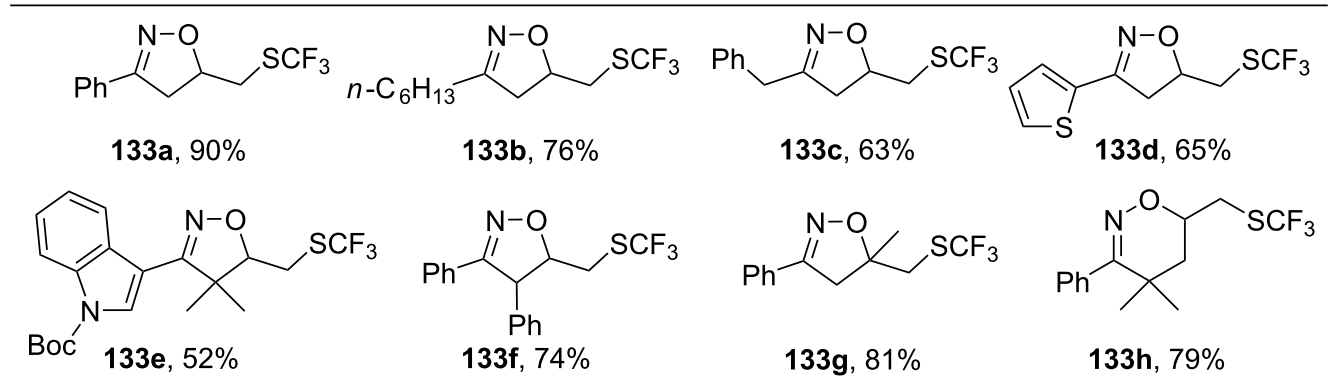

Scheme 44: Synthesis of trifluoromethylthiolated isoxazolines from unsaturated oximes
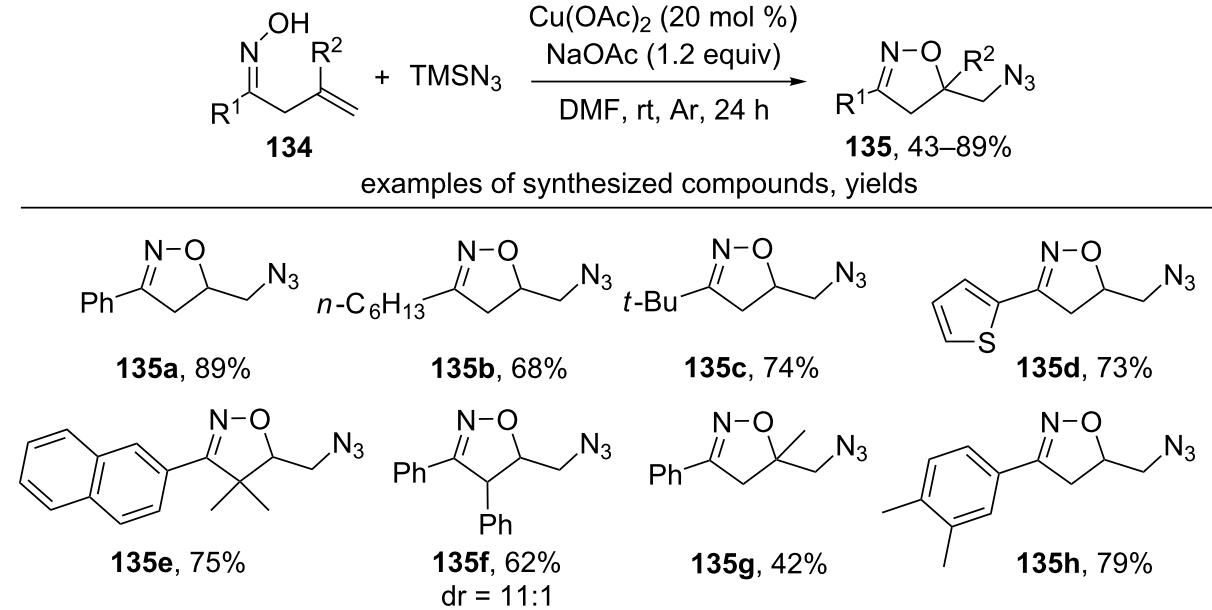
The reaction is applicable for $\beta, \gamma$-unsaturated oximes having both aryl (products 135a,d-h) and alkyl substituents (products $\mathbf{1 3 5 b , c})$ at the oxime fragment $\left(\mathrm{R}^{1}\right)$. An oxime with a disubstituted double bond $\left(\mathrm{R}^{2}=\mathrm{Me}\right)$ also reacts with the formation of isoxazoline $\mathbf{1 3 5 g}$ having a quaternary carbon atom.

Under the action of $t$-BuOOH (TBHP), $\beta, \gamma$-unsaturated oximes 136 undergo a cascade cyclization with $N$-aryl- $N$-methylmethacrylamides $\mathbf{1 3 7}$ affording substituted oxoindoles $\mathbf{1 3 8}$ (Scheme 46) [135].

In the majority of examples, aromatic $\beta, \gamma$-unsaturated oximes (examples 138a-c, e-h) were used. Oximes having a disubstituted double bond also successfully entered this reaction (example 138c). The relatively low yield of product $\mathbf{1 3 8 f}$ was explained by the steric effect of the ortho-methyl substituent in amide 137. In most cases, $N$-aryl- $N$-methylmethacrylamides were used for this cyclization to obtain oxindoles (products 138a-g) except for one example where a homologous amide was used to obtain six-membered lactam $\mathbf{1 3 8 h}$.

The catalytic system $\mathrm{Cu}(\mathrm{OAc})_{2}$ /bipyridine (bpy) was applied to perform the oxidative cyclization of unsaturated oximes 139 accompanied by the introduction of an amino group with the formation of isoxazolines $\mathbf{1 4 1}$ and cyclic nitrones $\mathbf{1 4 2}$ (Scheme 47) [136].
The best results were obtained using DTBP or aerial oxygen as an oxidant. Aliphatic, aromatic, and heteroaromatic amines 140, both primary and secondary, are applicable for this reaction.

The reaction of TEMPO with $\beta, \gamma$ - and $\gamma, \delta$-unsaturated oximes 143 leads to substituted unsaturated isoxazolines 144 and cyclic nitrones 145, respectively (Scheme 48) [137]. Presumably, the $\mathrm{C}$-centered radical formed after 5-exo-trig cyclization of the oxime radical recombines with TEMPO. The resulting adduct undergoes $\beta$-elimination of TEMPOH with the formation of final unsaturated compounds. The intermediate coupling product of the C-centered radical and TEMPO was observed when the reaction was carried out at lower temperature $\left(80{ }^{\circ} \mathrm{C}\right)$.

Isoxazolines 144 were synthesized from $\beta, \gamma$-unsaturated aryl oximes $\left(\mathrm{R}^{1}=\mathrm{Ar}\right)$ with electron-donating (examples 144a-c) and moderately electron-withdrawing substituents (example 144d). The reaction of $\gamma, \delta$-unsaturated aliphatic and aryl oximes with TEMPO yielded cyclic nitrones (products $\mathbf{1 4 5 a}-\mathbf{j}$ ). The majority of the synthesized cyclic nitrones were disubstituted in $\alpha$-position to the $\mathrm{C}=\mathrm{NO}$ group $(\mathbf{1 4 5 a} \mathbf{a}-\mathbf{f}, \mathbf{h}-\mathbf{j})$, the unsubstituted

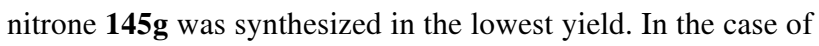
$\mathbf{1 4 5 j} \mathbf{- 1 4 5} \mathbf{j}$ ' the dehydrogenation of the side chain attached to $\mathrm{C}=\mathrm{NO}$ fragment was observed.

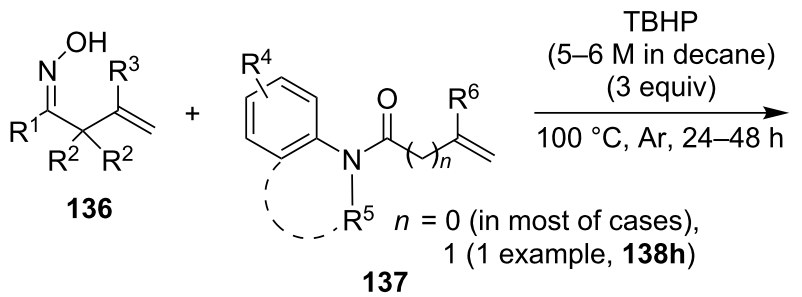

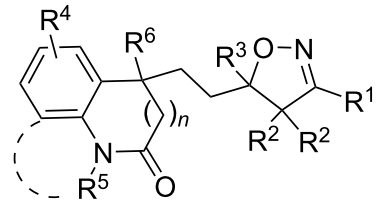

examples of synthesized compounds, yields

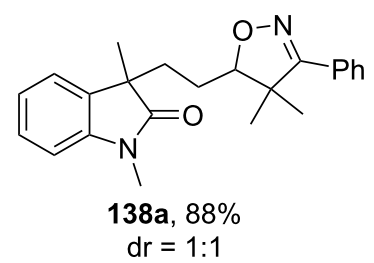<smiles>CN1C(=O)C(C)(CCC2ON=C(c3cccs3)C2(C)C)c2ccccc21</smiles><smiles>CCCCCCCCC1(C)C(=O)N(C)c2ccccc21</smiles><smiles>CN1C(=O)C(C)(CCC2ON=C(CCc3ccccc3)C2(C)C)c2ccccc21</smiles>

$\mathrm{dr}=1: 1$

$138 \mathrm{~d}, 60 \%$<smiles>CN1C(=O)C(C)(CCC2ON=C(c3ccccc3)C2(C)C)c2cc(C#N)ccc21</smiles>

$138 \mathrm{e}, 81 \%$ $\mathrm{dr}=1: 1$<smiles>Cc1cccc2c1N(C)C(=O)C2(C)CCC1ON=C(c2ccccc2)C1(C)C</smiles>

138f, $44 \%$ $\mathrm{dr}=1: 1$ $\mathrm{dr}=1: 1$<smiles>CC1(C)C(=O)N2CCc3cc(C#N)cc1c32</smiles> 

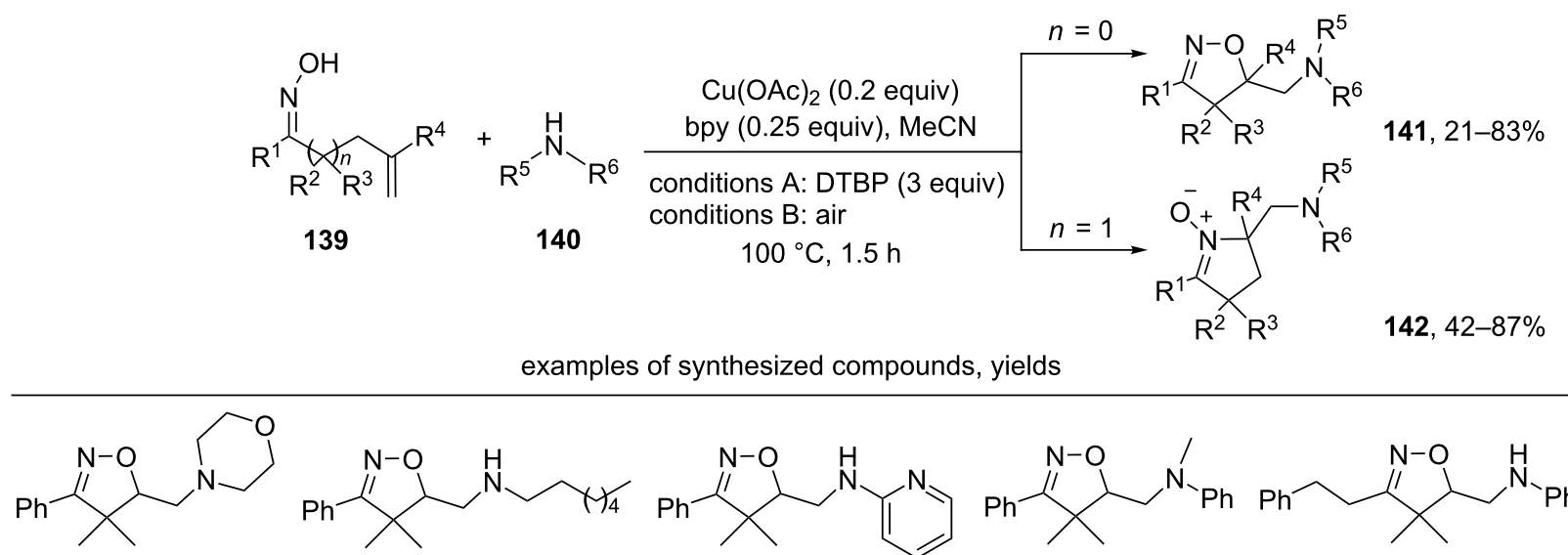<smiles>CC(CCCCNc1ccccn1)CCNCC1ON=C(c2ccccc2)C1(C)C</smiles><smiles>CN(CC1ON=C(c2ccccc2)C1(C)C)c1ccccc1</smiles>
141a, A: $80 \%$, B: $71 \%$<smiles>COc1ccc(C2=[N+]([O-])C(CNc3ccccc3)CC2(C)C)cc1</smiles><smiles>CC1(C)CC(CNc2ccccc2)[N+]([O-])=C1c1cccs1</smiles>

141c, A: $45 \%$, B: $30 \%$

141d, A: $51 \%$, B: $37 \%$

141e, A: $52 \%$, B: $49 \%$

142a, A: $83 \%$, B: $73 \%$

142b, A: $77 \%$, B: $68 \%$<smiles>CC1(C)CC(CNc2c(Cl)cccc2Cl)C(c2ccccc2)=[N+]1[O-]</smiles><smiles>CN(CC1CC(C)(C)C(c2ccccc2)=[N+]1[O-])c1ccccc1</smiles><smiles>CC1(C)CC(CN2CCCCC2)[N+]([O-])=C1c1ccccc1</smiles>

142c, $A: 46 \%$, B: $38 \%$ 142d, A: $62 \%$, B: $43 \%$

142e, A: $51 \%$, B: $36 \%$

Scheme 47: Copper-catalyzed oxidative cyclization of unsaturated oximes with the introduction of an amino group.

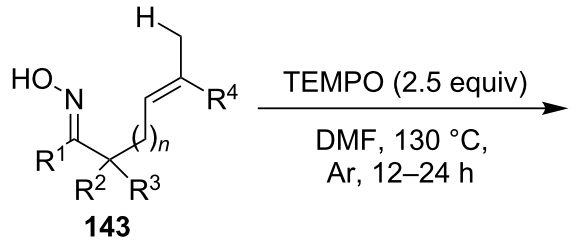

examples of synthesized compounds, yields

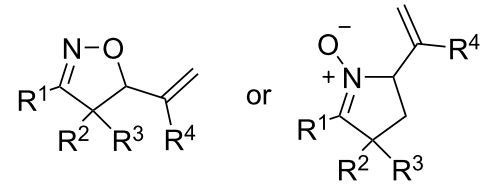

$144,86-92 \%$

$n=0$

$145,38-99 \%$

$n=1$

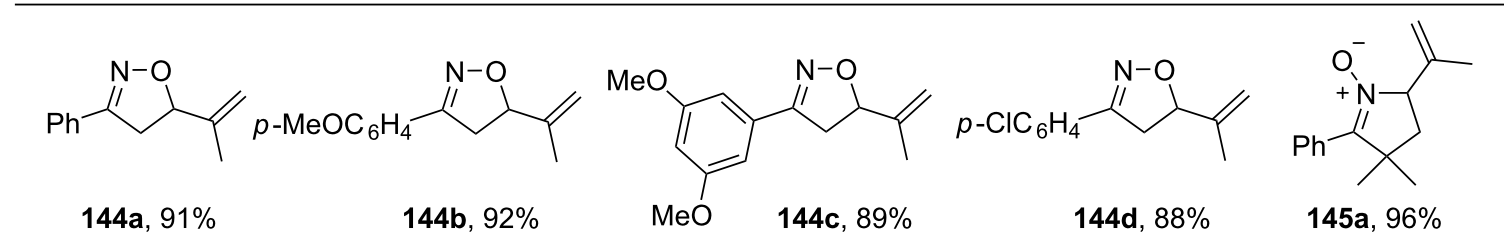<smiles>[2H]OCCC1=[N+]([O-])C(C(=C)C)CC1(C)C</smiles>

145b, $97 \%$

$145 c, 84 \%$

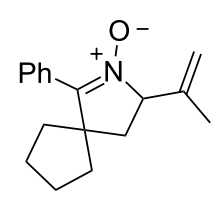

145d, $98 \%$

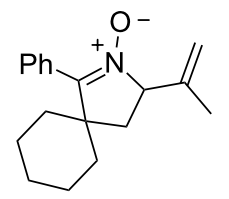

145e, $93 \%$

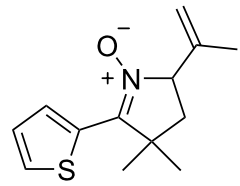

145f, $76 \%$<smiles>C=C(C)C1CCC(c2ccccc2)=[N+]1[O-]</smiles>

145g, $40 \%$<smiles>C=C(C)C1CC(C)(C)C(C2CCCCC2)=[N+]1[O-]</smiles>

$145 \mathrm{~h}, 99 \%$<smiles>C=C(C(C)C)C1CC(C)(C)C(c2ccccc2)=[N+]1[O-]</smiles>

$145 i$<smiles>CC(C)=C(C)C1CC(C)(C)C(c2ccccc2)=[N+]1[O-]</smiles>

$145 i^{\prime}$

$54 \%\left(75 \mathrm{i} / 75 \mathrm{i}^{\prime}=2.9: 1\right)$

145j, traces

145j', $60 \%$ 
Under the action of the $\mathrm{TMSCF}_{3} /$ trichloroisocyanuric acid/ TCCA/CuOAc/CsF system $\beta, \gamma$-unsaturated oximes 146 undergo oxidative cyclization to form substituted isoxazolines 147 with a trifluoromethyl group (Scheme 49) [138]. The authors note that the presence of 1,10-phenanthroline is necessary to stabilize the intermediate $\mathrm{CuCF}_{3}$.

Aromatic oximes with various electron-donating and electronwithdrawing substituents afford cyclization products in high yields (products 147a-d). In addition to aryl oximes, benzyl and tert-butyl substituted oximes (products 147e,f) were successfully used.

Oxidative cyclization of unsaturated oximes with the formation of isoxazolines or cyclic nitrones and the introduction of a nitrile group was achieved using the $\mathrm{CuCN} / N, N, N^{\prime}, N^{\prime \prime}, N^{\prime \prime}-$ pentamethyldiethyltriamine (PMDETA)/TBHP system (Scheme 50) [139]. Other aliphatic amine ligands $\left(N, N, N^{\prime}, N^{\prime}-\right.$ tetramethylethylenediamine and 1,1,4,7,10,10-hexamethyltriethylenetetramine) showed moderate results and aromatic

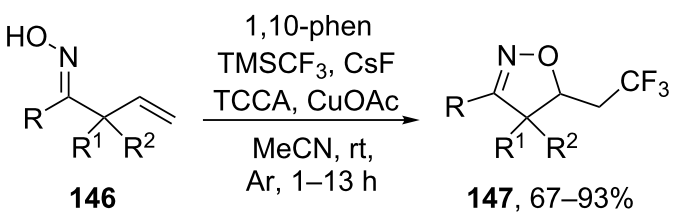

examples of synthesized compounds, yields

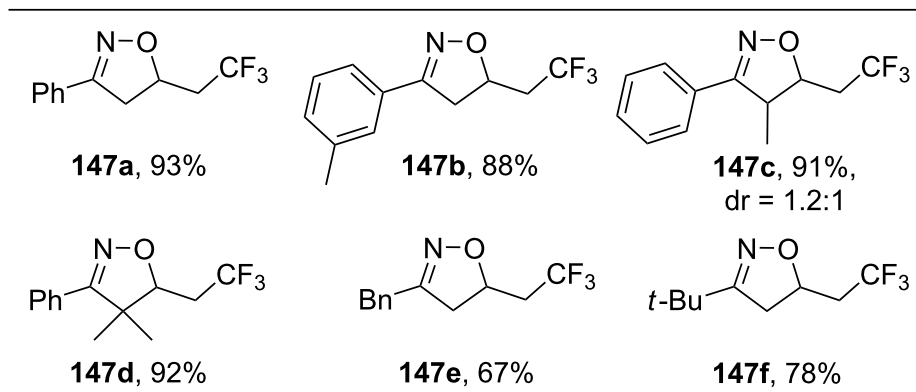

Scheme 49: Oxidative cyclization of $\beta, \gamma$-unsaturated oximes with the introduction of a trifluoromethyl group.

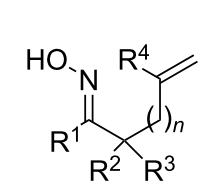

148

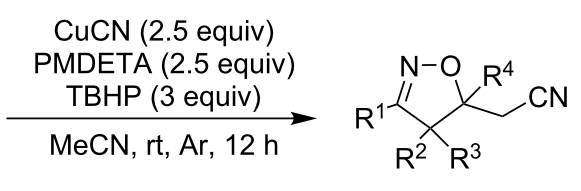

$149,44-72 \%$

$$
n=0
$$

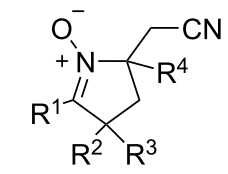

$150,38-46 \%$

$$
n=1
$$

examples of synthesized compounds, yields<smiles>N#CCC1CC(c2ccccc2)=NO1</smiles>

$149 a, 45 \%$<smiles>CC1(CC#N)CC(c2ccccc2)=NO1</smiles>

149 e, $46 \%$<smiles>CC1(C)C(c2ccccc2)=NOC1CC#N</smiles>

149b, $70 \%$<smiles></smiles>

$150 a, 45 \%$<smiles>CC1(C)C(C2CCCCC2)=NOC1CC#N</smiles>

$149 c, 56 \%$<smiles></smiles>

$150 \mathrm{~b}, 43 \%$<smiles></smiles>

149d, $70 \%$ 
nitrogen-containing ligands (2,2'-bipyridine and phenanthroline) were even less efficient for the synthesis of target the isoxazolines.

Both aromatic (products 149a,b,e) and aliphatic oximes (products $149 \mathbf{c}, \mathbf{d}$ ) undergo this transformation with the formation of isoxazolines. Oximes with a disubstituted double bond also enter this reaction (product 149e). The 5-exo-trig cyclization of $\gamma, \delta$-unsaturated oximes under these conditions leads to substituted cyclic nitrones (products 150a-d).

A similar cyanation reaction was realized using TMSCN as a cyanide source and the oxidative system $\mathrm{Cu}\left(\mathrm{NO}_{3}\right)_{2} / \mathrm{K}_{2} \mathrm{~S}_{2} \mathrm{O}_{8}$ (Scheme 51) [140].

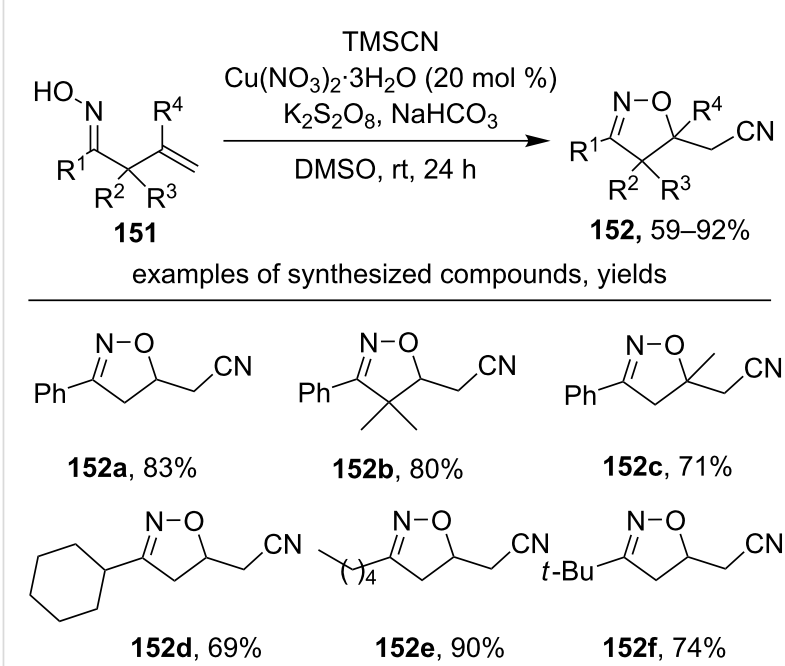

Scheme 51: Oxidative cyclization of $\beta, \gamma$-unsaturated oximes to isoxazolines with the introduction of a nitrile group.
Both aromatic (products 152a-c) and aliphatic (products 152d-f) $\beta, \gamma$-unsaturated oximes undergo this transformation. Oximes substituted at the $\alpha$-position $\left(\mathrm{R}^{1}, \mathrm{R}^{2}=\mathrm{Me}\right)$, as well as oximes having a disubstituted double bond, also give cyclization products with good yields (products $\mathbf{1 5 2 b}, \mathbf{c}$ ).

The interaction of $\beta, \gamma$-unsaturated oximes 153 with sodium sulfinates in the presence of copper(II) acetate leads to substituted isoxazolines 154 with the sulfonyl group (Scheme 52) [141].

Oximes, mainly aromatic ones, cyclize effectively (products 154a-d,f-h). Examples 154b-d demonstrate the effect of substituents in the phenyl ring of oxime $\left(\mathrm{R}^{1}\right)$ on the product yield. When a substituent is present in the ortho-position of the benzene ring, the yield decreases compared to para- and metasubstituted substrates. In addition to sodium aryl sulfinates, sodium methane sulfinate was used for the synthesis of product 154h in good yield. The presence of an electron-withdrawing group in the aromatic ring of sulfinate decreases the yield (product $\mathbf{1 5 4 f}$ compared to product $\mathbf{1 5 4 a}$ ), and the presence of an electron-donating group increases the yield of isoxazoline

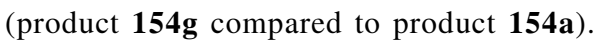

Another approach to the synthesis of isoxazolines with a sulfonyl moiety is the reaction of unsaturated oximes $\mathbf{1 5 5}$ with sulfonyl hydrazides $\mathbf{1 5 6}$ under the action of TBHP and a catalytic amount of iodine (Scheme 53) [142].

Aromatic $\beta, \gamma$-unsaturated oximes containing both electron-donating and electron-withdrawing substituents in the phenyl ring give cyclization products in good yields (products 157a-c). Aliphatic oximes also enter this reaction effectively (products

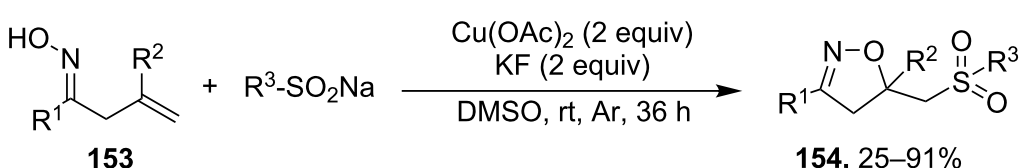

examples of synthesized compounds, yields<smiles>CCOCCC1=NOC(CS(=O)(=O)c2ccc(C)cc2)C1CS(=O)(=O)c1ccc(C)cc1</smiles>

$154 a, 80 \%$<smiles>Cc1ccc(S(=O)(=O)CC2CC(CC(C)C)=NO2)cc1</smiles>

$154 \mathrm{e}, 73 \%$ 154b, $72 \%$<smiles>O=S(=O)(CC1CC(c2ccccc2)=NO1)c1ccc(Cl)cc1</smiles>

154f, $49 \%$ 154c, $37 \%$<smiles>COc1ccc(S(=O)(=O)CC2CC(c3ccccc3)=NO2)cc1</smiles>

154g, $88 \%$ 154d, $75 \%$<smiles>CC1(CS(C)(=O)=O)CC(c2ccccc2)=NO1</smiles>

154h, $84 \%$ 


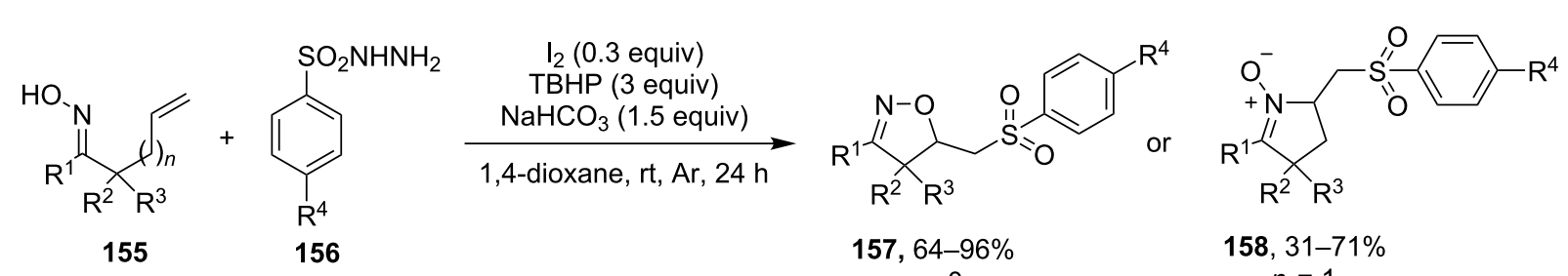

examples of synthesized compounds, yields<smiles>Cc1ccc(S(=O)(=O)CC2=NOC(CS(=O)(=O)c3ccc(C)cc3)C2)cc1</smiles>

157a, $91 \%$

157b, $96 \%$

157c, $90 \%$

$157 d, 90 \%$

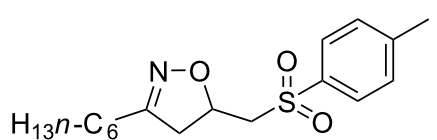

157 e, $79 \%$<smiles>Cc1ccc(S(=O)(=O)CC2CC(C)(C)C(c3ccccc3)=[N+]2[O-])cc1</smiles>

158a, $71 \%$<smiles>O=S(=O)(CC1CC(c2ccccc2)=NO1)c1ccc(Cl)cc1</smiles>

157f, $96 \%$<smiles>Cc1cccc(S(=O)(=O)CC2CC(c3ccccc3)=NO2)c1</smiles>

$157 \mathrm{~g}, 82 \%$<smiles>O=S(=O)(CC1CC(c2ccccc2)=NO1)c1ccccc1F</smiles>

$157 \mathrm{~h}, 35 \%$<smiles>CC1(C)CC(CS(=O)(=O)c2ccccc2)C([N+](=O)[O-])=[N+]1c1ccccc1</smiles>

$158 b, 62 \%$<smiles>CC1(C)CC(CS(=O)(=O)c2ccc(Cl)cc2)C([PH])C1=[N+]([O-])c1ccccc1</smiles>

$158 c, 31 \%$<smiles>CC1(C)CC(CS(=O)(=O)c2ccc(C(C)(C)C)cc2)[N+]([O-])=C1c1ccccc1</smiles>

158d, $65 \%$

Scheme 53: Oxidative cyclization of $\beta, \gamma$ - and $\gamma, \delta$-unsaturated oximes to isoxazolines with the introduction of a sulfonyl group.

157d,e). Under the same reaction conditions aromatic $\gamma, \delta$-unsaturated oximes give sulfonyl-substituted cyclic nitrones (products 158a-d).

Another example of the oxidative cyclization of oximes with the formation of an isoxazoline ring and $\mathrm{C}-\mathrm{S}$ bond is the reaction of aromatic $\beta, \gamma$-unsaturated oximes $\mathbf{1 5 9}$ with the $\mathrm{FeCl}_{3} /$ $\mathrm{KSCN} / \mathrm{K}_{2} \mathrm{~S}_{2} \mathrm{O}_{8}$ system that affords thiocyanates $\mathbf{1 6 0}$ (Scheme 54) [143].
Under the action of PIDA ( $\left.\mathrm{PhI}(\mathrm{OAc})_{2}\right), \beta, \gamma$-unsaturated oximes 161 react with diselenides and disulfides 162 to form isoxazolines 163 (Scheme 55) [144].

Various disulfides of both aromatic (products 163a,b,d-f) and aliphatic nature (product 163c) were used. The presence of electron-donating substituents in the para-position of the phenyl ring of disulfide increases the yield of the isoxazoline (example 163b), compared to electron-withdrawing substituents (exam-

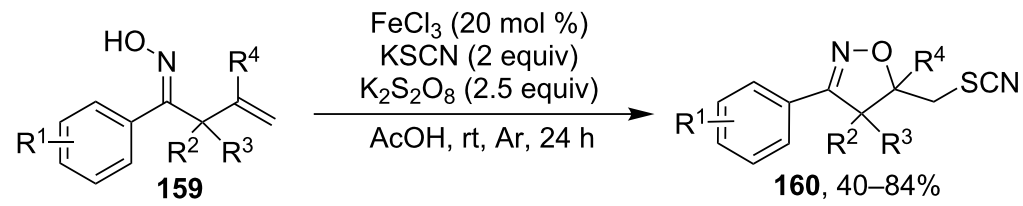

examples of synthesized compounds, yields

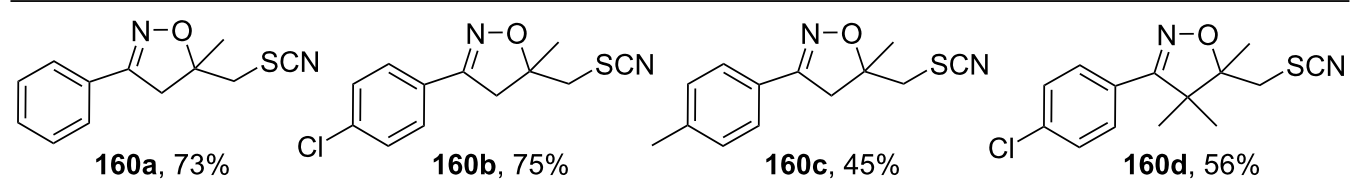<smiles>N#CCC1(c2ccccc2)CC(c2ccccc2)=NO1</smiles><smiles>N#CCC1(c2ccccc2)CC(c2ccc(Cl)cc2)=NO1</smiles><smiles>N#[Si]CC1(c2ccccc2)CC(c2ccc(C(F)(F)F)cc2)=NO1</smiles>

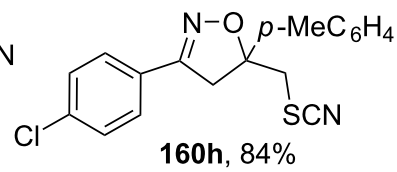

Scheme 54: Oxidative cyclization of $\beta, \gamma$-unsaturated oximes to isoxazolines with the introduction of a thiocyanate group 


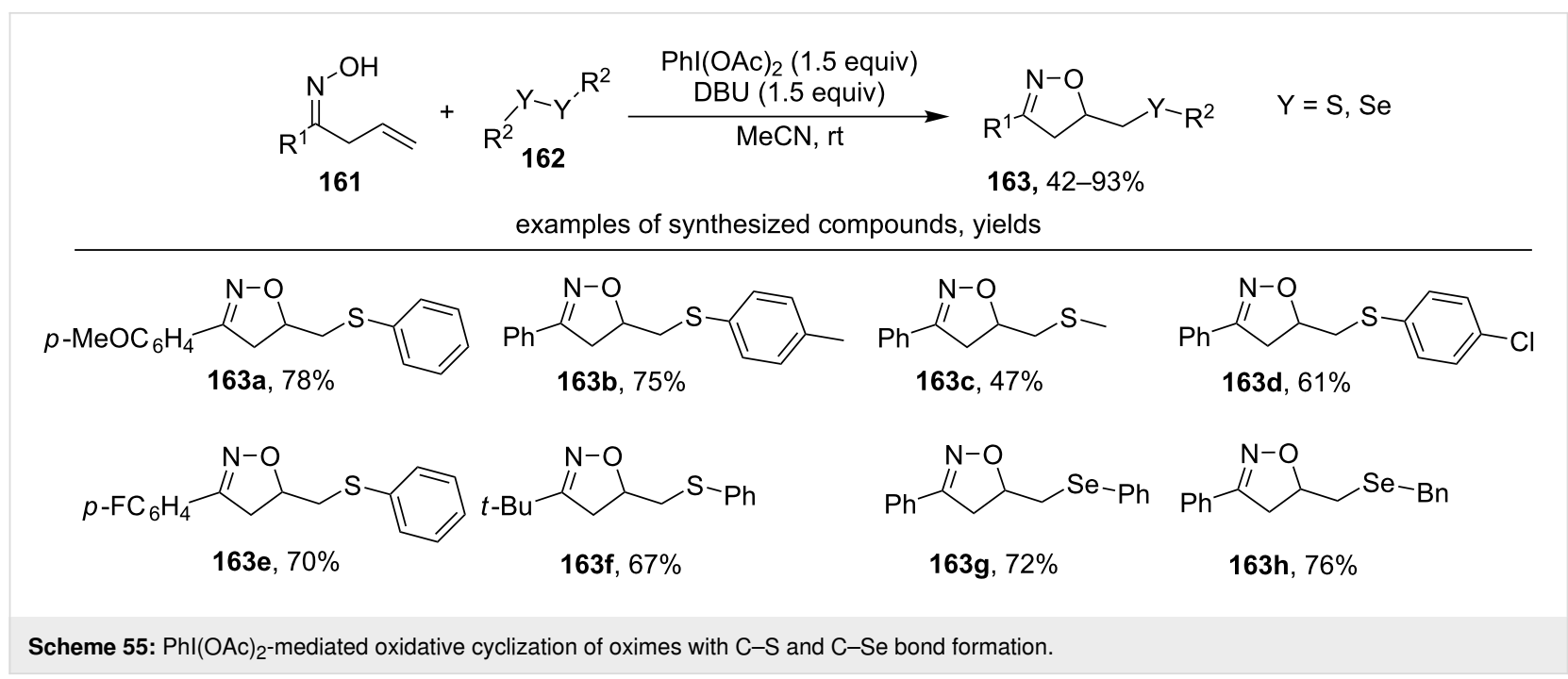

ple 163d). Like disulfides, diselenides lead to the corresponding Se-containing isoxazolines $\mathbf{1 6 3 g}, \mathbf{h}$ in high yields. $\beta, \gamma$-Unsaturated tosyl hydrazones react with disulfides and diselenides analogously to oximes [144].

Under the action of the PIDA/NaOAc/HOAlkyl system, $\beta, \gamma-$ unsaturated aryl oximes 164 undergo oxidative cyclization with the formation of substituted isoxazolines $\mathbf{1 6 5}$ containing an ether group (Scheme 56) [145]. The alcohol acts both as a solvent and as a reagent in this transformation.

Most of the tested oximes contained a tetrasubstituted $\mathrm{C}=\mathrm{C}$ double bond (examples 165a-i) but the product of cyclization involving a disubstituted $\mathrm{C}=\mathrm{C}$ double bond was also reported (example 165j). The ionic pathway was proposed for the formation of the products $\mathbf{1 6 5}$ as the most plausible but free radical pathway involving iminoxyl radicals was not ruled out [145]. In both considered reaction pathways the final stage was the formation of ether $\mathrm{C}-\mathrm{O}$ bond by a nucleophilic attack of the intermediate carbocation by the alcohol.

Under the action of the related oxidative system $\mathrm{PhI}(\mathrm{OAc})_{2} /$ DABCO in THF, cyclization of allyl-substituted oximes 166 without the introduction of a functional group at the terminal carbon atom was realized (Scheme 57) [146].

The authors proposed a mechanism in which a 5-exo-trig cyclization of the iminoxyl radical formed from oxime $\mathbf{1 6 6}$ under the

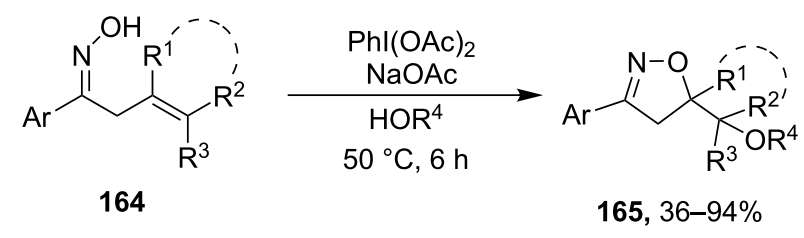

examples of synthesized compounds, yields<smiles>COc1ccc(C2=NOC(C)(C(C)(C)OC)C2)cc1</smiles>

$165 a, 90 \%$<smiles>CO[C@]1(C)CCCC[C@]12CC(c1ccccc1)=NO2</smiles>

$165 f, 92 \%$
$165 b, 82 \%$<smiles>CCOC(C)(C)C1(C)CC(c2ccccc2)=NO1</smiles>

165g, $77 \%$<smiles>COC(C)(C)C1(C)CC(c2ccc(C(F)(F)F)cc2)=NO1</smiles>

$165 c, 74 \%$<smiles>COC(C)(C)C1(C)CC(c2cccnc2)=NO1</smiles>

$165 d, 84 \%$<smiles>COC(C)(OC)C1(c2ccccc2)CC(c2ccccc2)=NO1</smiles>

$165 e, 36 \%$ 


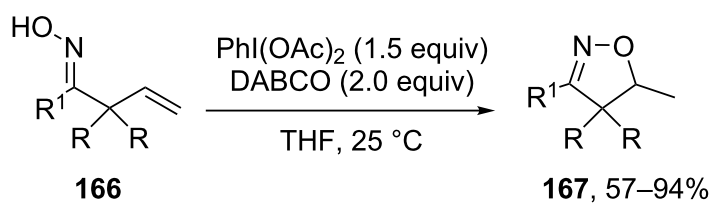

examples of synthesized compounds, yields

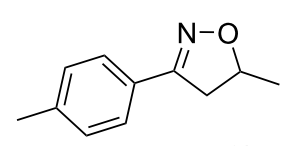

$167 a, 67 \%$

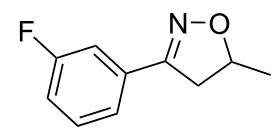

$167 d, 57 \%$<smiles>CC1CC(c2ccc(C(F)(F)F)cc2)=NO1</smiles>

$167 \mathrm{~b}, 69 \%$

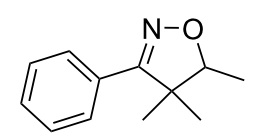

$167 e, 92 \%$<smiles>COc1cccc(C2=NOC(C)C2C)c1</smiles>

167c, $63 \%$

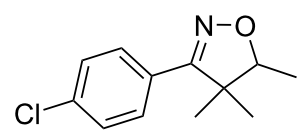

$167 f, 81 \%$

Scheme 57: Phl(OAc) $)_{2}$-mediated cyclization of unsaturated oximes to methylisoxazolines.

action of the $\mathrm{PhI}(\mathrm{OAc})_{2} / \mathrm{DABCO}$ system produced the primary $\mathrm{C}$-centered radical. Presumably, the final product $\mathbf{1 6 7}$ is formed via hydrogen atom transfer from THF to the intermediate C-centered radical [146]. This process is similar to the cobaltcatalyzed cyclization in the presence of 1,4-cyclohexadiene as hydrogen atom donor discussed above (Scheme 35) [125].

The reaction of unsaturated oximes 168 with ethynylbenziodoxolone (EBX) reagents 169 in the presence of copper(II) triflate leads to substituted isoxazolines $\mathbf{1 7 0}$ and cyclic nitrones $\mathbf{1 7 1}$ with an alkynyl group (Scheme 58) [147].

Various aromatic and some aliphatic oximes were tested as substrates (products 170a-l). The yield of the reaction product is weakly dependent on the substituent in the benzene ring (examples 170a, b,c). Oximes unsubstituted in $\alpha$-position $\left(\mathrm{R}^{2}=\mathrm{R}^{3}=\right.$ $\mathrm{H})$ also undergo this transformation (example 170d,l). Both various aromatic substituents (products 170e-g) and alkyl substituents (example 170h) may be present in the EBX reagent at $\mathrm{R}^{6}$. Under the same reaction conditions, $\gamma, \delta$-unsaturated oximes give substituted cyclic nitrones (products 171a-e).

The oxidative cyclization of C-glycoside ketoximes $\mathbf{1 7 2}$ was carried out under the action of catalytic amounts of TEMPO under oxygen $(1 \mathrm{~atm})$ with the formation of substituted isoxazoles 173 (Scheme 59) [148].

The proposed mechanism includes the oxidation of starting oxime to iminoxyl radical by TEMPO, 5-endo-trig cyclization and oxidative aromatization with the formation of the final isoxazole 173 [148].
Under the action of the Selectfluor/AgOAc system, $\beta, \gamma$-unsaturated oximes 174 undergo oxidative cyclization with the formation of fluoroalkyl isoxazolines 175 (Scheme 60) [149].

The majority of products were fluoromethyl isoxazolines (examples $175 \mathbf{a}-\mathrm{g}$ ). The exception was the product $175 \mathrm{~h}$, which was synthesized from oxime with an endocyclic $\mathrm{C}=\mathrm{C}$ double bond. The proposed mechanism includes the 5-exo-trig cyclization of the intermediate iminoxyl radical followed by fluorination of the formed $\mathrm{C}$-centered radical. The 5-exo-trig radical cyclization was confirmed by a control experiment with the addition of TEMPO as a trapping reagent for the C-centered radical. The TEMPO-adduct was obtained in $75 \%$ yield [149].

The formation of haloalkyl isoxazolines $\mathbf{1 7 7}$ was achieved upon the interaction of $\beta, \gamma$-unsaturated oximes 176 with $t$-BuONO and selected halogenating agents (Scheme 61) [150].

Both aromatic (products 177a-e,g) and aliphatic oximes (products $\mathbf{1 7 7 f}, \mathbf{g}$ ) successfully participate in this transformation. The yield of the reaction product weakly depends on the substituents in the aromatic ring of oxime (products 177a,b,c). Oximes with a disubstituted double bond $\left(\mathrm{R}^{4}=\mathrm{Me}\right.$, product $\left.\mathbf{1 7 7 d}\right)$, as well as $\alpha$-unsubstituted or $\alpha$-disubstituted oximes $\left(R^{2}=R^{3}=H\right.$ or Me) also produce isoxazolines with high yields (products 177a-d and 177e-h). Bromination and iodination of some substrates using $\mathrm{CBr}_{4}$ and $\mathrm{CHI}_{3}$ instead of $\mathrm{AlCl}_{3}$ were carried out (products 177i-l). The radical mechanism including 5-exo-trig cyclization of the intermediate iminoxyl radical was supported by a radical trapping control experiment with TEMPO and a radical clock experiment with cyclopropane ring opening [150]. 

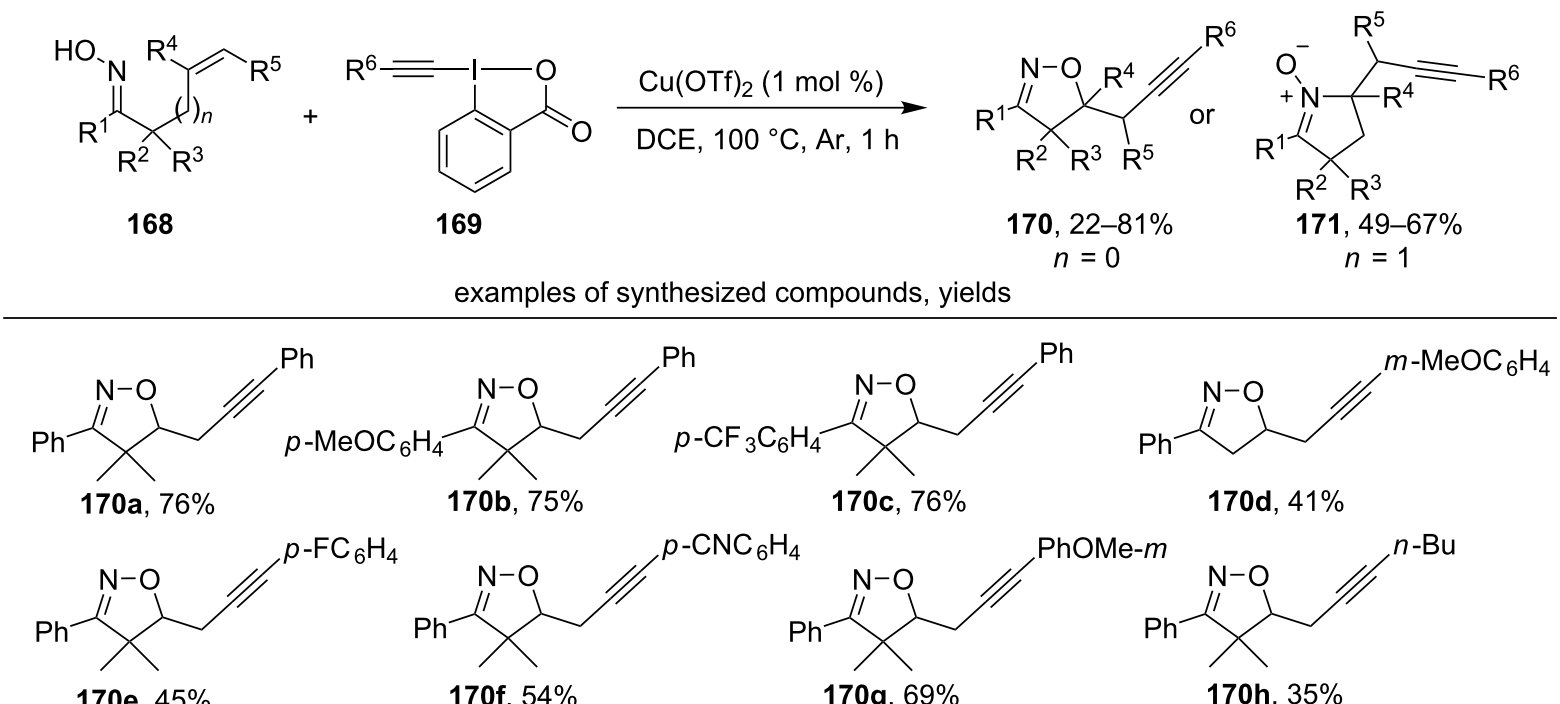

170 e, $45 \%$

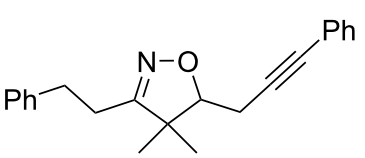

170j, $81 \%$<smiles>[2H]OCCC1=[N+]([O-])C(CC#Cc2ccccc2)CC1(C)C</smiles>

$171 \mathrm{a}, 64 \%$ 171b, $49 \%$

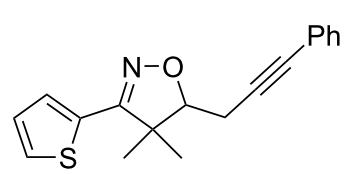

170k, $69 \%$

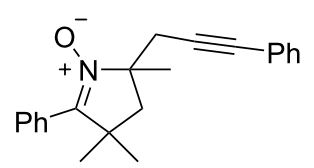

171c, $59 \%$

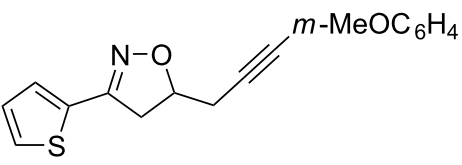

170I, $53 \%$

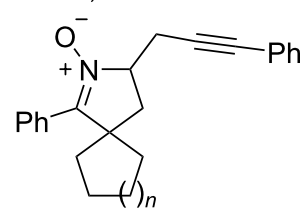

$n=1,171 \mathrm{~d}, 67 \%$

$n=2,171 \mathrm{e}, 62 \%$

Scheme 58: Oxidative cyclization-alkynylation of unsaturated oximes.
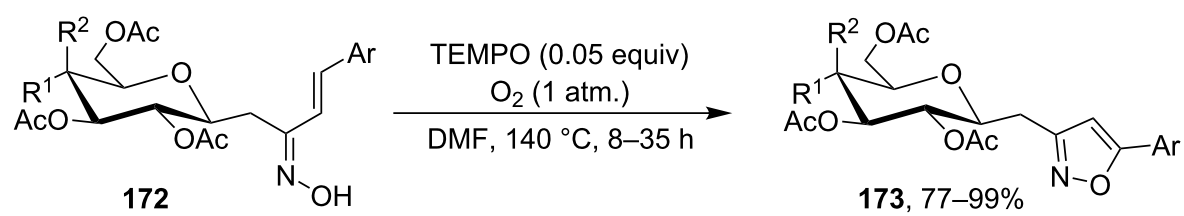

examples of synthesized compounds, yields

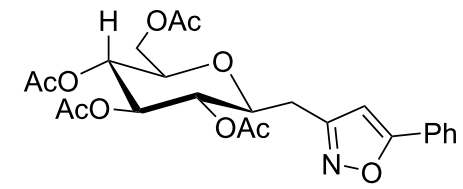

$173 a, 99 \%$

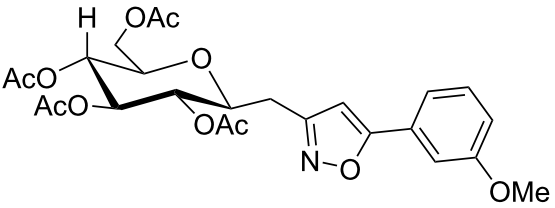

173b, $99 \%$

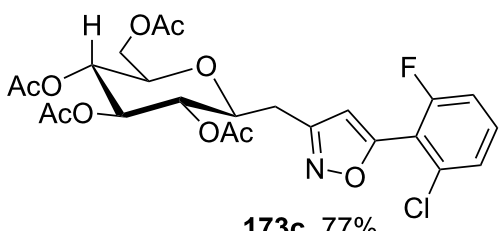

173c, $77 \%$

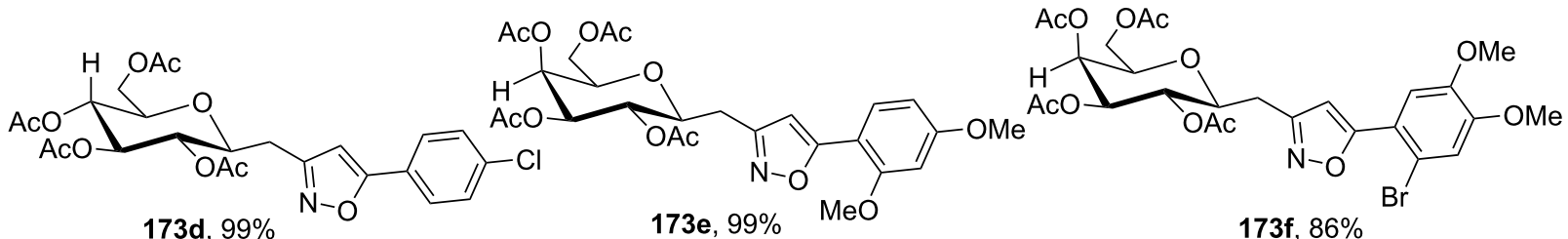

Scheme 59: TEMPO-mediated oxidative cyclization of C-glycoside ketoximes to C-glycosylmethylisoxazoles. 


$$
\mathrm{F}
$$

$175 a, 65 \%$<smiles>[15CH3]C1=NOC(CF)C1</smiles>

$175 e, 58 \%$<smiles>[R]C=CC([R])C([R])=NO</smiles>

174

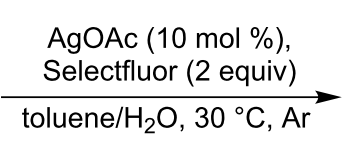
$\underset{\text { Selectfluor (2 equiv) }}{\longrightarrow}$<smiles>[R]C1=NOC(C([R])F)C1[R]</smiles>

$175,52-72 \%$

examples of synthesized compounds, yields<smiles>Cc1ccc(C2=NOC(CF)C2)cc1</smiles><smiles>N#Cc1ccc(C2=NOC(CF)C2)cc1</smiles>

175b, $68 \%$<smiles>FCC1CC(C2CCCCC2)=NO1</smiles>

$175 f, 55 \%$<smiles>C#Cc1ccc(C2=NOC(CF)C2)cc1</smiles>

$175 c, 57 \%$<smiles>FCC1CC(CCc2ccccc2)=NO1</smiles>

$175 \mathrm{~g}, 60 \%$<smiles>Cc1ccsc1C1=NOC(CF)C1</smiles>

$175 d, 60 \%$<smiles>F[C@H]1CCC[C@H]2C(c3ccccc3)=NO[C@H]12</smiles>

175h, $60 \%$ $\mathrm{dr}=19: 1$

Scheme 60: Silver-catalyzed oxidative cyclization of $\beta, \gamma$-unsaturated oximes with formation of fluoroalkyl isoxazolines.

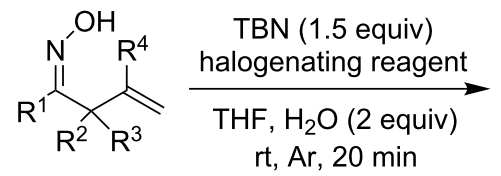

176<smiles>[R]C1=NOC([R])(C[Hg])C1([R])C[3H]</smiles>

$177,55-92 \%$ halogenating reagent $=$ for chlorination: $\mathrm{AlCl}_{3}$ ( 0.5 equiv) for bromination: $\mathrm{CBr}_{4}$ ( 1.5 equiv) for iodination: $\mathrm{CH}_{3}$ (2 equiv)

examples of synthesized compounds, yields

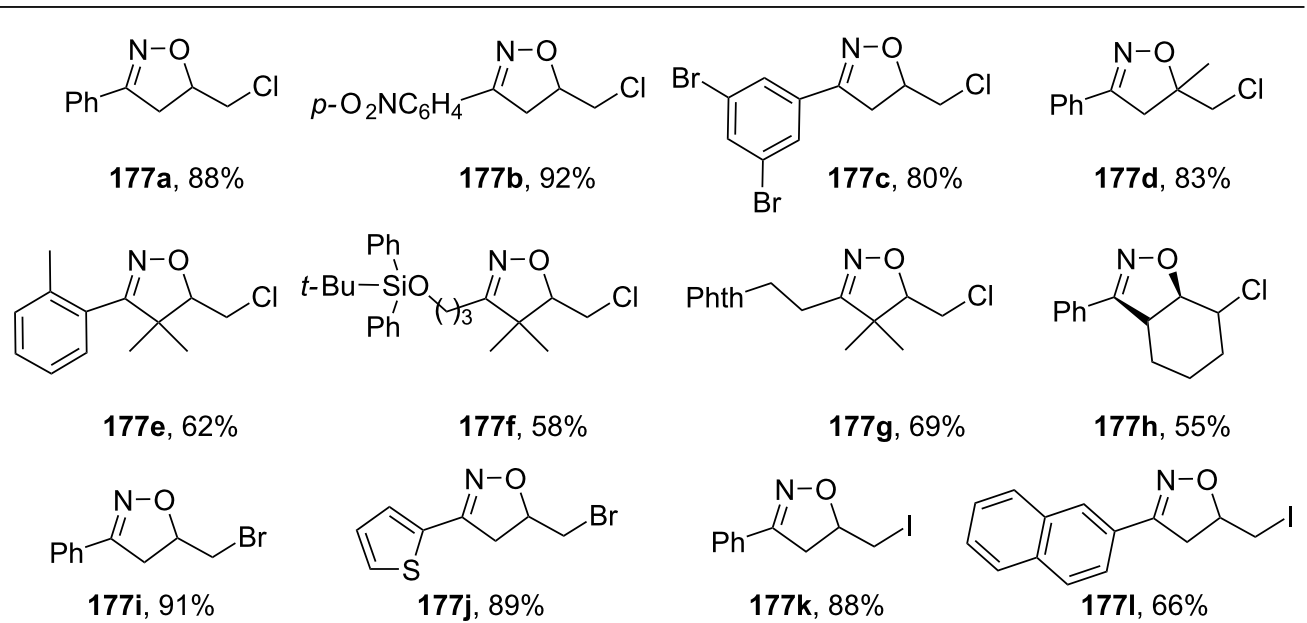

Scheme 61: Oxidative cyclization of $\beta, \gamma$-unsaturated oximes with the formation of haloalkyl isoxazolines.

A similar transformation of $\beta, \gamma$-unsaturated oximes $\mathbf{1 7 8}$ into haloalkylisoxazolines $\mathbf{1 7 9}$ was realized employing the catalytic system halogenating reagent/Cu(OTf $)_{2} /$ phenantroline $/ \mathrm{Na}_{2} \mathrm{CO}_{3}$ (Scheme 62) [151]. The authors proposed an analogous mechanism involving 5-exo-trig cyclization of intermediate iminoxyl radical.
Under the action of the $\mathrm{PhI}(\mathrm{OAc})_{2} / \mathrm{TEMPO}$ system on halogensubstituted unsaturated oximes 180, halomethyl isoxazoles $\mathbf{1 8 1}$ and cyclic nitrones $\mathbf{1 8 2}$ are formed (Scheme 63) [152]. The authors note that the reaction proceeds through the 5-exo-trig cyclization of iminoxyl radical followed by a 1,2-halogen radical shift. 
$\underset{\mathrm{R}^{2}}{\stackrel{\mathrm{Cu}(\mathrm{OTf})_{2}(5 \mathrm{~mol} \%)}{\mathrm{ReCN}^{1} \mathrm{Ar}, 80^{\circ} \mathrm{C}}}$

178

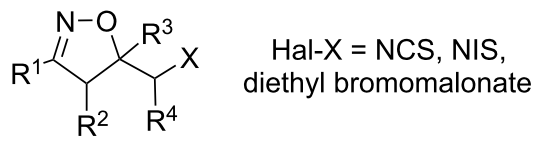

179, 41-97\%

$\mathrm{X}=\mathrm{Cl}, \mathrm{Br}$, I

examples of synthesized compounds, yields<smiles>BrCC1CC(c2ccccc2)=NO1</smiles>

179a, $85 \%$<smiles>CC1(C)C(c2ccc(Br)cc2)=NOC1CCl</smiles>

179e, $76 \%$<smiles>Oc1ccccc1C1=NOC(CBr)C1</smiles><smiles>ClCC1CC(c2cccs2)=NO1</smiles>

179f, $85 \%$<smiles>BrCC1CC(CCc2ccccc2)=NO1</smiles>

$179 c, 80 \%$

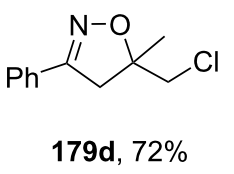<smiles>Cc1ccc(C2=NOC(CI)C2)cc1</smiles>

179g, $97 \%$<smiles>ICC1CC(CCc2ccccc2)=NO1</smiles>

179h, $96 \%$

Scheme 62: Cyclization of $\beta, \gamma$-unsaturated oximes into haloalkyl isoxazolines under the action of the halogenating reagent/Cu(OTf $)_{2} /$ phenantroline/ $\mathrm{Na}_{2} \mathrm{CO}_{3}$ system.

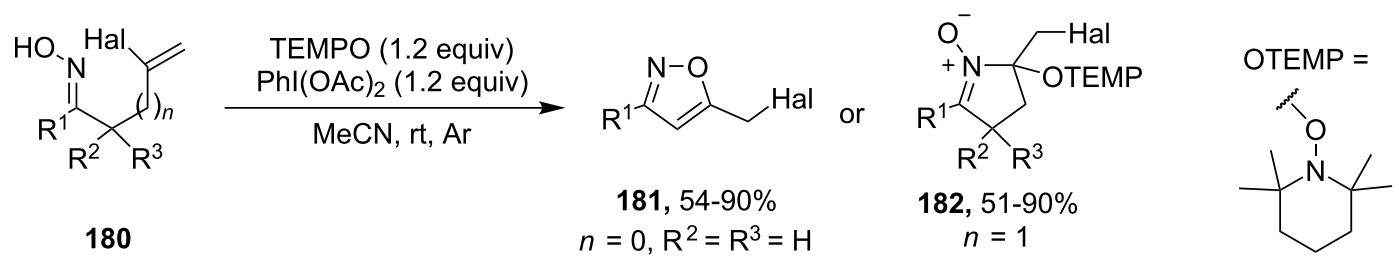

examples of synthesized compounds, yields<smiles>COCCc1cc(CCl)on1</smiles>

$181 \mathrm{a}, 83 \%$<smiles></smiles>

$182 a, 82 \%$<smiles>ClCc1cc(C2CCCCC2)no1</smiles>

$181 \mathrm{c}, 80 \%$<smiles>[O-][N+]1=C(c2ccccc2)CCC1([O-])CCl</smiles>

$182 \mathrm{c}, 83 \%$<smiles>BrCc1cc(-c2ccccc2)no1</smiles><smiles>ICc1cc(-c2ccccc2)no1</smiles><smiles>CCOC1(CCl)CC2(CCCC2)C(c2ccccc2)N1C(=O)[18O]</smiles>

$182 d, 84 \%$
$181 \mathrm{e}, 84 \%$

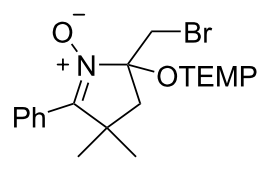

$182 e, 68 \%$

Scheme 63: Synthesis of haloalkyl isoxazoles and cyclic nitrones via oxidative cyclization and 1,2-halogen shift.

Chloro-, bromo-, and iodosubstituted $\beta, \gamma$-unsaturated oximes enter the reaction effectively (products 181a-e). When $\gamma, \delta$ unsaturated oximes were used instead of $\beta, \gamma$-unsaturated oximes, the formation of cyclic nitrones with a TEMPO fragment (products 182a-e) was observed. Chloro- and bromosubstituted $\gamma, \delta$-unsaturated oximes were applicable for this transformation, but iodo-substituted $\gamma, \delta$-oximes gave target products $\mathbf{1 8 2}$ only in trace amounts.

The TEMPO-mediated electrochemical cyclization of biaryl oximes 183 leads to $N$-heteroaromatic $N$-oxides 184 or $\mathrm{N}$-heteroaromatic compounds $\mathbf{1 8 5}$ depending on a cathode ma- 
terial (Scheme 64) [153]. Reactions were performed in an undivided cell under constant current conditions. Reticulated vitreous carbon (RVC) electrode was used as an anode.

The proposed mechanism includes the formation of an iminoxyl radical followed by its cyclization onto the phenyl ring and oxidative rearomatization to $\mathrm{N}$-heteroaromatic $N$-oxide $\mathbf{1 8 4}$. In the case of Pt-cathode it is the final product, and in the case of $\mathrm{Pb}$-cathode it is reduced to the $\mathrm{N}$-heteroaromatic compound $\mathbf{1 8 5}$ [153].

The rare example of the intramolecular cyclization of iminoxyl radicals involving a triple bond is shown in Scheme 65 [154]. In the presence of catalytic amounts of copper(II) salt and molecular oxygen (1 atm) 5-exo-dig cyclization of unsaturated oximes 186 occurs.

Various $\beta, \gamma$-unsaturated oximes $\mathbf{1 8 6}$ react with the formation of substituted isoxazoline $\alpha$-ketols $\mathbf{1 8 7 a - d}$. Using an oxime with a terminal triple bond, isoxazolone $\mathbf{1 8 7 e}$ was obtained. Under analogous conditions $\gamma, \delta$-unsaturated oximes afford cyclic nitrones 188a-e in moderate yields.
Under irradiation of blue LED (450-455 nm) of the mixture of oximes 189, sulfonyl hydrazides 190, silver(I) oxide and disodium salt of eosin $\mathrm{Y}$ in an inert atmosphere sulfones $\mathbf{1 9 1}$ are formed [155] (Scheme 66). In this case, hydrosulfonylation of the $\mathrm{C}=\mathrm{C}$ double bond takes place instead of typical cyclization of $\beta, \gamma$-unsaturated oximes $\mathbf{1 8 9}$ to isoxazolines.

Both aromatic (examples 191a-c, e-h) and aliphatic (example 191d) sulfonyl hydrazides undergo this reaction successfully. Good yields were obtained with both electron-donating (example 191b) and electron-withdrawing substituents (example 191c) in the aromatic ring of sulfonyl hydrazide. The introduction of a methyl group in the $\beta$-position relative to the oxime group leads to a decrease in yield (example 191h).

The authors proposed a radical mechanism in which the addition of the sulfonyl radical to the double $\mathrm{C}=\mathrm{C}$ bond, is followed by 1,5-HAT from the oxime hydroxy group to the carbon radical. An experiment with a deuterium label on the hydroxy group of oxime confirmed this hypothesis: the deuterium was found at the $\beta$-carbon atom of the product [155].

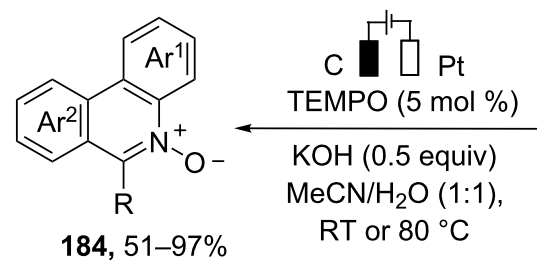<smiles>[R18]/C(=N/O)c1ccccc1-c1ccccc1</smiles>

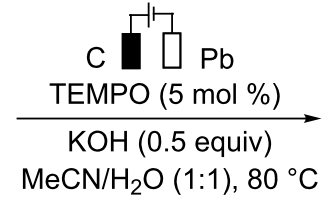

83

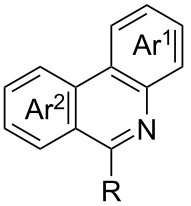

$185,38-98 \%$

examples of synthesized compounds, yields<smiles>COc1cc2c(C)[n+]([O-])c3cc(C)ccc3c2cc1OC</smiles>

184a, $97 \%$<smiles>COc1cc2c(C)nc3cc(C)ccc3c2cc1OC</smiles>

$185 a, 85 \%$<smiles>COc1ccc2c(c1)c1ccccc1c(C)[n+]2[O-]</smiles>

184b, $73 \%$ (>20:1)<smiles>C=C(OC)/C(=C\c1cnc(C)c2ccccc12)OC</smiles>

185b, 92\%

$(>20: 1)$<smiles>Cc1c2ccccc2c2ccsc2[n+]1[O-]</smiles>

184c, $66 \%$

$(>20: 1)$<smiles>Cc1ccc2c(c1)c(C)nc1ccccc12</smiles>

$185 c, 82 \%$<smiles>CCc1c2ccccc2c2ccccc2[n+]1[O-]</smiles>

184d, $75 \%$<smiles>CCCCNc1nc2ccccc2c2ccccc12</smiles>

185d, $54 \%$ 

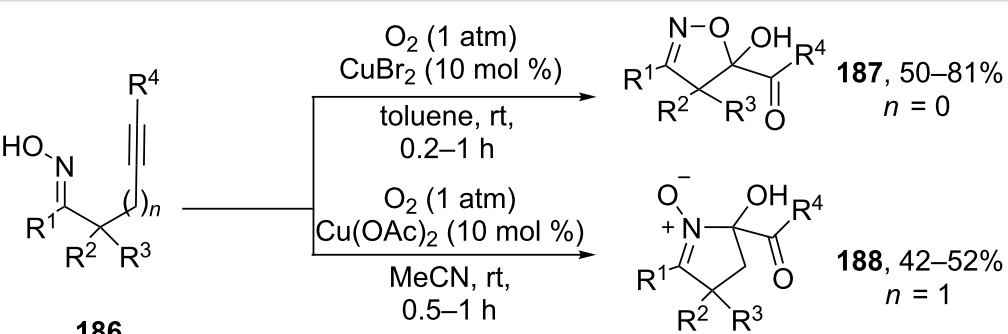

examples of synthesized compounds, yields
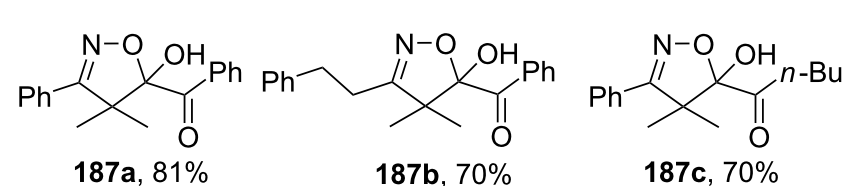<smiles>CC1(C)C(c2ccccc2)=NOC1(O)C(=O)C1CCCCC1</smiles><smiles>CC1(C)C(=O)ON=C1c1ccccc1</smiles><smiles>CC1(C)CC(O)(C(=O)c2ccccc2)N([O-])C1=O</smiles>

188a, $51 \%$

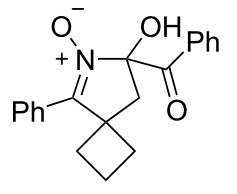

$188 b, 42 \%$

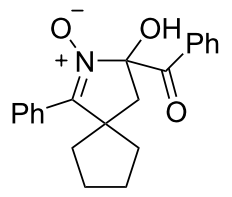

$188 \mathrm{c}, 50 \%$<smiles>O=C(c1ccccc1)C1(O)CC2(CCCCC2)C(c2cccs2)=[N+]1[O-]</smiles>

188d, $46 \%$

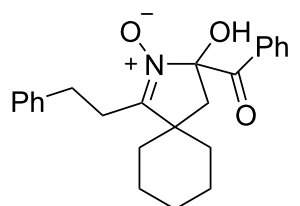

$188 \mathrm{e}, 50 \%$

Scheme 65: Copper-catalyzed cyclization and dioxygenation oximes containing a triple $\mathrm{C} \equiv \mathrm{C}$ bond.

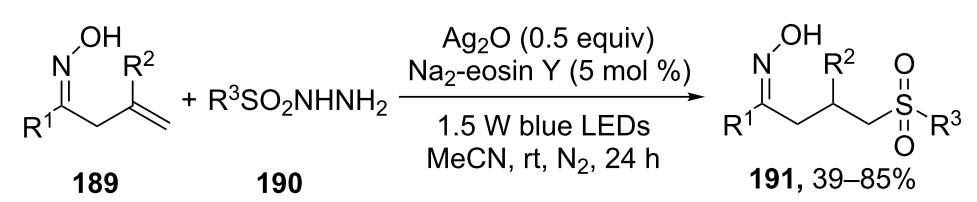

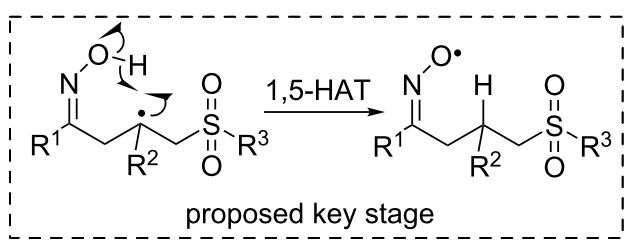

examples of synthesized products, yields<smiles>O=S(=O)(CCC/C(=N/O)c1ccccc1)c1ccccc1</smiles>

$191 \mathrm{a}, 79 \%$<smiles>Cc1ccc(S(=O)(=O)CCC/C(=N\O)c2ccccc2)cc1</smiles>

191b, $79 \%$<smiles>O=[N+]([O-])c1ccc(S(=O)(=O)CCC/C(=N\O)c2ccccc2)cc1</smiles>

191c, $74 \%$<smiles>CCCCOS(=O)CCC/C(=N\O)c1ccccc1</smiles><smiles>COc1ccc(/C(CCCS(=O)(=O)c2ccccc2)=N/O)cc1</smiles>

$191 \mathrm{e}, 85 \%$<smiles>O=S(=O)(CCCC(=NO)c1ccc(Cl)cc1)c1ccccc1</smiles>

191f, $71 \%$<smiles>O=S(=O)(O)c1ccccc1</smiles>

$191 \mathrm{~g}, 52 \%$<smiles>CC(C/C(=N\O)c1ccccc1)CS(=O)(=O)c1ccccc1</smiles>

$191 \mathrm{~h}, 39 \%$

Scheme 66: Photoredox-catalyzed sulfonylation of $\beta, \gamma$-unsaturated oximes by sulfonyl hydrazides.

The combination of Koser's reagent $\mathbf{1 9 3}$ and $\mathrm{Fe}(\mathrm{acac})_{2}$ as catalyst was used for the synthesis of sulfonates 194 from unsaturated oximes 192 [156] (Scheme 67).

In the presence of a substituent in the ortho-position of the benzene ring, the yield of the product decreases remarkably, probably due to steric hindrances during the reaction (example 194d). Aliphatic oximes (example 194e) and oximes with a disubstituted $\mathrm{C}=\mathrm{C}$ bond (example 194f) undergo this transformation with moderate yields. Free-radical mechanism involving the cyclization of the iminoxyl radical was confirmed by trapping of a C-centered radical, TEMPO-adduct 194a' was iso- 


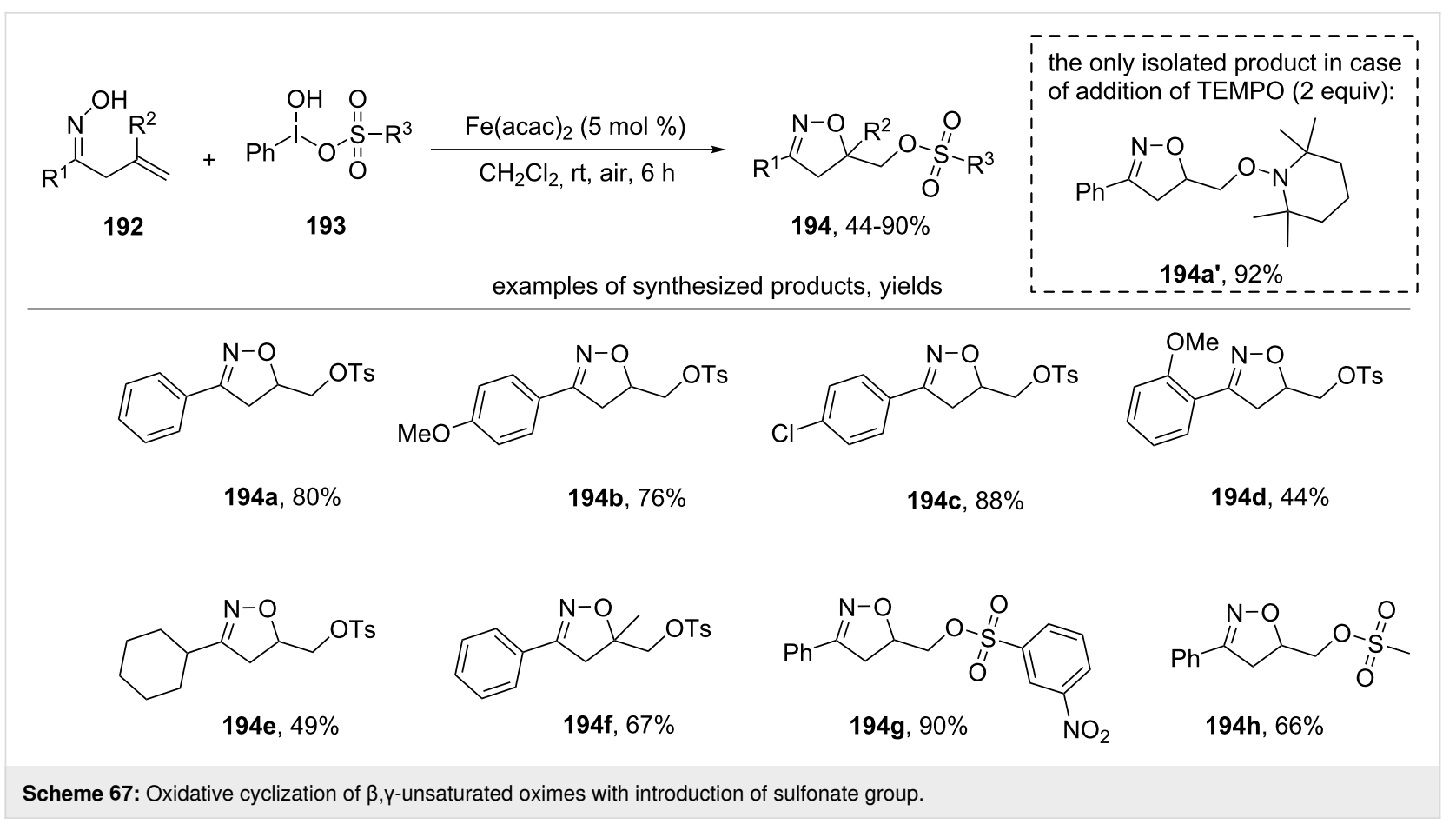

lated in $92 \%$ yield instead of $\mathbf{1 9 4 a}$ when TEMPO was added to the reaction mixture. The authors also showed that the presence of water in the system can lead to the formation of alcohol instead of sulfonate [156].

Under ultrasound irradiation $\beta, \gamma$-unsaturated oximes 195 react with $\mathrm{KHSO}_{5} \cdot 0.5 \mathrm{KHSO}_{4} \cdot 0.5 \mathrm{~K}_{2} \mathrm{SO}_{4}$ and diselenides 196 to form isoxazolines 197 [157] (Scheme 68)
The introduction of electron-withdrawing substituents (example 197b) into the benzene ring of diselenide leads to an increase in yield compared to the case of electron-donating substituents (example 197c). Dialkyl diselenides also undergo this transformation (example 197d). Similar yields of the target product 197a were obtained when rthe eaction mixture was heated by microwave irradiation or an oil bath instead of sonication. However, control experiments allowed to suggest that

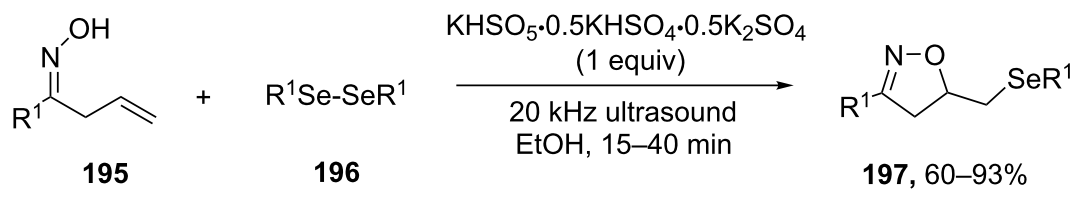

examples of synthesized products, yields<smiles>c1ccc([Se]CC2CC(c3ccccc3)=NO2)cc1</smiles>

$197 a, 85 \%$<smiles>Clc1ccc([Se]CC2CC(c3ccccc3)=NO2)cc1</smiles>

197b, 93\%<smiles>COc1ccc(CC2CC(c3ccccc3)=NO2)cc1</smiles>

$197 c, 60 \%$<smiles>CC(C)(C)[Se][Se]CC1CC(c2ccccc2)=NO1</smiles>

$197 d, 85 \%$<smiles>Fc1ccc(C2=NOC(C[SeH]c3ccccc3)C2)cc1</smiles>

197e, $80 \%$<smiles>Cc1ccc(C2=NOC(C[SeH]c3ccccc3)C2)cc1</smiles>

197f, $72 \%$<smiles>[SeH]c1ccccc1CC1CC(c2ccc3ccccc3c2)=NO1</smiles>

197g, $75 \%$ 
the reaction can proceed by both radical and ionic mechanisms. The authors proposed that under ultrasonic stimulation the mechanism is predominantly radical, while under microwave conditions the ionic mechanism becomes significant [157].

\section{Conclusion}

An unprecedented renaissance in the chemistry of oxime radicals has been observed during the last years. Over the past decade, a diverse pattern of methods for oxidative cyclization involving oxime radicals was developed. 5-Exo-trig cyclization of oxime radicals generated from unsaturated oximes can now be considered as a robust and general approach to the synthesis of functionalized isoxazolines, isoxazoles, and cyclic nitrones. Moreover, iminoxyl radicals were demonstrated to be promising intermediates for cyclizations involving $\mathrm{C}\left(\mathrm{sp}^{3}\right)-\mathrm{H}$ bonds, $\mathrm{C} \equiv \mathrm{C}$ triple bonds and aromatic $\pi$-systems.

The majority of iminoxyl-radical-mediated synthetic transformations are intramolecular reactions, presumably due to the lack of stability of the oxime radicals. Nevertheless, examples of intermolecular cross-dehydrogenative $\mathrm{C}-\mathrm{O}$ couplings employing oxime radicals as the key intermediates emerged recently.

The areas of the future development of the chemistry of iminoxyl radicals include: (1) the development of selective intermolecular reactions with oxime radicals; (2) the development of new oxidative systems for the generation of oxime radicals, including electrochemical and photochemical approaches; (3) the search for new stable oxime radicals which can be used as reagents for organic synthesis and other applications.

\section{Funding}

The work was funded by RFBR, project number 20-33-70109.

\section{ORCID ${ }^{\circledR}$ iDs}

Igor B. Krylov - https://orcid.org/0000-0001-7138-7319

Stanislav A. Paveliev - https://orcid.org/0000-0003-1668-9693

Alexander S. Budnikov - https://orcid.org/0000-0002-6189-2239

Alexander O. Terent'ev - https://orcid.org/0000-0001-8018-031X

\section{References}

1. Tretyakov, E. V.; Ovcharenko, V. I. Russ. Chem. Rev. 2009, 78, 971-1012. doi:10.1070/rc2009v078n11abeh004093

2. Muench, S.; Wild, A.; Friebe, C.; Häupler, B.; Janoschka, T.; Schubert, U. S. Chem. Rev. 2016, 116, 9438-9484. doi:10.1021/acs.chemrev.6b00070

3. Nishide, H.; Iwasa, S.; Pu, Y.-J.; Suga, T.; Nakahara, K.; Satoh, M. Electrochim. Acta 2004, 50, 827-831. doi:10.1016/j.electacta.2004.02.052
4. Hansen, K.-A.; Nerkar, J.; Thomas, K.; Bottle, S. E.; O’Mullane, A. P.; Talbot, P. C.; Blinco, J. P. ACS Appl. Mater. Interfaces 2018, 10, 7982-7988. doi:10.1021/acsami.7b18252

5. Nitroxide Mediated Polymerization: From Fundamentals to Applications in Materials Science; Gigmes, D., Ed.; Polymer Chemistry Series; Royal Society of Chemistry: Cambridge, UK, 2015. doi:10.1039/9781782622635

6. Audran, G.; Bagryanskaya, E.; Edeleva, M.; Marque, S. R. A.; Parkhomenko, D.; Tretyakov, E.; Zhivetyeva, S. Aust. J. Chem. 2018, 71, 334. doi: $10.1071 / \mathrm{ch} 17570$

7. Haugland, M. M.; Lovett, J. E.; Anderson, E. A. Chem. Soc. Rev. 2018, 47, 668-680. doi:10.1039/c6cs00550k

8. Kim, Y.; Wang, Y.; Chen, H.-Y.; Hilty, C. In-Vitro Dissolution Dynamic Nuclear Polarization for Sensitivity Enhancement of NMR with Biological Molecules. In Protein NMR; Ghose, R., Ed.; Springer: New York, NY, USA, 2018; Vol. 1688, pp 155-168. doi:10.1007/978-1-4939-7386-6_8

9. Bagryanskaya, E. G.; Marque, S. R. A. Chem. Rev. 2014, 114, 5011-5056. doi:10.1021/cr4000946

10. Cao, Q.; Dornan, L. M.; Rogan, L.; Hughes, N. L.; Muldoon, M. J. Chem. Commun. 2014, 50, 4524-4543. doi:10.1039/c3cc47081d

11. Ciriminna, R.; Ghahremani, M.; Karimi, B.; Pagliaro, M. ChemistryOpen 2017, 6, 5-10. doi:10.1002/open.201600086

12. Recupero, F.; Punta, C. Chem. Rev. 2007, 107, 3800-3842. doi:10.1021/cr040170k

13. Galli, C.; Gentili, P.; Lanzalunga, O. Angew. Chem., Int. Ed. 2008, 47, 4790-4796. doi:10.1002/anie.200704292

14. Coseri, S. Catal. Rev.: Sci. Eng. 2009, 51, 218-292. doi:10.1080/01614940902743841

15. Melone, L.; Punta, C. Beilstein J. Org. Chem. 2013, 9, 1296-1310. doi:10.3762/bjoc.9.146

16. Wertz, S.; Studer, A. Green Chem. 2013, 15, 3116. doi:10.1039/c3gc41459k

17. Chen, K.; Zhang, P.; Wang, Y.; Li, H. Green Chem. 2014, 16, 2344. doi:10.1039/c3gc42135j

18. Chen, K.; Xie, H. Chin. J. Catal. 2017, 38, 625-635. doi:10.1016/s1872-2067(17)62777-3

19. Lan, X.-W.; Wang, N.-X.; Xing, Y. Eur. J. Org. Chem. 2017, 5821-5851. doi:10.1002/ejoc.201700678

20. Bag, R.; De, P. B.; Pradhan, S.; Punniyamurthy, T. Eur. J. Org. Chem. 2017, 5424-5438. doi:10.1002/ejoc.201700512

21. Giglio, B. C.; Alexanian, E. J. Org. Lett. 2014, 16, 4304-4307. doi:10.1021/ol5020202

22. Quinn, R. K.; Schmidt, V. A.; Alexanian, E. J. Chem. Sci. 2013, 4, 4030-4034. doi:10.1039/c3sc51466h

23. Schmidt, V. A.; Alexanian, E. J. Chem. Sci. 2012, 3, 1672-1674. doi:10.1039/c2sc01042a

24. Giglio, B. C.; Schmidt, V. A.; Alexanian, E. J. J. Am. Chem. Soc. 2011, 133, 13320-13322. doi:10.1021/ja206306f

25. Schmidt, V. A.; Alexanian, E. J. J. Am. Chem. Soc. 2011, 133, 11402-11405. doi:10.1021/ja204255e

26. Schmidt, V. A.; Alexanian, E. J. Angew. Chem., Int. Ed. 2010, 49, 4491-4494. doi:10.1002/anie.201000843

27. Punta, C.; Rector, C. L.; Porter, N. A. Chem. Res. Toxicol. 2005, 18, 349-356. doi:10.1021/tx049685x

28. Jousserandot, A.; Boucher, J.-L.; Henry, Y.; Niklaus, B.; Clement, B.; Mansuy, D. Biochemistry 1998, 37, 17179-17191. doi:10.1021/bi981175c

29. Sturgeon, B. E.; Glover, R. E.; Chen, Y.-R.; Burka, L. T.; Mason, R. P. J. Biol. Chem. 2001, 276, 45516-45521. doi:10.1074/jbc.m106835200 
30. Papavasileiou, K. D.; Tzima, T. D.; Sanakis, Y.; Melissas, V. S. ChemPhysChem 2007, 8, 2595-2602. doi:10.1002/cphc.200700434

31. Sanakis, Y.; Goussias, C.; Mason, R. P.; Petrouleas, V. Biochemistry 1997, 36, 1411-1417. doi:10.1021/bi9622074

32. Gunther, M. R.; Hsi, L. C.; Curtis, J. F.; Gierse, J. K.; Marnett, L. J.; Eling, T. E.; Mason, R. P. J. Biol. Chem. 1997, 272, 17086-17090. doi:10.1074/jbc.272.27.17086

33. Gunther, M. Toxicology 2002, 177, 1-9. doi:10.1016/s0300-483x(02)00191-9

34. Okazaki, R.; Inagaki, Y. J. Synth. Org. Chem., Jpn. 1978, 36, 377-386. doi:10.5059/yukigoseikyokaishi.36.377

35. Ingold, K. U. The Only Stable Organic Sigma Radicals: Di-tert -Alkyliminoxyls. In Stable Radicals; Hicks, R. G., Ed.; John Wiley \& Sons, Ltd.: Chichester, UK, 2010; pp 231-244. doi:10.1002/9780470666975.ch6

36. Ingold, K. U. Iminoxyl radicals, RR'C=NO. In Radicals Centered on N, $S, P$ and Other Heteroatoms. Nitroxyls; Fischer, H., Ed.; Springer-Verlag: Berlin, Heidelberg, Germany, 1983; Vol. 13c, pp 257-265. doi:10.1007/10201373_57

37. Fischer, H.; Hellwege, K.-H., Eds. Organic N-Centered Radicals and Nitroxide Radicals; Landolt-Börnstein - Group II Molecules and Radicals; Springer-Verlag: Berlin, Germany, 1979. doi:10.1007/b19955

38. Thomas, J. R. J. Am. Chem. Soc. 1964, 86, 1446-1447. doi:10.1021/ja01061a043

39. Stone, T. J.; Waters, W. A. Proc. Chem. Soc., London 1962, 253. doi:10.1039/ps9620000237

40. Krylov, I. B.; Kompanets, M. O.; Novikova, K. V.; Opeida, I. O.; Kushch, O. V.; Shelimov, B. N.; Nikishin, G. I.; Levitsky, D. O.; Terent'ev, A. O. J. Phys. Chem. A 2016, 120, 68-73. doi:10.1021/acs.jpca.5b10722

41. Amorati, R.; Lucarini, M.; Mugnaini, V.; Pedulli, G. F.; Minisci, F.; Recupero, F.; Fontana, F.; Astolfi, P.; Greci, L. J. Org. Chem. 2003, 68, 1747-1754. doi:10.1021/jo026660z

42. Flesia, E.; Surzur, J.-M.; Tordo, P. Org. Magn. Reson. 1978, 11, 123-126. doi:10.1002/mrc.1270110305

43. Rozantsev, E. G. In Free Nitroxyl Radicals; Ulrich, H., Ed.; Springer US: Boston, MA, USA, 1970. doi:10.1007/978-1-4757-0710-6

44. Krylov, I. B.; Paveliev, S. A.; Shelimov, B. N.; Lokshin, B. V.; Garbuzova, I. A.; Tafeenko, V. A.; Chernyshev, V. V.; Budnikov, A. S.; Nikishin, G. I.; Terent'ev, A. O. Org. Chem. Front. 2017, 4, 1947-1957. doi:10.1039/c7qo00447h

45. Mendenhall, G. D.; Ingold, K. U. J. Am. Chem. Soc. 1973, 95, 2963-2971. doi:10.1021/ja00790a038

46. Krylov, I. B.; Terent'ev, A. O.; Timofeev, V. P.; Shelimov, B. N.; Novikov, R. A.; Merkulova, V. M.; Nikishin, G. I. Adv. Synth. Catal. 2014, 356, 2266-2280. doi:10.1002/adsc.201400143

47. Gilbert, B. C.; Norman, R. O. C.; Price, D. C. Proc. Chem. Soc., London 1964, 234. doi:10.1039/ps9640000201

48. Lemaire, H.; Rassat, A. Tetrahedron Lett. 1964, 5, 2245-2248. doi:10.1016/s0040-4039(00)71695-9

49. Gilbert, B. C.; Norman, R. O. C. J. Chem. Soc. B 1966, 86. doi:10.1039/j29660000086

50. Fox, W. M.; Symons, M. C. R. J. Chem. Soc. A 1966, 1503. doi:10.1039/j19660001503

51. Butler, R. N.; Scott, F. L.; O'Mahony, T. A. F. Chem. Rev. 1973, 73, 93-112. doi:10.1021/cr60282a001

52. Koch, R.; Wollweber, H.-J.; Müller-Starke, H.; Wentrup, C. Eur. J. Org. Chem. 2015, 5143-5149. doi:10.1002/ejoc.201500728
53. Brokenshire, J. L.; Roberts, J. R.; Ingold, K. U. J. Am. Chem. Soc. 1972, 94, 7040-7049. doi:10.1021/ja00775a030

54. Siatecki, Z.; Chmielewski, P. J.; Jezierski, A. Magn. Reson. Chem. 1992, 30, 163-168. doi:10.1002/mrc.1260300213

55. Lagercrantz, C.; Ekström, M.; Spassov, S.; Hörnfeldt, A.-B.; Lönnberg, H.; Berg, J.-E.; Bartók, M.; Pelczer, I.; Dombi, G. Acta Chem. Scand., Ser. B 1988, 42, 414-416. doi:10.3891/acta.chem.scand.42b-0414

56. Lin, T.-s.; Mastin, S. H.; Ohkaku, N. J. Am. Chem. Soc. 1973, 95, 6845-6846. doi:10.1021/ja00801a061

57. Petrosyan, V. A.; Niyazymbetov, M. E.; Ul'yanova, é. V. Russ. Chem. Bull. 1990, 39, 546-550. doi:10.1007/bf00959580

58. Fukunishi, K.; Kitada, K.; Naito, I. Synthesis 1991, 237-238. doi:10.1055/s-1991-26433

59. Brokenshire, J. L.; Mendenhall, G. D.; Ingold, K. U. J. Am. Chem. Soc. 1971, 93, 5278-5279. doi:10.1021/ja00749a064

60. Eisenhauer, B. M.; Wang, M.; Brown, R. E.; Labaziewicz, H.; Ngo, M.; Kettinger, K. W.; Mendenhall, G. D. J. Phys. Org. Chem. 1997, 10, 737-746. doi:10.1002/(sici)1099-1395(199710)10:10<737::aid-poc944>3.0.co;2$\mathrm{n}$

61. Eisenhauer, B. M.; Wang, M.; Labaziewicz, H.; Ngo, M.; Mendenhall, G. D. J. Org. Chem. 1997, 62, 2050-2053. doi:10.1021/jo962136e

62. Lindsay, D.; Horswill, E. C.; Davidson, D. W.; Ingold, K. U. Can. J. Chem. 1974, 52, 3554-3556. doi:10.1139/v74-528

63. Lagercrantz, C.; Torssell, K. Ark. Kemi 1967, 29, 203-218.

64. Hoffman, S.; Jezierski, A.; Jezowska-Trzebiatowska, B. Bull. Pol. Acad. Sci., Chem. 1986, 34, 251-255.

65. Zeilstra, J. J.; Engberts, J. B. F. N. Tetrahedron 1973, 29, 4299-4302. doi:10.1016/0040-4020(73)80274-1

66. Symons, M. C. R. J. Chem. Soc. 1965, 2276-2277.

67. Chong, S.-S.; Fu, Y.; Liu, L.; Guo, Q.-X. J. Phys. Chem. A 2007, 111, 13112-13125. doi:10.1021/jp075699a

68. Lucarini, M.; Pedulli, G. F.; Alberti, A. J. Org. Chem. 1994, 59, 1980-1983. doi:10.1021/jo00087a009

69. Alberti, A.; Barbaro, G.; Battaglia, A.; Guerra, M.; Bernardi, F.; Dondoni, A.; Pedulli, G. F. J. Org. Chem. 1981, 46, 742-750. doi:10.1021/jo00317a018

70. Pratt, D. A.; Blake, J. A.; Mulder, P.; Walton, J. C.; Korth, H.-G.; Ingold, K. U. J. Am. Chem. Soc. 2004, 126, 10667-10675. doi:10.1021/ja047566y

71. Dao, R.; Wang, X.; Chen, K.; Zhao, C.; Yao, J.; Li, H. Phys. Chem. Chem. Phys. 2017, 19, 22309-22320. doi:10.1039/c7cp03809g

72. Mahoney, L. R.; Mendenhall, G. D.; Ingold, K. U. J. Am. Chem. Soc. 1973, 95, 8610-8614. doi:10.1021/ja00807a018

73. Mickel, M.; Kim, H.-C.; Hampp, N. Green Chem. 2003, 5, 8-14. doi:10.1039/b208812f

74. Chhabra, M.; Mishra, S.; Sreekrishnan, T. R. Biochem. Eng. J. 2015, 93, 17-24. doi:10.1016/j.bej.2014.09.007

75. Morozova, O. V.; Shumakovich, G. P.; Shleev, S. V.; Yaropolov, Y. I. Appl. Biochem. Microbiol. 2007, 43, 523-535. doi:10.1134/s0003683807050055

76. Galli, C.; Gentili, P. J. Phys. Org. Chem. 2004, 17, 973-977. doi:10.1002/poc.812

77. Coseri, S.; Mendenhall, G. D.; Ingold, K. U. J. Org. Chem. 2005, 70, 4629-4636. doi:10.1021/jo0504060

78. Ngo, M.; Larson, K. R.; Mendenhall, G. D. J. Org. Chem. 1986, 51, 5390-5393. doi:10.1021/jo00376a061 
79. Mahoney, L. R.; DaRooge, M. A. J. Am. Chem. Soc. 1970, 92 890-899. doi:10.1021/ja00707a026

80. Mulder, P.; Saastad, O. W.; Griller, D. J. Am. Chem. Soc. 1988, 110, 4090-4092. doi:10.1021/ja00220a088

81. Jonsson, M.; Lind, J.; Eriksen, T. E.; Merényi, G. J. Chem. Soc., Perkin Trans. 2 1993, 1567-1568. doi:10.1039/p29930001567

82. Wayner, D. D. M.; Lusztyk, E.; Ingold, K. U.; Mulder, P. J. Org. Chem. 1996, 61, 6430-6433. doi:10.1021/jo952167u

83. Pratt, D. A.; de Heer, M. I.; Mulder, P.; Ingold, K. U. J. Am. Chem. Soc. 2001, 123, 5518-5526. doi:10.1021/ja004081a

84. Pratt, D. A.; DiLabio, G. A.; Mulder, P.; Ingold, K. U. Acc. Chem. Res. 2004, 37, 334-340. doi:10.1021/ar010010k

85. Cornejo, J. J.; Larson, K. D.; Mendenhall, G. D. J. Org. Chem. 1985, 50, 5382-5383. doi:10.1021/j000225a078

86. Schenk, C.; De Boer, T. J. Tetrahedron 1979, 35, 2119-2122. doi:10.1016/0040-4020(79)87027-1

87. Krylov, I. B.; Paveliev, S. A.; Shumakova, N. S.; Syroeshkin, M. A.; Shelimov, B. N.; Nikishin, G. I.; Terent'ev, A. O. RSC Adv. 2018, 8, 5670-5677. doi:10.1039/c7ra13587d

88. Bityukov, O. V.; Vil', V. A.; Sazonov, G. K.; Kirillov, A. S.; Lukashin, N. V.; Nikishin, G. I.; Terent'ev, A. O. Tetrahedron Lett. 2019, 60, 920-924. doi:10.1016/j.tetlet.2019.02.042

89. Terent'ev, A. O.; Zdvizhkov, A. T.; Levitsky, D. O.; Fleury, F.; Pototskiy, R. A.; Kulakova, A. N.; Nikishin, G. I. Tetrahedron 2015, 71, 8985-8990. doi:10.1016/j.tet.2015.09.047

90. Terent'ev, A. O.; Sharipov, M. Y.; Krylov, I. B.; Gaidarenko, D. V.; Nikishin, G. I. Org. Biomol. Chem. 2015, 13, 1439-1445. doi:10.1039/c4ob01823k

91. Terent'ev, A. O.; Vil', V. A.; Bityukov, O. V.; Nikishin, G. I. Russ. Chem. Bull. 2014, 63, 2461-2466. doi:10.1007/s11172-014-0763-8

92. Terent'ev, A.; Borisov, D.; Semenov, V.; Chernyshev, V.; Dembitsky, V.; Nikishin, G. Synthesis 2011, 2091-2100. doi:10.1055/s-0030-1260027

93. Terent'ev, A. O.; Borisov, D. A.; Yaremenko, I. A.; Chernyshev, V. V.; Nikishin, G. I. J. Org. Chem. 2010, 75, 5065-5071. doi:10.1021/j0100793j

94. Krylov, I. B.; Terent'ev, A. O. Russ. J. Org. Chem. 2015, 51, 10-13. doi:10.1134/s1070428015010029

95. Chen, Z.-Y.; Liang, H.-J.; Chen, R.-X.; Chen, L.; Tang, X.-Z.; Yan, M.; Zhang, X.-J. Adv. Synth. Catal. 2019, 361, 3324-3330. doi:10.1002/adsc. 201900370

96. Han, Z.; Shen, S.; Zheng, F.; Hu, H.; Zhang, J.; Zhu, S. Tetrahedron Lett. 2019, 60, 151188. doi:10.1016/j.tetlet.2019.151188

97. Lopes, E. F.; Penteado, F.; Thurow, S.; Pinz, M.; Reis, A. S.; Wilhelm, E. A.; Luchese, C.; Barcellos, T.; Dalberto, B.; Alves, D.; da Silva, M. S.; Lenardão, E. J. J. Org. Chem. 2019, 84, 12452-12462. doi:10.1021/acs.joc.9b01754

98. Dong, K.-Y.; Qin, H.-T.; Bao, X.-X.; Liu, F.; Zhu, C. Org. Lett. 2014, 16, 5266-5268. doi:10.1021/ol502246t

99. Tripathi, C. B.; Mukherjee, S. Angew. Chem., Int. Ed. 2013, 52, 8450-8453. doi:10.1002/anie.201304173

100. Triandafillidi, I.; Kokotos, C. G. Org. Lett. 2017, 19, 106-109. doi:10.1021/acs.orglett.6b03380

101.Praveen, C.; Kalyanasundaram, A.; Perumal, P. Synlett 2010, 777-781. doi:10.1055/s-0029-1219342

102.He, Y.-T.; Li, L.-H.; Yang, Y.-F.; Wang, Y.-Q.; Luo, J.-Y.; Liu, X.-Y.; Liang, Y.-M. Chem. Commun. 2013, 49, 5687. doi:10.1039/c3cc42588f
103.Dong, K.-Y.; Qin, H.-T.; Liu, F.; Zhu, C. Eur. J. Org. Chem. 2015, 1419-1422. doi:10.1002/ejoc.201403538

104.Sun, Y.; Abdukader, A.; Zhang, H.; Yang, W.; Liu, C. RSC Adv. 2017, 7, 55786-55789. doi:10.1039/c7ra11436b

105.Li, X.-T.; Gu, Q.-S.; Dong, X.-Y.; Meng, X.; Liu, X.-Y. Angew. Chem., Int. Ed. 2018, 57, 7668-7672. doi:10.1002/anie.201804315

106.Jiang, D.; Peng, J.; Chen, Y. Org. Lett. 2008, 10, 1695-1698. doi:10.1021/ol8002173

107.Zhu, M.-K.; Zhao, J.-F.; Loh, T.-P. J. Am. Chem. Soc. 2010, 132, 6284-6285. doi:10.1021/ja100716x

108. Li, X.-T.; Lv, L.; Gu, Q.-S.; Liu, X.-Y. Tetrahedron 2018, 74, 6041-6046. doi:10.1016/j.tet.2018.08.037

109.Wei, Q.; Chen, J.-R.; Hu, X.-Q.; Yang, X.-C.; Lu, B.; Xiao, W.-J. Org. Lett. 2015, 17, 4464-4467. doi:10.1021/acs.orglett.5b02118

110.Zhu, M.; Fun, W.; Guo, W.; Tian, Y.; Wang, Z.; Xu, C.; Ji, B. Eur. J. Org. Chem. 2019, 1614-1619. doi:10.1002/ejoc.201801790

111.Zhang, Y.; Ji, M. Eur. J. Org. Chem. 2019, 7506-7510. doi:10.1002/ejoc.201901468

112. Forrester, A. R.; Thomson, R. H.; Woo, S.-O J. Chem. Soc., Perkin Trans. 1 1975, 2340. doi:10.1039/p19750002340

113. Kong, W.; Guo, Q.; Xu, Z.; Wang, G.; Jiang, X.; Wang, R. Org. Lett. 2015, 17, 3686-3689. doi:10.1021/acs.orglett.5b01646

114.Zhu, X.; Wang, Y.-F.; Ren, W.; Zhang, F.-L.; Chiba, S. Org. Lett. 2013, 15, 3214-3217. doi:10.1021/ol4014969

115. Shotter, R. G.; Sesardić, D.; Wright, P. H. Tetrahedron 1975, 31 , 3069-3072. doi:10.1016/0040-4020(75)80149-9

116.Shi, D.; Qin, H.-T.; Zhu, C.; Liu, F. Eur. J. Org. Chem. 2015, 5084-5088. doi:10.1002/ejoc.201500780

117.Zhang, F.-L.; Wang, Y.-F.; Chiba, S. Org. Biomol. Chem. 2013, 11, 6003. doi:10.1039/c3ob41393d

118.Wang, Y.-F.; Zhang, F.-L.; Chiba, S. Org. Lett. 2013, 15, 2842-2845. doi:10.1021/ol4011745

119. Lemercier, B. C.; Pierce, J. G. Org. Lett. 2015, 17, 4542-4545. doi:10.1021/acs.orglett.5b02256

120. Parker, P. D.; Pierce, J. G. Synthesis 2016, 48, 1902-1909. doi:10.1055/s-0035-1561597

121.Liu, Y.-Y.; Yang, X.-H.; Yang, J.; Song, R.-J.; Li, J.-H. Chem. Commun. 2014, 50, 6906. doi:10.1039/c4cc02084g

122.Soni, V. K.; Kim, J.; Cho, E. J. Adv. Synth. Catal. 2018, 360, 2626-2631. doi:10.1002/adsc.201800238

123. Atmaram, S.; Forrester, A. R.; Gill, M.; Napier, R. J.; Thomson, R. H.; Tezuka, T. Acta Chem. Scand., Ser. B 1982, 36, 641-647. doi:10.3891/acta.chem.scand.36b-0641

124.Han, B.; Yang, X.-L.; Fang, R.; Yu, W.; Wang, C.; Duan, X.-Y.; Liu, S. Angew. Chem., Int. Ed. 2012, 51, 8816-8820. doi:10.1002/anie.201203799

125. Li, W.; Jia, P.; Han, B.; Li, D.; Yu, W. Tetrahedron 2013, 69, 3274-3280. doi:10.1016/j.tet.2013.02.032

126. Yamamoto, D.; Oguro, T.; Tashiro, Y.; Soga, M.; Miyashita, K.; Aso, Y.; Makino, K. Eur. J. Org. Chem. 2016, 5216-5219. doi:10.1002/ejoc.201600998

127.Hu, X.-Q.; Chen, J.; Chen, J.-R.; Yan, D.-M.; Xiao, W.-J. Chem. - Eur. J. 2016, 22, 14141-14146. doi:10.1002/chem.201602597

128. Yang, X.-L.; Chen, F.; Zhou, N.-N.; Yu, W.; Han, B. Org. Lett. 2014, 16, 6476-6479. doi:10.1021/ol503335k

129.Xu, Y.; Chen, H.; Li, W.; Xie, Q.; Yu, L.; Shao, L. Org. Biomol. Chem. 2018, 16, 4996-5005. doi:10.1039/c8ob01229f 
130.Peng, X.-X.; Deng, Y.-J.; Yang, X.-L.; Zhang, L.; Yu, W.; Han, B. Org. Lett. 2014, 16, 4650-4653. doi:10.1021/ol502258n

131.Zhang, X.-W.; Xiao, Z.-F.; Zhuang, Y.-J.; Wang, M.-M.; Kang, Y.-B. Adv. Synth. Catal. 2016, 358, 1942-1945. doi:10.1002/adsc.201600147

132.Wang, D.-J.; Chen, B.-Y.; Wang, Y.-Q.; Zhang, X.-W. Eur. J. Org. Chem. 2018, 1342-1346. doi:10.1002/ejoc.201701651 133.Zhu, L.; Wang, G.; Guo, Q.; Xu, Z.; Zhang, D.; Wang, R. Org. Lett. 2014, 16, 5390-5393. doi:10.1021/ol502624z

134.Zhu, L.; Yu, H.; Xu, Z.; Jiang, X.; Lin, L.; Wang, R. Org. Lett. 2014, 16, 1562-1565. doi:10.1021/ol403687k

135. Yang, X.-L.; Long, Y.; Chen, F.; Han, B. Org. Chem. Front. 2016, 3, 184-189. doi:10.1039/c5qo00352k

136.Liu, R.-H.; Wei, D.; Han, B.; Yu, W. ACS Catal. 2016, 6, 6525-6530. doi:10.1021/acscatal.6b02065

137.Chen, F.; Yang, X.-L.; Wu, Z.-W.; Han, B. J. Org. Chem. 2016, 81, 3042-3050. doi:10.1021/acs.joc.6b00180

138.Zhang, W.; Su, Y.; Wang, K.-H.; Wu, L.; Chang, B.; Shi, Y.; Huang, D.; Hu, Y. Org. Lett. 2017, 19, 376-379. doi:10.1021/acs.orglett.6b03582

139.Chen, F.; Zhu, F.-F.; Zhang, M.; Liu, R.-H.; Yu, W.; Han, B. Org. Lett. 2017, 19, 3255-3258. doi:10.1021/acs.orglett.7b00826

140.Meng, F.; Zhang, H.; Guo, K.; Dong, J.; Lu, A.-M.; Zhu, Y. J. Org. Chem. 2017, 82, 10742-10747. doi:10.1021/acs.joc.7b02133

141.Wang, L.-J.; Chen, M.; Qi, L.; Xu, Z.; Li, W. Chem. Commun. 2017, 53, 2056-2059. doi:10.1039/c7cc00090a

142.Xu, Z.-Q.; Zheng, L.-C.; Li, L.; Duan, L.; Li, Y.-M. Org. Biomol. Chem. 2019, 17, 898-907. doi:10.1039/c8ob02879f

143.Ji, F.; Fan, Y.; Yang, R.; Yang, Y.; Yu, D.; Wang, M.; Li, Z. Asian J. Org. Chem. 2017, 6, 682-685. doi:10.1002/ajoc.201700050

144. Yu, J.-M.; Cai, C. Org. Biomol. Chem. 2018, 16, 490-498. doi:10.1039/c7ob02892j

145.Ye, C.; Kou, X.; Yang, G.; Shen, J.; Zhang, W. Tetrahedron Lett. 2019, 60, 1148-1152. doi:10.1016/j.tetlet.2019.03.046

146.Hu, X.-Q.; Feng, G.; Chen, J.-R.; Yan, D.-M.; Zhao, Q.-Q.; Wei, Q.; Xiao, W.-J. Org. Biomol. Chem. 2015, 13, 3457-3461. doi:10.1039/c5ob00029g

147.Han, W.-J.; Wang, Y.-R.; Zhang, J.-W.; Chen, F.; Zhou, B.; Han, B. Org. Lett. 2018, 20, 2960-2963. doi:10.1021/acs.orglett.8b01004

148. Llantén, H.; Barata-Vallejo, S.; Postigo, A.; Colinas, P. A. Tetrahedron Lett. 2017, 58, 1507-1511. doi:10.1016/j.tetlet.2017.03.005

149.Liu, Y.-Y.; Yang, J.; Song, R.-J.; Li, J.-H. Adv. Synth. Catal. 2014, 356, 2913-2918. doi:10.1002/adsc.201400242

150.Zhang, X.-W.; Xiao, Z.-F.; Wang, M.-M.; Zhuang, Y.-J.; Kang, Y.-B. Org. Biomol. Chem. 2016, 14, 7275-7281. doi:10.1039/c6ob01374k

151.Li, X.; Ding, Y.; Qian, L.; Gao, Y.; Wang, X.; Yan, X.; Xu, X. J. Org. Chem. 2019, 84, 12656-12663. doi:10.1021/acs.joc.9b02031

152.Chen, H.-L.; Wei, D.; Zhang, J.-W.; Li, C.-L.; Yu, W.; Han, B. Org. Lett. 2018, 20, 2906-2910. doi:10.1021/acs.orglett.8b00967

153.Zhao, H.-B.; Xu, P.; Song, J.; Xu, H.-C. Angew. Chem., Int. Ed. 2018, 57, 15153-15156. doi:10.1002/anie.201809679

154.Peng, X.-X.; Wei, D.; Han, W.-J.; Chen, F.; Yu, W.; Han, B. ACS Catal. 2017, 7, 7830-7834. doi:10.1021/acscatal.7b03078

155. Yang, S.; Wang, L.; Wang, L.; Li, H. J. Org. Chem. 2020, 85 , 564-573. doi:10.1021/acs.joc.9b02646

156.Yang, S.; Li, H.; Li, P.; Yang, J.; Wang, L. Org. Biomol. Chem. 2020, 18, 715-724. doi:10.1039/c9ob02424g

157.Araujo, D. R.; Lima, Y. R.; Barcellos, A. M.; Silva, M. S.; Jacob, R. G.; Lenardão, E. J.; Bagnoli, L.; Santi, C.; Perin, G. Eur. J. Org. Chem. 2020, 586-592. doi:10.1002/ejoc.201901611

\section{License and Terms}

This is an Open Access article under the terms of the Creative Commons Attribution License (http://creativecommons.org/licenses/by/4.0). Please note that the reuse, redistribution and reproduction in particular requires that the authors and source are credited.

The license is subject to the Beilstein Journal of Organic Chemistry terms and conditions: (https://www.beilstein-journals.org/bjoc)

The definitive version of this article is the electronic one which can be found at:

doi:10.3762/bjoc. 16.107 